ADRIANA TREJGER KACHANI

\title{
Checagem do corpo em transtornos alimentares: relação entre comportamentos e cognições
}

Tese apresentada à Faculdade de Medicina da Universidade de São Paulo para obtenção do título de Doutor em Ciências

Programa de: Fisiopatologia Experimental Orientadora: Patrícia Brunfentrinker Hochgraf

(Versão corrigida. Resolução COPGr 5890, de 20 de dezembro de 2010. A versão original está disponível na Biblioteca FMUSP)

SÃO PAULO

2012 
Dados Internacionais de Catalogação na Publicação (CIP)

Preparada pela Biblioteca da

Faculdade de Medicina da Universidade de São Paulo

Creprodução autorizada pelo autor

\section{Kachani, Adriana Trejger}

Checagem do corpo em transtornos alimentares : relação entre comportamentos e cognições / Adriana Trejger Kachani. -- São Paulo, 2012.

Tese(doutorado)--Faculdade de Medicina da Universidade de São Paulo.

Programa de Fisiopatologia Experimental.

Orientadora: Patrícia Brunfentrinker Hochgraf.

Descritores: 1.Transtorno alimentares 2.Checagem corporal 3.Cognição 4.Imagem corporal 5.Mulheres

USP/FM/DBD-008/12 
Para minhas filhas queridas, Bianca e Julia. Que vocês nunca sejam escravas de seus corpos. 


\section{AGRADECIMENTOS}

À Profa. Dra. Patrícia Brufentrinker Hochgraf, minha orientadora e amiga querida, a quem serei eternamente grata por ter me incentivado e conduzido ao mundo acadêmico;

Ao Prof. Dr. Táki Athanássios Cordás, coorientador deste trabalho, com quem aprendi tantas coisas; por ser uma luz no meu caminho;

À Prof. Dra. Silvia Brasiliano, pela presença sempre carinhosa e acolhedora; pela eterna disponibilidade e ajuda infinita;

Ao Prof. Dr. Mauro Fisberg, por ser aquele professor que a gente nunca esquece...

À Prof. Dra. Maria Aparecida Conti, pela ajuda na tradução e validação de escalas;

Ao Depto. de Ginecologia e Obstetrícia e, principalmente, ao Prof. Dr. Edmund Chada Baracat, que disponibilizou suas pacientes para formarem o grupo controle;

A Marcela Salim Kotait, Ester Soares Paulino, Mariana Barillari e Fernanda Pisciolaro, pelo apoio na aplicação das escalas;

A Érika Hazome Hayashi, Maria Umbelina Santos de Jesus e Abykeyla Mellisse Tosatti, que tanto me auxiliaram na busca bibliográfica;

A Livia Maria Amaral de Brito, companheira de trabalho, pelo "ouvido" sempre à disposição, ajuda incondicional e o grande carinho;

Ao Carl, meu marido querido, companheiro de todas as horas, por nunca reclamar, sempre entender, sempre apoiar;

Por fim, a todas as pacientes que participaram desta pesquisa. 


\section{SUMÁRIO}

Lista de figuras

Lista de tabelas

Lista de abreviaturas e siglas

Resumo

Abstract

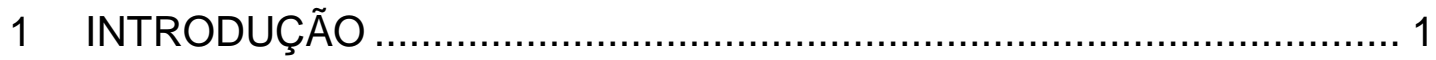

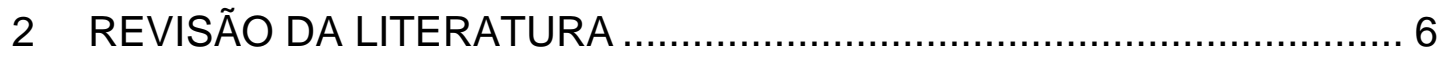

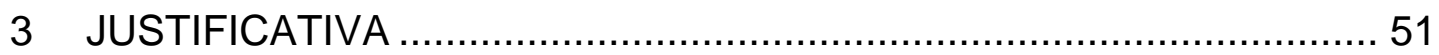

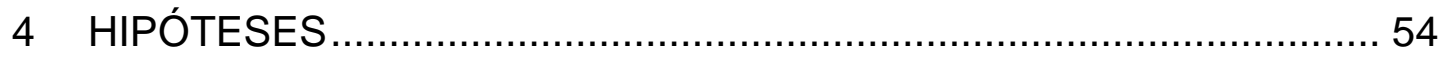

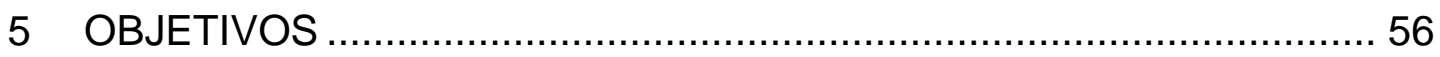

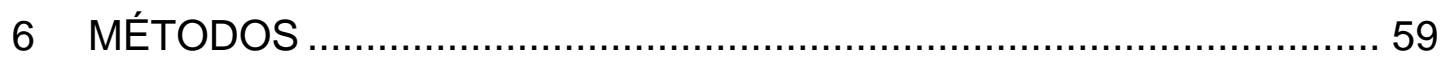

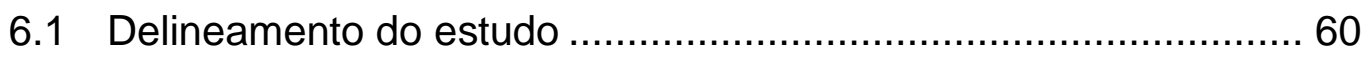

6.2 Local .......................................................................... 60

6.3 Casuística .................................................................... 61

6.4 Instrumentos de avaliação ..............................................6 68

6.5 Variáveis estudadas ....................................................... 78

6.6 Análise estatística ............................................................ 80

6.7 Análise de risco ......................................................... 83

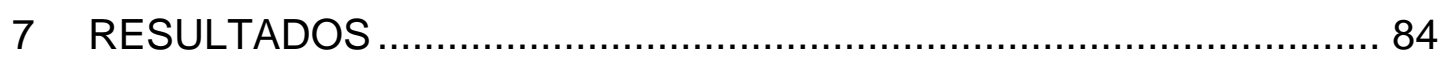

7.1 Descrição das variáveis ................................................. 85

7.2 Análise inferencial dos resultados ....................................... 104

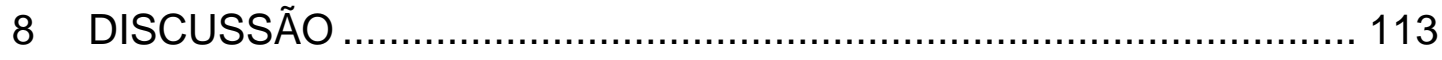

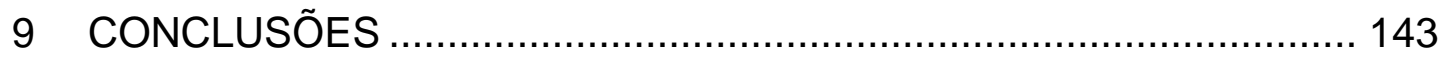

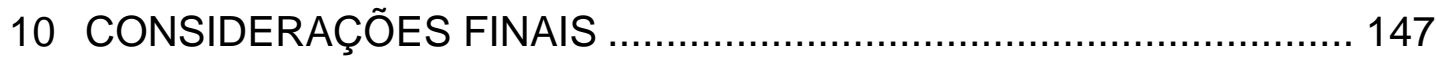

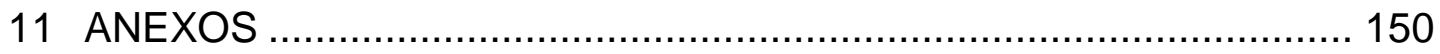

12 REFERÊNCIAS ................................................................. 177 


\section{LISTA DE FIGURAS E QUADROS}

Figura 1: Modelo de fatores que influenciam o desenvolvimento e a manifestação da imagem corporal (Slade, 1994).

Quadro 1: Conteúdo das subescalas do BCCS

Quadro 2: Silhuetas de Stunkard e seus respectivos IMCs * .74

Quadro 3: Classificação nutricional para os intervalos de IMC, segundo World Health Organization, 1997 


\section{LISTA DE TABELAS}

Tabela 1: Frequências de pacientes com anorexia nervosa e bulimia nervosa em relação às categorias de idade.

Tabela 2: Frequências de pacientes e controles em relação às categorias de idade.

Tabela 3: Frequências de pacientes com anorexia nervosa e bulimia nervosa em relação às categorias de educação

Tabela 4: Frequências de pacientes com anorexia nervosa e bulimia nervosa em relação às categorias de idade e educação.

Tabela 5: Frequências de indivíduos controle em relação às categorias de idade e educação

Tabela 6: Comparação das características sociodemográficas dos grupos estudados - 2009 a 2010

Tabela 7: Comparação da idade dos grupos estudados - 2009 a $2010 \ldots 86$

Tabela 8: Comparação do IMC e peso desejado entre os grupos estudados - 2009 a 2010

Tabela 9: Comparação do tempo de tratamento entre os grupos $\mathrm{AN}$ e $\mathrm{BN}-2009$ a 2010

Tabela 10: Comparação dos escores do EAT, BITE, Figuras de Stunkard, BSQ e BDI entre os grupos estudados - 2009 a 201090

Tabela 11: Comparação dos resultados do YBOCKS entre os grupos AN e BN - 2009 a 2010

Tabela 12: Comparação da pontuação da escala BCAQ entre os grupos estudados - 2009 a 2010

Tabela 13: Formas de checagem e áreas corporais mais medidas dos três grupos estudados - 2009 a 2010

Tabela 14: Formas de checagem mais prevalentes em cada um dos grupos estudados - 2009 a 2010 
Tabela 15: Comparação das áreas corporais mais checadas pelos grupos estudados -2009 a 2010

Tabela 16: Comparação dos escores de evitação de checagem entre os grupos estudados - 2009 a 2010

Tabela 17: Comparação da pontuação da escala BCCS entre os grupos estudados - 2009 a 2010

Tabela 18: Motivos que levam os três grupos estudados à checagem corporal, segundo o BCCS - 2009 a 2010.

Tabela 19: Relação entre idade, medidas antropométricas, tempo de tratamento e checagem corporal - 2009 a 2010

Tabela 20: Relação entre tempo de tratamento e pontuação de BCCS nos grupos AN e BN - 2009 a 2010.

Tabela 21: Correlação entre atitude alimentar (pontuação do EAT) e a checagem corporal (pontuação do BCAQ) entre os três grupos estudados - 2009 a 2010

Tabela 22: Relação entre sintomas e gravidade de bulimia nervosa com a checagem corporal nos três grupos estudados - 2009 a 2010107

Tabela 23: Relação entre satisfação/ insatisfação corporal e checagem corporal nos três grupos estudados - 2009 a 2010

Tabela 24: Relação entre imagem corporal e checagem corporal nos três grupos estudados - 2009 a 2010

Tabela 25: Correlação entre sintomas depressivos (pontuação do BDI) e a checagem corporal (pontuação do BCAQ) entre os três grupos estudados -2009 a 2010

Tabela 26: Relação entre sintomas obsessivo-compulsivos e a checagem corporal dos grupos AN e BN - 2009 a 2010

Tabela 27: Correlação entre as escalas BCAQ, BCCS, EAT, BSQ, BDI e autoavaliação (EU) na escala de Silhuetas de Stunkard 2009 a 2010 


\section{LISTA DE ABREVIATURAS}

$\begin{array}{ll}\text { AMBULIM } & \text { Programa de Transtornos Alimentares } \\ \text { AN } & \text { Anorexia nervosa } \\ \text { ANOVA } & \text { Análise de variância } \\ \text { ANCOVA } & \text { Análise de covariância } \\ \text { APA } & \text { American Psychiatry Association } \\ \text { BCAQ } & \text { Body Checking and Avoidance Questionnaire } \\ \text { BCCS } & \text { Body Checking and Cognitions Scale } \\ \text { BDI } & \text { Beck Depression Inventory } \\ \text { BITE } & \text { Bulimic Inventory of Edinburg } \\ \text { BN } & \text { Bulimia nervosa } \\ \text { BSQ } & \text { Body Shape Questionnaire } \\ \text { d.p. } & \text { Desvio padrão } \\ \text { EAT } & \text { Eating Attitudes Test } \\ \text { EF } & \text { Ensino Fundamental } \\ \text { EM } & \text { Ensino Médio } \\ \text { EV } & \text { Escore de evitação } \\ \text { FMUSP } & \text { Faculdade de Medina da Universidade de São Paulo } \\ \text { HC } & \text { Hospital das Clínicas } \\ \text { IMC } & \text { Índice de Massa Corpórea } \\ \text { Ipq } & \text { Instituto de Psiquiatria } \\ \text { OMS } & \text { Organização Mundial da Saúde } \\ \text { TANE } & \text { Transtorno alimentar não especificado } \\ \text { TAs } & \text { Transtornos alimentares } \\ \text { TOC } & \text { Transtorno obsessivo-compulsivo } \\ \text { YBOCKS } & \text { Yale-Brown Obsessive-Compulsive Scale } \\ & \end{array}$




\section{RESUMO}

Kachani AT. Checagem do corpo em transtornos alimentares : relação entre comportamentos e cognições [tese]. São Paulo: Faculdade de Medicina, Universidade de São Paulo; 2011. 203p.

INTRODUÇÃO: Pacientes com transtornos alimentares (TAs) costumam checar 0 corpo repetidamente com atitudes tais como: pesar-se constantemente, estudar a si mesmo no espelho, experimentar roupas para avaliar se estão adequadas ou não, beliscar o corpo, comparar seu corpo com 0 de outras pessoas, entre outras práticas. Esses comportamentos podem prolongar-se por muito tempo, várias vezes ao dia. Por outro lado, alguns pacientes têm atitude oposta e evitam ao máximo checar seus corpos. Os referidos comportamentos estão associados ao constructo central da doença: superavaliação do corpo, do peso e da alimentação. OBJETIVOS: Comparar comportamentos de checagem corporal em pacientes com anorexia nervosa (AN), bulimia nervosa (BN) e controles. MÉTODO: Aplicação de escalas padronizadas que avaliam checagem corporal, sintomas de AN e BN, imagem corporal, sintomas de depressão e transtorno obsessivo-compulsivo. A pesquisa foi realizada no Programa de Transtornos Alimentares (AMBULIM) do Instituto de Psiquiatria do Hospital das Clínicas da Faculdade de Medicina da Universidade de São Paulo (IPq HC-FMUSP) (grupo AN, $n=44$ e grupo $B N, n=41$ ) e Ambulatório de Ginecologia do HC-FMUSP (grupo controle, $n=40$ ). RESULTADOS: O grupo BN relatou checar mais o corpo (média $=57,83$ ) do que os outros grupos (média $\mathrm{AN}=46,05$ e média controle $=22,80 ; p$ valor $<0,001$ ) e também evitar mais a checagem corporal do que os outros dois grupos (media $\mathrm{AN}=$ 1,91; média $\mathrm{BN}=4,05$; média controle $=0,80 ; \mathrm{p}$ valor $<0,001$ ). $\mathrm{O}$ método mais comum para a checagem corporal foi a visualização no espelho, e a área corporal mais checada foi a barriga. Pacientes com AN indicam buscar, na checagem corporal, a verificação objetiva e o controle da dieta e ganho de peso, enquanto pacientes com BN indicam buscar segurança e garantia a respeito do corpo, além de antecipar as consequências de não checar. Já o grupo controle possui baixa motivação para se checar. A checagem corporal se relacionou com o peso desejado $(p=-340 ; p$ valor $<0,001)$, com a restrição alimentar $(b=0,501 ; p$ valor $<0,001)$, com a gravidade de sintomas bulímicos no grupo BN (média $=67,08 ; p$ valor $=0,021$ ), com a insatisfação corporal no grupo AN (média $=46,05$; $p$ valor $=0,001$ ) e BN (média $=57,83$; $p$ valor $=0,022$ ), com distorção da imagem corporal no grupo BN (média = $57,83 ; p$ valor $=0,030)$, com sintomas depressivos $(p=0,509 ; p$ valor $<0,001)$ e com alguns sintomas obsessivo-compulsivos, especialmente em pacientes com AN (média obsessões somáticas $=57,38 ; p$ valor $=0,004$; 
média compulsão por rituais para comer $=58,33$; $p$ valor $=0,043$ ). CONCLUSÕES: Os resultados indicam existir diferenças nos comportamentos de checagem corporal e nas cognições relacionadas a esses comportamentos, nos três grupos estudados. O grupo BN relatou checar mais o corpo e também evitar mais a checagem corporal do que os outros dois grupos. $O$ grupo que se preocupou menos com a checagem do corpo foi o grupo controle. As motivações para a checagem foram diferentes entre os grupos, sendo que o grupo controle teve baixa motivação para esse comportamento.

Descritores: 1.Transtornos alimentares 2.Checagem corporal 3.Cognição 4.Imagem corporal 5.Mulheres 


\section{ABSTRACT}

Kachani AT. Body checking and eating disorders : relationship between behaviors and cognitions [thesis]. São Paulo: "Faculdade de Medicina, Universidade de São Paulo"; 2011. 203p.

INTRODUCTION: Patients with eating disorders (ED) tend to repeatedly engage in body checking behaviors which includes constantly weighing themselves, looking in the mirror, trying on clothes to check for tightness, pinching body parts and comparing their own body to that of other people, among others. These behaviors may take a few seconds or carry on for several minutes many times a day. On the other hand, some other patients take an opposite attitude and completely avoid checking their body. These behaviors are associated with the core pathology of ED: overevaluation of body weight and eating. OBJECTIVES: To compare body checking behaviors in patients with anorexia nervosa (AN), bulimia nervosa (BN), and controls. METHODS: Standard scales for the assessment of body checking, anorexia and bulimia nervosa symptoms, body image, depression and obsessivecompulsive disorder symptoms were used. The study was conducted at the Eating Disorders Program (AMBULIM) of the Institute of Psychiatry, University of São Paulo, School of Medicine (IPq - HC - FMUSP) (AN group, $n=44$; and BN group, $n=41$ ) and at the Department of Gynecology, HCFMUSP (control group, $n=40$ ). RESULTS: The BN group reported more body checking (mean $=57.83$ ) than all other groups $(\mathrm{AN}$ mean $=46.05$; control mean $=22.80 ; p<0.001)$ as well as more body avoidance $($ AN mean $=$ 1.91 , $\mathrm{BN}$ mean $=4.05$, control mean $=0.80 ; \mathrm{p}<0.001)$. The most common body checking behavior was looking in the mirror, and the body part most frequently checked was the belly. Patients with AN seem to engage in body checking for objective verification and body and diet control while patients with $\mathrm{BN}$ engage in it for safety beliefs and reassurance of their own body. The control group showed low motivation to engage in body checking. Body checking was associated with the desired weight $(p=-340, p<0.001)$, dietary restriction $(p=0.501, p<0.001)$, severity of bulimic symptoms in the BN group ( mean $=67.08, p=0.021$ ), body dissatisfaction in the AN (mean $=46.05, p=$ 0.001 ) and $B N$ groups (mean $=57.83, p=0.022$ ), body image distortion in the $\mathrm{BN}$ group (mean $=57.83, p=0.030)$, depressive symptoms $(p=0.509$, $p<0.001$ ) and some obsessive-compulsive symptoms, especially in patients with AN (mean somatic obsessions $=57.38, p=0.004$, mean compulsive rituals eating $=58.33, p=0.043$ ). CONCLUSIONS: Body checking behaviors and related cognitions were apparently different in the three groups studied. Patients with BN reported more body checking and body avoidance than 
patients with $\mathrm{AN}$ and controls. Controls engaged less in body checking. Motivations for engaging in body checking were different in all groups studied and controls showed low motivation to engage in body checking.

Descriptors: 1.Eating disorders 2.Body checking 3.Cognition 4.Body image 5.Women 
Apesar de o estudo formal da imagem corporal ter tido início no começo do século $\mathrm{XX}$, foi somente há aproximadamente 25 anos que um aumento do interesse popular e acadêmico sobre o assunto ocorreu. Nesse período, os trabalhos focaram a qualidade e a intensidade do distúrbio da imagem corporal, evoluindo para um entendimento sofisticado a respeito dos fatores psicológicos e sociais que a influenciam (Dionne e Davis, 2004). Fatores como a crítica da sociedade (Heinberg e Thompson, 1992; Haimovitz et al. 1993), o estado do humor (Henriques et al., 1996; Taylor e Cooper, 1992), o consumo alimentar (Wardle e Foley, 1989; Thompson et al., 1993) e a influência da mídia (Becker et al., 2002; Birkeland et al., 2005; Niemeyer e Kruse, 2008) foram amplamente estudados.

Um tema menos discutido foi o feedback do próprio corpo, expresso pela checagem corporal. $\mathrm{O}$ dado é importante, visto que existem diferentes formas e medidas corporais disponíveis para que os indivíduos possam comparar seus próprios corpos com o de celebridades, atletas e padrões pré-estipulados pelas organizações de saúde (Nemerhoff et al., 1994; Dionne e Davis, 2004; Niemeyer e Kruse, 2008). Os parâmetros para 0 cálculo do índice de massa corporal (IMC) são amplamente divulgados nos dias de hoje e seu uso tornou-se um conhecimento popular. Aqueles que não têm o hábito de se compararem - ou exibem pouca preocupação com a forma do corpo - são cada vez mais incentivados a ter o costume de aferir 
suas medidas pelos próprios profissionais da saúde, e a maioria dos programas de perda de peso incluem a monitoração da checagem do corpo como protocolo de seus atendimentos (Wing e Hill, 2001). Esse tipo de feedback é tradicionalmente usado como um componente importante na mudança do comportamento alimentar, porém alguns trabalhos têm demonstrado que, para certos indivíduos, a checagem tem se tornado muito frequente, sendo que, para aqueles com transtornos alimentares (TAs), essa frequência pode ser bem maior (Reas et al., 2002; Fairburn et al., 2003; Dionne e Davis, 2004; Shafran et al., 2004; Mountford et al., 2006). Da mesma forma, a insatisfação corporal pode ser um grande motivador de atitudes saudáveis para a maioria da população (por exemplo, engajamento em dietas e atividades físicas monitoradas), mas para aqueles com vulnerabilidade para TAs ou para outros transtornos psiquiátricos pode ser um fator de risco ou mesmo um fator precipitante dessas síndromes (Dionne e Davis, 2004).

Dessa forma, programas modernos de imagem corporal têm sugerido às suas pacientes que "joguem fora suas balanças" e que evitem checar seus corpos, baseados em trabalhos que têm apontado que o feedback sobre o corpo pode afetar o humor, a autoestima e satisfação corporal (Ogden e Evans, 1996; Ogden e Whyman, 1997). A preocupação exagerada com o corpo pode levar a uma sensação de falha e incapacidade, o que no contexto da imagem corporal pode significar não viver dentro de um ideal (e ser lembrado disso o tempo todo pela mídia), comprometendo a autoestima e refletindo na insatisfação corporal (Dionne e Davis, 2004). 
Embora o assunto seja mais estudado nas áreas de psiquiatria e psicologia, ele também diz respeito, em grandes medidas, à área de atuação da nutrição. Na prática clínica, a aferição de medidas antropométricas durante a consulta - e em especial a pesagem - transforma-se em momentos "dramáticos" para as pacientes com TAs, momentos esses que podem prejudicar a consulta, caso o nutricionsita não esteja habituado a situações como essas. Por esse motivo, entre outros fatores, a American Dietetic Association (ADA) divide o tratamento nutricional de pacientes com TAs em duas fases: educacional e experimental, e orienta que, durante a segunda fase, é necessário que o nutricionista envolvido seja treinado, atuando com o psicoterapeuta num trabalho que busque aliar conhecimentos básicos de psicologia à nutrição (ADA, 1994).

A fase educacional precede a experimental e inclui coleta e transmissão de informações, estabelecimento de uma relação de cooperação com o profissional, educação alimentar, orientação para a família, entre outros aspectos, e qualquer nutricionista graduado está apto a fazê-la (ADA, 1994).

Já a fase experimental tem objetivos mais terapêuticos, que buscam ajudar o paciente a separar comportamentos relacionados com o peso e o alimento, de sentimentos e questões psicológicas. Nessa fase, o nutricionista incrementa as mudanças para uma reeducação alimentar até que o padrão de consumo alimentar seja normalizado; auxilia no aumento ou diminuição do peso de forma gradativa orientando sua manutenção sem comportamentos anormais de ingestão; além de 
aconselhar o comportamento alimentar em situações de risco (ADA, 1994; Alvarenga et al., 2004).

Nutricionistas que atuam no tratamento dos TAs enfrentam uma complexa dinâmica humana, que pode se tornar especialmente estressante em razão da importância das questões alimentares da doença. Portanto, precisam desenvolver algumas habilidades psicoterápicas - sempre apoiados pelos outros profissionais da equipe - para compreensão do potencial de comportamentos disfuncionais, a fim de que não concordem inconscientemente com 0 estilo de vida dos pacientes (ADA, 2001, Alvarenga et al., 2004). 
2 REVISÃO DA LITERATURA 


\section{Transtornos Alimentares}

Os transtornos alimentares (TAs) são síndromes comportamentais cujos critérios diagnósticos têm sido amplamente debatidos nos últimos 30 anos. Segundo a 4ª . versão do Manual Diagnóstico e Estatístico de Transtornos Mentais (DSM-IV - American Psychiatric Association, 1994), os TAs são classificados em anorexia nervosa (AN), bulimia nervosa (BN) e transtorno alimentar não especificado (TANE), e apresentam alguns aspectos psicopatológicos comuns, entre eles uma ideia prevalente que envolve preocupação excessiva com o peso e forma corporal, além do medo de engordar. Essa ideia leva os pacientes a se engajarem em dietas restritivas ou a utilizarem métodos inapropriados para alcançarem um corpo idealizado por eles. Consequentemente, os pacientes têm um controle patológico do peso corporal e distúrbios da percepção do formato de seus corpos, o que pode levá-los a um comportamento alimentar gravemente perturbado. Costumam julgar a si mesmos, baseando-se quase que exclusivamente em sua aparência física, com a qual se mostram sempre insatisfeitos (Claudino e Borges, 2002; Saikali et al., 2004).

Mais especificamente, a AN é marcada por restrições alimentares associadas ou não ao excesso de atividade física e comportamentos purgativos, como uso de laxantes, diuréticos, enemas e vômitos autoinduzidos, com a intenção de alcançar e manter um baixo peso corporal (Machado et 
al., 2007). Já a BN é caracterizada pela ingestão exagerada de alimentos (um consumo de alimentos definitivamente superior àquela que a maioria das pessoas ingeriria em um período de tempo similar, em circunstâncias semelhantes). Esses episódios são acompanhados de sensação de perda de controle, culpa e vergonha, seguidas pelas medidas purgativas recémcitadas, além de períodos de jejum prolongado (Sapoznik et al., 2005).

Os TAs são frequentemente crônicos e associados com um alto índice de comorbidade (Vilela et al., 2004). Estão distribuídos de forma heterogênea na população, sendo as mulheres jovens mais vulneráveis (Gorgati e Amigo, 2005). Estima-se que a prevalência de TAs para adultos seja de 0,5 a 3,7\% (APA, 1994), mas se fôssemos levar em consideração as síndromes parciais (não utilizadas neste trabalho), a prevalência aumentaria para 2 a 5\% (Hay, 2002). A prevalência de AN em mulheres tem sido descrita como $0,5 \%$, e sua incidência parece ter aumentado nas últimas décadas. Já a prevalência de BN é de aproximadamente 1 a $3 \%$, dependendo da população estudada (APA, 1994).

O diagnóstico é realizado com base na história clínica e alimentar do paciente, associada às informações de familiares e/ou pessoas próximas (Machado et al., 2007). Os critérios diagnósticos, segundo o Manual Diagnóstico e Estatístico de Transtornos Mentais (DSM-IV) (APA, 1994), encontram-se no Anexo 1 (Machado et al., 2007).

Os TAs têm etiologia multifatorial presumida, isto é, uma pluralidade de fatores interage entre si de modo complexo para produzir e/ou perpetuar a doença (Morgan et al., 2002). Esses fatores podem ser classificados em predisponentes (os que aumentam a chance do aparecimento da doença, 
mas não o tornam inevitável), precipitantes (aqueles que marcam o aparecimento dos sintomas de TAs) e os mantenedores (determinam se o transtorno vai ser perpetuado ou não) (Morgan e Claudino, 2005).

Os fatores predisponentes incluem traços de personalidade, risco para desenvolvimento da obesidade, fatores traumáticos na infância e adolescência (por exemplo, abuso sexual) e a realização de uma dieta restritiva, sendo que esses dois últimos podem também ser considerados fatores precipitantes (Morgan et al., 2002). Entre os fatores precipitantes encontramos a dieta e eventos estressores que envolvem uma desorganização da vida ou uma ameaça à integridade física, como, por exemplo, doença, gravidez, abuso sexual ou físico, proximidade da menarca (Cordás et al., 2004). Já os fatores mantenedores compreendem as alterações fisiológicas e psicológicas produzidas pela desnutrição e pelos constantes episódios de compulsão, tais como diminuição da cognição, insatisfação e/ou distorção da imagem corporal e aumento da depressão (Morgan et al., 2002).

Uma vez que os traços de personalidade são fatores predisponentes importantes para o desenvolvimento de TAs, faz-se necessário caracterizálos. A personalidade pré-mórbida de um indivíduo com AN pode ser descrita com traços de obsessão, perfeccionismo, passividade e introversão. Já as características de personalidade de pacientes com BN são sociabilidade, comportamento gregário e impulsividade, sendo este último um aspecto central do temperamento desses indivíduos, e consistente com o descontrole e a purgação (Diaz-Marsa et al., 2000; Morgan et al., 2002; Gorgati e Amigo, 
2005). Mas a baixa autoestima e a autoavaliação negativa são fatores de risco importantes tanto para AN quanto para a BN, uma vez que existe uma forte associação entre a internalização de um corpo ideal, insatisfação corporal e comportamento alimentar inadequado. Essas questões serão discutidas mais adiante (Stice et al., 1994; Shaw et al., 2004).

Indivíduos obesos parecem ser mais propensos à insatisfação com seu corpo (Foster e Matz, 2004), fazendo com que a tendência à obesidade seja um fator predisponente para o desenvolvimento de TAs, visto que repercute numa maior necessidade de fazer dieta. Na puberdade, o importante aumento da gordura corporal em meninas adolescentes requer uma reorganização do corpo e pode reforçar as preocupações com o peso (Gowers e Shore, 2001). A obesidade também prediz - na maioria das vezes - uma infância e adolescência povoadas de brincadeiras relacionadas ao peso, com efeitos deletérios na autoestima e na satisfação corpórea, aumentando a pressão social para emagrecer, especialmente em adolescentes com baixa confiança em si mesmos (Morgan e Claudino, 2002).

Estudo de coorte realizado por Patton et al. (1999) observou 2.032 adolescentes durante um ano e verificou que aqueles que faziam dietas restritas tiveram um risco 18 vezes maior para o desenvolvimento de TAs e aqueles com dietas moderadas tiveram risco de desenvolver TAs 5 vezes aumentado.

Segundo Shepherd et al. (2006) há uma alta prevalência de adolescentes que fazem dietas ou que têm comportamentos alimentares 
inadequados a fim de controlar seu peso. Essas condutas, além de não se manterem a longo prazo, aumentam o risco de TAs, elevando-as a fatores desencadeantes significantes. Num trabalho qualitativo, os autores acompanharam 30 adolescentes do sexo feminino participantes de um tratamento de prevenção de obesidade e publicaram algumas de suas falas, indicando que elas costumam restringir a alimentação a fim de se sentirem bonitas: "Garotas fazem dietas para estarem bonitas"; "A maioria das garotas não estão bonitas do jeito que gostariam (sic), então fazem dietas para melhorarem seu visual"; "Garotas ficam deprimidas com seu peso".

É importante salientar que a dieta isoladamente não é suficiente para produzir um TA, mas que, ao interagir com outros fatores, pode levar a esse desfecho (Hsu, 1997). Por outro lado, a restrição alimentar pode favorecer o aparecimento de compulsões alimentares, típicas do ciclo compulsão/ purgação da bulimia nervosa (BN). Já para aqueles indivíduos que conseguem aumentar cada vez mais a restrição alimentar sem ter compulsões, instala-se a desnutrição, fator de risco para a distorção de imagem corporal, que uma vez estabelecida aumenta o medo de engordar e o desejo de emagrecer, perpetuando a anorexia nervosa (AN) (Gowers e Shore, 2001).

Os distúrbios de imagem corporal não são suficientes para o diagnóstico de TA, mas têm importante relevância no prognóstico e resposta ao tratamento (Hamilton e Waller, 1993). Problemas relacionados à imagem corporal (IC) são comuns em pacientes com TAs, sendo critério diagnóstico para a síndrome (APA, 1994; Skrzypeck et al., 2001; Van den Berg et al., 2002). Em metanálise realizada por Stice (2002a) a fim de verificar os 
fatores de risco para TAs, o autor observou que a internalização de ideais de beleza vigentes e a supervalorização do corpo no autoconceito individual são componentes importantes da insatisfação corporal, que, por sua vez, aumenta a probabilidade da interligação dos componentes da sintomatologia alimentar: dietas restritivas, compulsões alimentares e afetos negativos.

Distorções cognitivas relacionadas à avaliação do corpo são comuns em indivíduos com transtornos alimentares e incluem: pensamento dicotômico: o indivíduo pensa em extremos com relação à sua aparência ou é muito crítico em relação a ela; comparação injusta: o indivíduo compara sua aparência com padrões extremos; atenção seletiva: o indivíduo focaliza um aspecto específico da aparência; erro cognitivo: o indivíduo acredita que os outros pensam como ele em relação à sua aparência (Saikali et al., 2004).

Porém, trabalhos têm demonstrado que a terapia cognitivacomportamental tem sido menos efetiva na melhoria da imagem corporal do que nos outros sintomas dos TAs, o que indica a necessidade de aprofundamento do estudo (Rosen, 1996). A imagem corporal é uma das questões mais difíceis de serem tratadas nos TAs, e a insatisfação corporal no fim do tratamento pode predizer um mau prognóstico (Bruch, 1962; Delinsky e Wilson, 2006; Mountford et al, 2006).

\section{Imagem Corporal}

A história do conceito da imagem corporal iniciou-se no século $\mathrm{XVI}$, na França, com o médico-cirurgião Ambroise Pare, que percebeu a existência do membro fantasma (alucinação de que o membro ausente pós- 
amputação está presente). Os franceses também deixaram outras contribuições: Bonnier, em 1905, descreveu um distúrbio da imagem corporal que chamou de "esquematia", ou seja, distorção do tamanho das áreas corpóreas (Barros, 2005). Foi nessa época - começo do século XX que o interesse no estudo da imagem corporal surgiu entre os neurologistas, que se preocupavam em relacionar certas formas de percepção distorcida do corpo com lesões cerebrais específicas (Tavares, 2003).

Mas foi na escola britânica que os estudos de imagem corporal aprofundaram-se tanto nos aspectos neurológicos quanto nosofisiológicos e psicológicos. O neurologista Henry Head, do London Hospital, descreveu uma série de distorções da experiência corporal em diversas síndromes neurológicas, contribuindo com rico material clínico (Tavares, 2003). Foi o primeiro a usar o termo "esquema corporal" e também o primeiro a construir uma teoria na qual "cada indivíduo constrói um modelo ou figura de si mesmo que constitui um padrão de comparação e exigência básica para a coerência na execução de cada nova postura ou movimento corporal” (Barros, 2005).

Contudo, talvez a maior contribuição ao conceito de imagem corporal tenha vindo do escritor alemão Paul Schilder, em 1935, que desenvolveu sua experiência na neurologia, psiquiatria e psicologia. Schilder considerava a imagem corporal um fenômeno multifacetado, que deveria ser analisado não somente no contexto orgânico, mas também no contexto da psicanálise e da sociologia, definindo a imagem corporal como "a imagem do nosso corpo que formamos em nossa mente" (Barros, 2005; Di Pietro e Silveira, 2009). Mais recentemente, Slade (1988) expandiu este conceito, definindo-o 
como a imagem que temos em nossas mentes do tamanho, contorno e forma de nossos corpos, bem como nossos sentimentos com relação a essas características e às partes constituintes de nosso corpo. Dessa forma, a imagem corporal teria um componente de percepção e outro de atitude (Slade,1994). Por percepção, podemos entender o conjunto de processos pelos quais reconhecemos, organizamos e entendemos sensações recebidas dos estímulos ambientais (Sternberg, 2000). Por atitude entendemos modo de agir, postura em relação ao mundo (Houaiss, 2004). Essas alterações na percepção do corpo e atitude em relação a ele são chamados de distúrbios da imagem corporal.

\section{Distúrbios da imagem corporal}

No começo dos anos 1960, Hilde Bruch fez observações pioneiras da imagem corporal em pacientes com TAs. Nessa época, a pesquisadora percebeu a inflexível superavaliação corporal de mulheres com AN e como esta era uma questão central e diagnóstica na psicopatologia da doença (Bruch, 1962). Bruch desenvolveu, então, a primeira teoria sistemática a respeito dos problemas da imagem corporal nos transtornos alimentares. Segundo ela (1962), a distorção da imagem corporal encontrada em alguns pacientes pode ser até mais preocupante do que a desnutrição, visto que leva a uma ausência da preocupação com a magreza, mesmo quando está em estágio muito avançado. No fim da década de 1980, novas evidências apontaram que os distúrbios da imagem corporal não eram restritos a 
pacientes com TAs, podendo acometer também indivíduos saudáveis (Thompson et al., 1993; Slade, 1994).

Indivíduos com distúrbios da imagem corporal (por exemplo: distorção da imagem corporal e transtorno dismórfico corporal) podem superestimar as dimensões corporais, o que implica no componente perceptivo. Já a insatisfação corporal, ou seja, a diferença entre o tamanho atual do corpo e do "corpo idealizado" estaria relacionada ao componente atitudinal do conceito (Gleaves et al., 2000; Scagliuzi et al., 2006).

A insatisfação corporal pode ser descrita como a discrepância entre o corpo ideal e o corpo percebido (Fingeret et al., 2004). Ortega et al. (1996) verificaram que um terço das mulheres com índice de massa corporal (IMC) $<20 \mathrm{~kg} / \mathrm{m}^{2}$ gostaria de perder peso. Em outro trabalho, Kiefer et al. (2000) observaram que $19 \%$ das pacientes com IMC adequado também gostariam de perder peso. Kjaerbye-Yhygesen et al. (2004) verificaram que $10 \%$ de mulheres com IMC entre 18,5 e $21 \mathrm{~kg} / \mathrm{m}^{2}$ de sua amostra gostariam de perder peso. Todos esses resultados apontam uma insatisfação corporal, porém é bom lembrar que existe na população feminina algo conhecido como insatisfação normativa, ou seja, a incidência da insatisfação corporal e consequentes dietas de forma difundida e aceita como normais pela sociedade (Ogden e Evans, 1996).

O trabalho realizado por Canpolat et al. (2005) apontou que uma grande insatisfação corporal, mesmo aliada a um baixo IMC, tem um impacto importante no início e manutenção de dietas, que, conforme explicado anteriormente, pode ser um motivo desencadeador dos TAs. 
Já a distorção da imagem corporal se caracteriza por afetar a percepção que o indivíduo tem da própria imagem corporal, o que pode levá-lo a ter preocupações irracionais sobre seu corpo. Sciacca et al. (1991) acreditam que a maioria das mulheres superestima seus corpos. Em estudo com amostra significativa de mulheres ( $n=676$ ), Crawford e Campbell (1999) observaram que 95\% delas estavam acima do peso que consideravam ideal, apesar de somente $45 \%$ estarem objetivamente com sobrepeso $\left(\mathrm{IMC}>25 \mathrm{~kg} / \mathrm{m}^{2}\right)$. Os autores também verificaram que $30 \%$ das entrevistadas gostariam de ter seu IMC $<20 \mathrm{~kg} / \mathrm{m}^{2}$ caracterizando então não somente distorção da imagem corporal, como também insatisfação corporal. Madrigal et al. (2000) apontam boa documentação na literatura sobre as relações entre o peso corporal e a percepção da imagem corporal, o que pode ser reforçado pelo trabalho de Kakeshita \& Almeida (2006), que estudaram 106 universitárias e constaram a tendência de mulheres eutróficas ou com sobrepeso em superestimar seu peso, o que se inverte à medida que aumenta $\mathrm{o} I \mathrm{MC}$, chegando à subestimação nas obesas. Slade (1994) aponta que existe uma variação na acurácia do julgamento corporal entre os TAs, obesidade e controles. Em indivíduos obesos ou com AN, o julgamento costuma ser distorcido. Já em pacientes com BN ou controles, a percepção do corpo costuma ser exata.

Quando o indivíduo tem preocupações irracionais sobre defeitos em alguma parte do corpo (seja ela do corpo como um todo ou em detalhes sutis da aparência), provocando reações exageradas, com importante prejuízo no funcionamento pessoal, familiar, social e profissional, é caracterizado o Transtorno Dismórfico Corporal (TDC) (Phillips et al., 
2001; Torres et al., 2005), porém esse quadro dos distúrbios de imagem corporal foge ao escopo deste trabalho.

As teorias da percepção construtivista podem explicar a distorção da imagem corporal. Essas teorias se baseiam no fato de que o indivíduo constrói uma compreensão cognitiva e perceptiva de um estímulo, usando várias fontes de informação, mas principalmente a informação sensorial como fundamento para a estrutura. De acordo com a teoria, durante a percepção levantamos e testamos rapidamente várias hipóteses relativas a perceptos, baseados no que sentimos (os dados sensoriais), no que sabemos (conhecimento armazenado na memória) e no que podemos inferir (utilizando processos cognitivos de alto nível). Assim, consideramos expectativas anteriores, o que sabemos sobre o contexto e o que podemos inferir baseados nos dados. Conhecida como percepção inteligente, a teoria estabelece que um pensamento superior desempenha um importante papel na percepção. Um exemplo seria a constância da cor: sabemos que um objeto permanece com a mesma cor, apesar das variações na iluminação; percebemos uma banana como amarela mesmo no escuro (Sternberg, 2000).

Outro conceito adquirido há alguns anos foi o da "elasticidade" da imagem corporal (Myers e Bioccia, 1992). Haimovitz et al. (1993) dedicaramse a discutir a instabilidade e a sensibilidade da imagem corporal de acordo com determinadas situações. Em suas pesquisas, 140 universitárias vivenciaram situações como: passear na praia com indivíduos atraentes usando biquínis, almoçar com amigos na lanchonete da universidade, preparar-se para ir à universidade em suas próprias casas, e, finalmente, 
experimentar roupas de banho no provador de uma loja de departamentos. Ao final do experimento, puderam observar que a imagem corporal flutuava de acordo com a situação. Altabe e Thompson (1990) verificaram que mulheres poderiam ter a imagem corporal alterada dependendo da fase do ciclo menstrual. Durante a fase lútea tardia e a fase menstrual, a insatisfação costuma ser maior, independentemente do ganho de peso real dessa fase. Já Wardle e Foley (1989) compararam três aspectos da imagem corporal (estimativa do tamanho do corpo, satisfação corporal e sensação de estar gordo) antes e depois do café da manhã. Os indivíduos participantes da pesquisa demonstraram maior insatisfação corporal após a refeição, independentemente do valor energético consumido. Ainda a respeito da relação consumo alimentar e imagem corporal, Thompson et al. (1993) observaram a mudança da satisfação corporal em 40 mulheres após o consumo de um milkshake. Aquelas que consumiram a versão mais calórica superestimaram seus corpos e estavam com o humor mais alterado do que aquelas que consumiram a bebida na versão menos calórica. Esse último trabalho está diretamente relacionado com a teoria do thought-shape, ou seja, a certeza de que certos pensamentos envolvidos com alimentos poderiam engordar. O thought-shape possui três componentes: 1) pensar em comida engorda (likelihood); 2) pensar em comidas proibidas é igual a comer (relacionado à moral) e 3) comer algo proibido aumenta o sentimento de estar gordo (relacionado a sentimentos) (Shafran e Robinson, 2004).

Outros fatores situacionais podem influenciar a imagem corporal num determinado momento, tais como a flutuação do ciclo menstrual, comentários 
rápidos de amigos e familiares, estados de humor transitórios, percepção de ingestão alimentar inadequada, entre outros (Dionne et al., 2004).

Stice (2004) explica que os distúrbios de imagem corporal acontecem em decorrência de:

1. Internalização das normas socioculturais referentes ao corpo ideal;

2. Autoavaliação negativa do próprio corpo;

3. Percepções distorcidas relacionadas à imagem corporal.

\section{Como é formada a imagem corporal?}

A consciência corporal é um processo dinâmico e que emerge da capacidade de atenção seletiva em relação às várias partes do corpo. Essa consciência está presente nas crianças recém-nascidas, que movimentam partes do corpo que não veem (por exemplo, a face); indivíduos cegos têm consciência do volume de seus corpos; pacientes amputados relatam a sensação de membros que não mais existem; enquanto outros, com paralisia unilateral, afirmam que não possuem um membro existente, mesmo vendo que ele está presente. Essas constatações indicam que as sensações são mais importantes do que a visão na hora da formação da autoimagem (Kinsbourne, 2004). Por outro lado, a literatura ainda não conseguiu definir claramente as bases neurológicas da imagem corporal. Sabe-se que a região somatossensorial, localizada no lóbulo parietal anterior do córtex pré-frontal cerebral, é a responsável pela recepção das sensações, estimuladas pelo ambiente externo. Em seguida, essas informações são interpretadas pelo lóbulo parietal posterior, que localiza o corpo no espaço (Kinsbourne, 2004). 
A fim de entender melhor a formação da imagem corporal e as diferenças entre indivíduos saudáveis dos pacientes com TAs, trabalhos recentes utilizando ressonância magnética funcional têm analisado possíveis alterações cerebrais relacionadas ao assunto (Miyake et al., 2009a; Miyake et al., 2009b; Boghi et al., 2010; Vocks et al., 2010). Um exemplo são os achados de Vocks et al. (2010), que expuseram mulheres com AN e BN a suas imagens e de outras mulheres de biquíni. Ao olharem suas próprias imagens, a área cerebral ativada nas pacientes foi o lóbulo parietal direito , enquanto ao observar as fotos de outras mulheres, a área mais ativada foi a amídala (localizada no sistema límbico, responsável pelo conteúdo emocional e memória), especialmente nas mulheres com AN. Trabalho semelhante realizado por Myake et al. (2010a) mostrou que mulheres com AN e controles, comparadas a pacientes com BN, ativaram com mais intensidade a amídala e córtex pré-frontal. Uma pesquisa do mesmo grupo (Miyake et al., 2010b), avaliando a resposta cerebral a palavras relacionadas à imagem corporal, observou que a amídala foi mais ativada nas pacientes com $A N$, enquanto o córtex pré-frontal foi mais ativado em pacientes com BN. Todos esses trabalhos apontam para a possibilidade de haver diferenças na resposta neural à percepção de anormalidade corporal entre indivíduos controle e pacientes com TAs, e também entre os subtipos da doença.

Nesse contexto, discute-se uma possível relação entre as regiões cerebrais envolvidas e o processamento da imagem corporal, sugerindo que as alterações neurológicas estão mais relacionadas à etiopatogenia e manutenção dos TAs do que às suas consequências (Bogui et al., 2011), 
como afirmavam alguns trabalhos do começo do século XXI. Nesse período, diversos estudos de neuroimagem apontaram atrofia da massa cinzenta e branca e aumento ventricular de mulheres com AN - decorrentes da desnutrição destas pacientes -, restituídos após a realimentação (Inui et al., 2002; Swaize et al., 2003; Miwa et al., 2004). Visto a importância do processamento neurológico da imagem corporal em pacientes com TAs e a grande controvérsia acerca do assunto, estudos mais aprofundados devem ser realizados nos próximos anos a fim de que essas valiosas informações possam ser esclarecidas (Vocks et al., 2010).

Na área cognitiva-comportamental, ao contrário do que habitualmente se supõe, a imagem corporal não está diretamente relacionada com o peso. Dependendo do indivíduo, uma perda de peso de $9 \mathrm{~kg}$ pode proporcionar uma melhora na imagem corporal igual a uma perda de $25 \mathrm{~kg}$, o que levou a ciência a se questionar quais são os fatores que realmente influenciam na imagem corporal, ou sob quais fatores o peso influenciaria na imagem corporal (Foster e Matz, 2004).

Em 1994, Slade propôs o modelo de formação de imagem corporal que é utilizado ainda nos dias de hoje. A Figura 1 ilustra a teoria proposta. Segundo essa proposta, sete itens seriam responsáveis pelo desenvolvimento e manifestação da imagem corporal:

a) História de percepções: estímulos físicos percebidos na história do indivíduo influenciam no desenvolvimento da noção, fazendo com que o indivíduo associe o que é visto ao que é lembrado (Sternberg, 2000). Assim, durante a vida, o indivíduo recebe estímulos visuais e 
táteis a respeito de sua aparência física e forma do corpo que formarão uma representação mental de seu corpo (Slade, 1994).

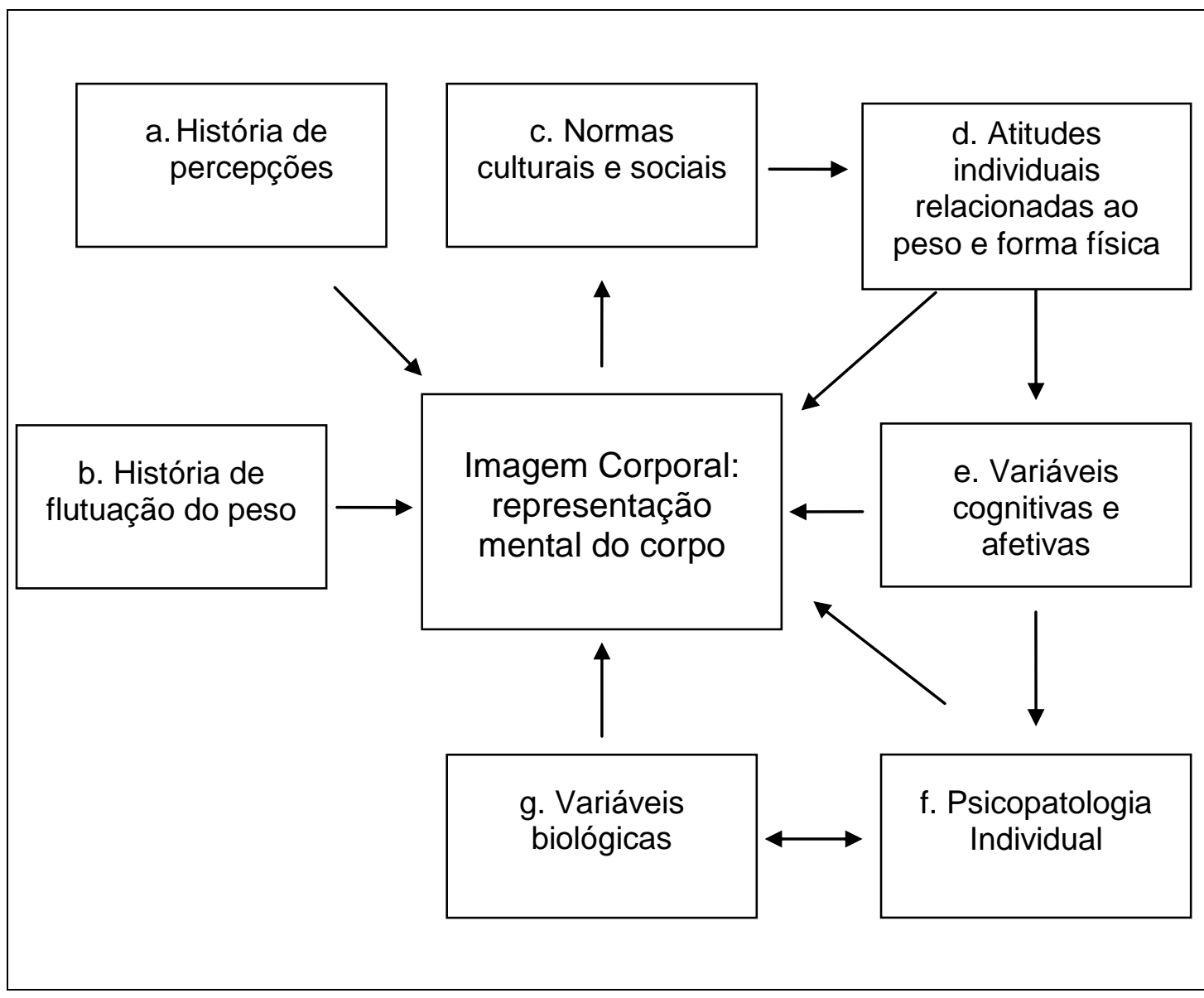

Figura 1: Modelo de fatores que influenciam o desenvolvimento e a manifestação da imagem corporal (Slade, 1994)

b) História de flutuação do peso: a preocupação em voltar a "ser gordo" permeia o imaginário daqueles que já tiveram sobrepeso e obesidade, num fenômeno conhecido como Phantom fat, ou seja, o medo de vivenciar novamente o sofrimento por causa do peso. Ao que parece, a satisfação corporal se mantém até dois anos 
após a perda de peso, quando então a insatisfação corporal e o medo de recuperar o peso aparecem (Annis et al., 2004).

c) Normas sociais e culturais: normas sociais fazem do corpo um terreno cheio de significados simbólicos: informam sobre a posição social do indivíduo e, muitas vezes, demonstram um sinal de mudança em seu status social (Saikali et al., 2004). A questão da influência da cultura na imagem corporal será discutida num capítulo a parte.

d) Atitudes individuais relacionadas ao peso e forma física: ideias como "fazer regime", "usar medicação" e "se cuidar bastante" fazem parte do repertório vivencial das mulheres desde a adolescência (Conti, 2008).

e) Variáveis cognitivas e afetivas: expressões verbais e comentários paternos relativos a comida, peso e forma física podem influenciar diretamente a autoestima dos filhos. Alguns trabalhos mostram que os pais são a segunda maior fonte de informações sobre dietas (Paxton et al., 1999), e seis entre sete meninas que fazem dietas restringem sua alimentação por influência dos pais (Byely et al., 2000). Gross e Nelson (2000) observaram que mensagens negativas podem predizer em adolescentes o desejo de perder peso, e a crença da crítica da mãe em relação ao peso das filhas pode levar à insatisfação corporal e a sintomas bulímicos (Stunkard, 1997; Hanna e Bond, 2006).

f) Psicopatologia individual: características de personalidade, tais como o narcisismo e sua relação com a imagem corporal, têm sido muito estudadas (Tavares, 2003; Waller et al., 2008). Transtornos 
do humor e transtorno obssessivo-compulsivo (TOC) também têm recebido atenção (Fontenelle et al., 2002) e serão discutidos numa outra seção.

g) Variáveis biológicas: sabe-se que a taxa de metabolismo basal baixa está diretamente relacionada ao ganho de peso (Schoeller, 2009). A época da menarca também pode ser impactante na influência da imagem corporal. Psicologicamente, essa é uma época difícil para as meninas, que socialmente têm que encarar uma maturidade que nem sempre possuem, repercutindo muitas vezes em insegurança, baixa autoestima e insatisfação corporal (Levine e Smolak, 2004). É na puberdade também que a mulher ganha $50 \%$ de sua massa corporal, com contribuição especial do ganho de gordura, que é depositada principalmente nos quadris, busto e nádegas, deixando as meninas longe do ideal estético vigente (Castilho e Barras Filho, 2000; Vitalle et al., 2003; Levine e Smolak, 2004). Paralelamente, inicia-se a diminuição do crescimento, o que influencia diretamente no valor de IMC, na prevalência de obesidade, e, possivelmente, na imagem corporal (Castilho e Barras Filho, 2000; Vitalle et al., 2003).

Segundo alguns autores, a imagem corporal é construída na adolescência, quando o corpo estabelece seu formato (Graham et al., 2000; Branco et al., 2006). Nessa fase de vida, as adolescentes costumam apresentar uma autopercepção não condizente com a realidade, o que inclui 
a falta de noção do seu estado nutricional, e é aí que podem iniciar sentimentos de insatisfação com a imagem corporal (Branco et al., 2006).

Em pesquisa qualitativa que objetivou observar os aspectos que compõem o conceito de imagem corporal pela ótica do adolescente, Conti (2008) observou que as meninas eram mais detalhistas a respeito de sua imagem do que os meninos. Trabalhos recentes mostram também que a insatisfação corporal e as estratégias extremas a fim de melhorar a autoimagem aparecem na adolescência (Parkes et al., 2008), quando o indivíduo começa a perceber o quanto o estigma da obesidade pode ser limitante em suas vidas (Annis et al., 2004).

\section{Influência social na imagem corporal}

Recentemente, percebeu-se que os diversos significados atribuídos e elegidos para o corpo são também decorrentes da multiplicidade de culturas em que este está inserido. Assim, o corpo é o lugar de diferentes formas de sociabilidade e espelha a vida social de uma comunidade (Novaes, 2010). O comportamento de toda e qualquer pessoa é influenciado pela presença e ações de outros, que são observados e imitados. A imitação ocorre quando um seguidor copia o comportamento de um modelo. Uma das teorias da imitação sugere que as pessoas imitam porque tiveram reforço para fazê-lo no passado (Harrison, 1975). Geralmente, o modelo é um executante competente, cujo comportamento recebe recompensa. Assim, é perfeitamente razoável que o imitador espere ser recompensado por comportar-se da mesma maneira. Mas quem é imitado? Normalmente, superiores na 
hierarquia etária, na classificação social ou na classificação intelectual. Tecnicamente, superiores em qualquer campo. No entanto, muitas vezes não se distingue quais aspectos devem ser imitados do comportamento de seus superiores, ou seja, não se distingue aspectos sadios de outros inadequados (Harrison, 1975). Dessa forma, adolescentes costumam imitar o modelo de comportamento alimentar de seus pais, que muitas vezes não é propício (Stice, 2002a).

Reações imitativas são muitas vezes reforçadas, tornando o comportamento altamente resistente. Conhecido como reforço social, esse mecanismo é comumente administrado por outras pessoas, que retribuem um comportamento aprovado por elas com amor, afeição, sorrisos, olhares amistosos e aprovações verbais. É importante saber que a pessoa que administra a aprovação social não precisa estar fisicamente presente para influenciar opiniões, e que os efeitos da aprovação podem perseverar no tempo. Dessa forma, um dos grandes desafios é como esse comportamento aprovado pode ser enfraquecido ou eliminado (Harrison, 1975).

O grupo em que um indivíduo se encontra pode estimular a imitação e o reforço social. Membros de um grupo costumam avaliar e influenciar seus pares resultando em pressões externas. Por outro lado, as normas de um grupo ditam o modo pelo qual a pessoa avaliará seu próprio comportamento, resultando em pressões internas. Amigos da escola podem ter influência direta, não só servindo de modelo como também exercendo pressões e fazendo gozações. Para garotas, a opinião dos meninos (e o que elas 
pensam ser sua opinião) também pode ser uma fonte de pressão (Dunkley et al., 2001). Em trabalho de 2001 que verificava quais itens exerciam maior poder sobre a influência na imagem corporal de adolescentes, foi observado que a opinião dos rapazes, das garotas populares da escola e das amigas só perdia para a influência da mídia (Dunkley et al., 2001).

Em revisão acerca da influência dos pares sobre a imagem corporal, Stice (2002 a,b) esclarece como o grupo pode influenciar no comportamento alimentar: 1) pacientes bulímicos relatam ter iniciado o comportamento bulímico por sentirem-se pressionados por seus amigos para ser magros; 2) brincadeiras de mau gosto e piadas a respeito do peso podem levar a insatisfação corporal; 3) muitas vezes amigos ensinam formas de controle de peso inadequadas. Segundo o autor (Stice, 2002a), a família representando então outro tipo de grupo, mais especificamente os pais também exerce pressões para que seus filhos sejam magros.

Alguns trabalhos parecem também apontar que estudantes obesos costumam ser discriminados na escola, e em trabalhos experimentais em que se apresentavam fotos de indivíduos com problemas físicos, as fotos de obesos eram as mais rejeitadas. Relatos de indivíduos obesos costumam conter queixas de discriminação e exclusão social em decorrência de seu peso (Puhl e Brownell, 2002).

Alguns estudos têm observado que a influência da aculturalização na imagem corporal pode ser tão grande que chega a interferir na identidade racial (Fichter et al., 2005; Nasser, 2006). É o caso do trabalho de Skrebline e Sujoldzic (2003), que estudaram imigrantes croatas adolescentes do sexo 
feminino. Nesse processo, a fim de se misturarem com garotas da mesma faixa etária, as imigrantes engajaram-se em hábitos alimentares inadequados para obter um corpo adequado ao padrão vigente. $\mathrm{O}$ trabalho apontou que $25 \%$ das imigrantes estavam em dieta contra $13 \%$ das adolescentes locais. As garotas em dieta apresentaram baixa autoestima e insatisfação corporal.

As normas de um grupo são aprendidas e interiorizadas pelos seus membros, que se sentem satisfeitos por correspondê-las e, assim, mantêm seu comportamento. A isso se denomina conformidade do grupo, ou seja, uma uniformidade na ação e reação, e podemos, então, verificar semelhanças no grupo e diferenças entre grupos (Harrison, 1975). Mas é sempre bom lembrar que, considerando a diversidade de tamanhos, formas e raças que as pessoas apresentam, sempre que um único padrão de beleza é eleito e aceito - seja ele magro, musculoso ou gordo - existirão pessoas marginalizadas (Scagliusi e Lourenço, 2010). Isso porque na sociedade contemporânea ocidental, o corpo possui um valor próprio, independente da pessoa que o "carrega", substituindo a alma em sua função moral e ideológica (Baudrillard, 1991), especialmente nas mulheres. Enquanto no universo masculino o desvio com relação ao padrão de beleza está vinculado a trabalho e falta de tempo, para as mulheres, não cultivar a beleza é falta de vaidade - um qualitativo depreciativo da moral. Como diria a estilista francesa Coco Chanel: "Podemos nos acostumar com a feiúra, mas não com a negligência". Esse fenômeno diz respeito à noção de que o sujeito pode e deve ser engenheiro de si mesmo e estaria apto a montar, remontar e recriar suas formas redesenhando as fronteiras de seu corpo (Novaes, 2010). 


\section{Cultura e Imagem Corporal}

Normas socioculturais têm sido consideradas primordiais para elaboração do estereótipo de corpo ideal e consequente associação entre magreza e atributos positivos, principalmente entre as mulheres (Stice et al., 1994). Para elas, o desejo de melhorar a aparência física, diminuir o descontentamento com o corpo e deixar de ser alvo de discriminações, parece motivar a mudança quanto ao tamanho e forma corporal, nem que seja necessário para isso buscas incansáveis para a redução de peso (Almeida et al., 2005).

Paralelamente, análises têm estabelecido que modelos, atrizes e outros ícones femininos vêm se tornando mais magras ao longo das décadas (Stice e Shaw, 2002). Nossa cultura está saturada de representações de corpos de mulheres cuja forma e tamanho são dificilmente encontrados no dia a dia (Nemeroff et al., 1994). Difundida pela mídia, a magreza está estabelecida como bela e necessária para que o indivíduo seja bem aceito na sociedade em que vive (Niemeyer e Kruse, 2008). Nesse contexto, indivíduos com propensão a TAs sentem-se pressionados pela mídia para serem magros e reportam terem aprendido técnicas não saudáveis de controle de peso, como vômitos, exercícios rigorosos e dietas drásticas através deste veículo (Stice e Shaw, 2002).

Atitudes culturais que enfatizam a importância da beleza, a necessidade de atrativos estéticos, a comparação com outras pessoas ou com padrões idealizados e a aceitação pelo grupo social têm sido sugeridas como aspectos relevantes no desenvolvimento e manutenção dos sintomas 
de TAs (Schomer e Kachani, 2009). Para difundir essas atitudes, nunca como hoje as pessoas puderam adquirir tanta informação sobre aquilo que se passa no mundo e as personalidades implicadas nos acontecimentos (Souza, 2006). Essas informações são apreendidas pelos indivíduos e unem-se à sua imagem corporal, transformando-os em camaleões que se adaptam àquilo que as circunstâncias exigem. O mundo passa então a ser percebido a partir de tais influências (Barros, 2005).

O número de programas televisivos, revistas sobre dietas e anúncios que divulgam maneiras de atingir o corpo perfeito têm crescido muito nos últimos anos, repercutindo no aumento de casos de TAs, uma vez que indivíduos com maior vulnerabilidade genética e sob um importante impacto ambiental e cultural podem ter a expressão fenotípica de TAs favorecida (Hamilton e Waller, 1993, Stice et al., 1994; Torres et al., 2005).

Se partirmos do pressuposto de que a construção do sujeito é feita também pelos discursos que o cercam, a mídia se torna uma instância em que o poder se exercita, desempenhando papel essencial na constituição da identidade moderna e na produção de conceitos comportamentais. Encontramos uma sofisticada "maquinaria pedagógica" (incluindo revistas, jornais, televisão, filmes, músicas e publicidade) exercendo um importante papel na formação das pessoas, ensinando modos de ser, estar e se portar no mundo que amplia a educação dos corpos (Niemeyer e Kruse, 2008). A teoria da comparação social tem sido utilizada para explicar o fenômeno. Comparações relativas à aparência fazem com que indivíduos se engajem em pensamentos e avaliações negativos sobre si mesmos. Uma vez que 
não encontram o "padrão-ouro" de beleza que gostariam, é estabelecida a insatisfação corporal (Birkeland et al., 2005).

Trabalho realizado com adolescentes nas Ilhas Fiji antes da chegada dos meios de comunicação em massa e após três anos de instalação da televisão apontou que os TAs foram significativamente mais prevalentes após exposição à mídia eletrônica, uma vez que as participantes do projeto estavam mais propensas a perder peso numa tentativa de se igualar aos ídolos televisivos (Becker et al., 2002).

Na década de 1990, pesquisas já indicavam que não importa o quanto se assiste à televisão, mas sim a que se assiste. Em 1996, Tiggerman e Pickering avaliaram o tempo de TV e os programas assistidos por 94 adolescentes, relacionando-os com a subescala de tendência para dietas do "Questionário de Transtornos Alimentares" (EDI - Garner et al., 1983). Apesar de a maioria das jovens assistir uma média de 20 a 25 horas semanais de televisão, foram os tipos de programas assistidos que se relacionaram positivamente com a insatisfação corporal. É comum novelas, seriados e filmes apresentarem mulheres estereotipadas, porém os programas de videoclipes tiveram papel definitivo na relação entre as adolescentes e tendência a dietas. Segundo os autores, as personagens de novelas, seriados e filmes possuem outros papéis além de símbolos sexuais, enquanto que, nos videoclipes, as modelos se assemelham mais a como as adolescentes gostariam de ser e de se comportar. Esses programas tendem a mostrar mulheres bonitas e magras, precariamente vestidas e envolvidas em comportamentos sexualizados, em um padrão 
compatível com a pressão social que acontece nesta faixa etária para que desenvolvam uma identidade sexual.

Uma vez que os TAs costumam se iniciar na adolescência (Tiggerman e Pickering, 1996), uma fase de vida vulnerável, na qual os jovens se tornam seguidores de modismos, aparecendo preocupações ligadas ao corpo e à aparência (Branco et al., 2006), alguns autores procuraram explorar o impacto da mídia impressa nessa população, visto que essa população também está exposta a esses veículos, com matérias que apresentam cada vez mais conteúdos ligados a dietas, com aumento de matérias sobre regimes alimentares, práticas de atividade física e/ou ambos (Luff e Gray, 2009).

Foi pensando nisso que Dunkley et al. (2001) avaliaram os fatores de pressão para um corpo perfeito em 577 garotas com idade entre 13 e 17 anos e verificaram que a moda e a mídia impressa e eletrônica eram os fatores de maior impacto. Em estudo anterior, Field et al. (1999) já haviam observado que $69 \%$ das 548 adolescentes estudadas relataram que as fotos de revistas influenciavam na ideia de corpo perfeito, e $47 \%$ delas confessaram querer perder peso por causa das figuras das revistas. A frequência de leitura de revistas foi positivamente relacionada com a prevalência de dietas e prática de atividade física.

Discute-se igualmente a respeito de que diferenças individuais e de contexto na sociedade podem ser decisivas na evolução dos distúrbios da imagem corporal (Dionne e Davis, 2004). Comenta-se muito a respeito da “Teoria da Comparação Social”, elaborada por Festinger, em 1954. Segundo 
essa teoria, os indivíduos são muito sensíveis à comparação, críticas da sociedade e, principalmente, aos seus respectivos feedbacks (Heinberg e Thompson, 1992). Dessa forma, a teoria poderia predizer que comparações com modelos femininos atraentes poderiam diminuir a autoestima de mulheres saudáveis. Em trabalho de 1995, Heinberg e Thompson (1995) observaram que somente aquelas mulheres com alta insatisfação corporal pioravam sua imagem corporal ao serem expostas a comerciais com fotos de mulheres com "corpo ideal", sugerindo que mulheres com risco a exposição seriam aquelas já com altos índices de distúrbio da imagem corporal.

O primeiro trabalho a verificar o impacto das fotos das modelos sobre pacientes com TAs foi realizado em 1993, por Hamilton e Waller. Nesse estudo clássico, os autores compararam o impacto de fotos de modelos femininos e a decorrente autoavaliação dos corpos de 24 pacientes (mulheres) com o impacto de fotos de revistas de decoração sobre a estimativa dos corpos dessas mesmas mulheres. Os autores perceberam que a superestimativa ocorria após a visão dos corpos esquálidos das modelos, mas não necessariamente após a observação das fotos de decoração, indicando que a mídia, apesar de não ser a única responsável pela distorção de imagem corporal de pacientes com TAs, pode ter alguma importância clínica no distúrbio da imagem corporal tão comumente apresentado.

No Brasil, uma revista direcionada ao público adolescente foi analisada qualitativamente por Niemeyer e Kruse (2008). As autoras observaram que a revista estimulava as leitoras em comportamentos que o próprio veículo considera "anoréxicos", mostrando que o corpo magro é o 
corpo perfeito, definindo e classificando corpos, apontando "imperfeições", prescrevendo alternativas para corrigir "desvios" com medidas que vão desde o uso de determinadas roupas até privações alimentares representadas por variadas dietas e exercícios físicos, sujeitando a leitora à busca da imagem ideal. Por outro lado, a revista tem um discurso contraditório, uma vez que alerta as adolescentes sobre os perigos dos transtornos alimentares.

Sabe-se que o contexto social é um componente etiológico importante dos TAs, já que pode impactar negativamente a imagem corporal, as atitudes e as crenças alimentares (Becker et al., 2002). Assim, apesar de trabalhos epidemiológicos terem demonstrado uma maior prevalência de TAs em sociedades industrializadas do que naquelas em desenvolvimento, outros apontaram ainda a associação positiva entre exposição à mídia e índices de TAs, principalmente em sociedades de transição cultural dentro da política de globalização (Stice e Shaw, 1994; Tiggerman e Pickering 1996; Field et al., 1999).

Mas os comunicólogos se protegem contra as acusações e alegam que, antes de acusar a mídia de influenciadora negativa na imagem corporal dos indivíduos, devemos levar em consideração as diferentes teorias dos efeitos da comunicação, em particular as que se fundam em pesquisas empíricas. Olhando por esse prisma, a mídia teria maior impacto nas percepções da realidade e nas cognições do que nas mudanças de atitude e comportamentos (Souza, 2006). Um exemplo seria a "Teoria das Balas Mágicas" ou "Agulha Hipodérmica", que pretende traduzir 
metaforicamente $\mathrm{o}$ fato de as pessoas não apresentarem a mesma resposta mecânica ao serem atingidas pelas mensagens midiáticas (estímulos). Nessa teoria, a comunicação é vista como um processo reativo enquanto a sociedade é avaliada como sendo constituída por indivíduos aglomerados numa massa uniforme e passiva (Souza, 2006).

Em 1938, a célebre emissão radiofônica "Invasão Marciana", de Orson Welles, em comemoração ao Dia das Bruxas, veio mostrar que as pessoas não reagem todas da mesma maneira às mensagens midiaticamente difundidas (Souza, 2006). A referida emissão, adaptada do livro A Guerra dos Mundos, publicado pela primeira vez em 1898 por HG Wells, assustou muitos americanos, levando alguns ao suicídio. Foi então que um grupo de pesquisadores liderado por Cantril (1940) concluiu que, embora o poder dos meios seja grande, as características psicológicas e a personalidade das pessoas as predispõem ou não para reagir de determinada maneira às mensagens midiáticas.

Outro exemplo é a "Teoria dos Usos e Gratificações", que coloca a atenção sobre o indivíduo, especialmente sobre seus hábitos de consumo midiático, procurando entender os usos que as pessoas fazem da comunicação para satisfazerem necessidades e serem gratificadas através desse consumo ou da simples exposição a esses meios. Ou seja, em vez de analisar o que os meios fazem às pessoas, procura-se observar o uso que as pessoas fazem da comunicação social (Montero, 1993). O primeiro dos estudos a respeito dessa teoria foi o de Herzof, em 1944 (referenciada por Souza, 2006: 511), sobre o consumo de 
radionovelas nos Estados Unidos. A pesquisadora concluiu que as mulheres eram a maioria dos ouvintes das radionovelas, e que estas procuravam libertação emocional, conselhos, explicações para as coisas da vida, preparação para enfrentarem o cotidiano, etc. Em 1979, Blumler, analisando a teoria, realçou o caráter social das necessidades pessoais e salientou que os motivos que levam ao uso dos meios de comunicação podem gerar tipos específicos de influência por parte da mídia, sejam eles de caráter cognitivo, de entretenimento ou de identificação pessoal, gerando efeitos de facilidade de aquisição de conhecimentos ou reforço de identidade pessoal.

Para os pesquisadores Ball-Rokeach e DeFleur (1976), o consumo de mensagens midiáticas visaria satisfazer três objetivos ou efeitos:

a) Efeitos cognitivos: associados à apreensão e integração das mensagens, com repercussão na percepção da realidade. Nesse nível deve-se considerar a ambiguidade de informações, a formação de atitudes, as crenças, os valores desses indivíduos e a agenda setting (capacidade de agendar temas que serão objeto de debate público em determinado momento);

b) Efeitos afetivos: referem-se aos sentimentos e emoções provocados pela comunicação social;

c) Efeitos comportamentais: referem-se aos efeitos das mensagens sobre o comportamento das pessoas. Entre esses efeitos, encontramos a ativação ou desativação de comportamentos. Os efeitos comportamentais são consequência dos efeitos cognitivos e afetivos. 
Finalizando, alguns autores insistem que não devem ser feitos juízos de valor sobre o significado cultural da comunicação social enquanto não se explora a orientação do público (Katz et al., 1974). Recentemente, estudos concluíram que a comunicação pode ter efeitos comportamentais diretos, intencionais ou não, em certas pessoas e em determinadas situações. Esses efeitos correspondem à imitação de cenas vistas na mídia ou à imitação de atitudes, comportamentos e modo de vida de determinados personagens e personalidades midiáticas. Assim, Souza (2006) retoma a "Teoria das Balas Mágicas", afirmando que a imitação de comportamentos e atitudes observados na mídia existe, porém depende de algumas variáveis: consequências da ação observada, realismo da ação, atração, interesse e motivação do telespectador pela imagem, entre outras. Se parearmos as teorias da comunicação com estudos que relacionam mídia e imagem corporal, a teoria da comunicação concordaria com a teoria de que a mídia influencia atitudes e comportamentos ligados à imagem corporal somente daqueles indivíduos que têm uma predisposição aos TAs.

Corroborando com tal teoria, Weinberg e Cordás (2006) lembram que a importância da mídia na disseminação dos TAs é discutível quando são analisados registros de AN em outras épocas e outras culturas, em que não havia todo o aparato midiático que temos hoje em dia. As santas e beatas da Idade Média, com seus jejuns autoimpostos, não perseguiam um ideal de beleza, mas um ideal de ascese e de comunhão com Deus. Também faziam da recusa alimentar uma forma de conservarem a virgindade e opor-se a casamentos arranjados. Assim, os TAs deixam de 
ser um transtorno contemporâneo e se mostram um comportamento recorrente através da história.

De qualquer forma, profissionais da área de nutrição são responsáveis por auxiliar os pacientes em debates que promovam visões mais realistas do que são formatos e tamanhos corporais adequados e minimizem a aparência como indicativo de valor, enfatizando outras características como determinantes da importância agregada à pessoa (Scagliusi e Lourenço, 2010).

\section{A checagem do corpo}

Já é intrínseco ao tratamento de obesidade e dos TAs o controle das medidas antropométricas, mais especificamente a pesagem do corpo. O protocolo pretende comparar o peso recomendado pelos profissionais da saúde e fornecer ao paciente um feedback de sua evolução (Ogden e Whyman, 1997). A questão é que pesar e aferir medidas envolvem a comparação com normas sociais que podem facilitar a percepção de anormalidade e/ou insatisfação com o corpo.

Num estudo experimental, Ogden e Evans (1996) pesaram mulheres eutróficas sem problemas aparentes relacionados à imagem corporal e classificaram-nas em três categorias: baixo peso, normal e sobrepeso, de acordo com uma tabela fictícia. Os resultados indicaram uma deterioração no humor e autoestima daquelas do grupo de sobrepeso, sugerindo que, a curto prazo, a checagem das medidas pode não ser uma intervenção tão boa como se costuma acreditar. Isso porque, se a checagem está relacionada com uma 
mudança na percepção corporal, ela pode ser maléfica ao objetivo que se presta - a mudança de peso (Ogden e Evans, 1996).

Em 1997, Ogden e Whyman compararam humor, autoestima, imagem corporal e comportamento alimentar de 30 mulheres eutróficas que se pesavam diariamente com outras tantas que se pesavam quinzenalmente. Os resultados indicaram que aquelas que se pesavam frequentemente aumentaram a ansiedade e a depressão e pioraram a autoestima. Os resultados não indicaram relação significante com a imagem corporal e mudança no comportamento alimentar, apesar de aquelas que não se pesavam diariamente terem tido seu peso aumentado durante a pesquisa.

Checar o corpo frequentemente faz com que o indivíduo foque o tratamento sobre o peso corporal, exacerbando a sua autocrítica. Nesse contexto, o ganho ou a manutenção do peso podem ser encaradas como derrotas e a perda de peso, como sucesso (Ogden e Whyman, 1997).

Uma vez que é uma prática socialmente aceita, muitos são os indivíduos que costumam checar seus corpos com frequência, sem constrangimento (Farrel et al., 2004; Shafran et al., 2007). A prática de verificar o corpo repetidamente pode incluir atitudes como aferição constante de peso, estudar a si mesmo no espelho ou experimentar roupas para avaliar se estão adequadas ou não. Outros exemplos incluem examinar partes específicas do corpo no espelho, usar o tamanho das roupas para julgar, monitorar o quanto as coxas se esparramam quando um indivíduo se senta, beliscar a pele, e comparar seus corpos com o de outras pessoas (Rosen, 1996; Walker et al., 2009). Em pacientes com TAs esses comportamentos podem 
levar alguns segundos ou se prolongar por vários minutos, muitas vezes ao dia (Fairburn et al., 2003). A questão é que o exame cuidadoso pode ser propenso a aumentar aparentes defeitos, principalmente quando a verificação corporal não é realizada de forma holística, mas, sim, de uma forma seletiva (Delinsky \& Wilson, 2006). Quando um indivíduo examina alguma parte do corpo com a qual está insatisfeito, mais proeminente o problema se torna. E aqui cabe citar um ditado popular: "Quem procura, acha” (Fairburn, 2008). Uma curiosidade é trazida por Nahoum (1987). Segundo o autor, a difusão da técnica de feitura de espelhos foi fundamental para a transformação da imagem social do corpo. Até o começo do século XVII, o uso de espelhos era restrito à elite e somente a partir do século $X X$ sua utilização se tornou popular, sendo um objeto fácil de se encontrar entre utensílios domésticos, o que pode ter influenciado na checagem corporal. Em suas palavras: "Como viver num corpo que não se vê? Como mirar celulite na água do poço? Seu queixo duplo, no fundo da panela? Como construir uma imagem corporal tendo por espelho os olhos do outro?" (1987, p.23).

Estudo realizado por Jansen et al. (2005), em que foi avaliada a atenção visual para partes específicas do corpo por meio da eletrooculografia (aparelho que registra o movimento dos olhos), foi observado que, ao se olharem no espelho, as pacientes com TAs tendiam a focar a atenção nas partes do corpo que menos gostavam. Já os indivíduos controle faziam o contrário, ou seja, atentavam mais justamente para as partes que mais gostavam em seus corpos. Nesse mesmo trabalho, foi verificado que pacientes com TAs, ao compararem seus corpos com os de outros 
indivíduos, costumam focar as partes que os outros têm de mais bonitas, e o que eles (os pacientes) têm maior insatisfação, o que aumenta muito a chance de ficarem desgostosos com seus próprios corpos. Na maioria das vezes, a comparação é feita de forma superficial, e pacientes com TAs não costumam procurar indivíduos com as mesmas características do que as suas para se compararem, o que pode ser um problema caso o alvo da comparação não tenha a mesma altura ou idade, por exemplo. Vale a pena salientar que a comparação com outras pessoas é uma forma de checagem do corpo bastante comum - e que passa despercebida por muitos clínicos (Fairburn, 2008).

A insatisfação corporal não é objetivamente relacionada com o peso, porém é transferida para esse referencial visto que é uma variável mais fácil de ser controlada do que, por exemplo, uma ossatura larga (Jansen et al., 2006). Assim, a facilidade de se ter uma balança em casa possibilita essa forma de checagem corporal várias vezes ao dia. Como resultado, flutuações normais de peso que passariam despercebidas pela maioria das pessoas são notadas por pacientes com esse comportamento. A frequência na pesagem e constantes decepções com os resultados podem tornar o comportamento altamente aversivo, inclusive durante as sessões de terapia nutricional. É por isso que, ao checar o peso de um paciente com TAs, é importante discutir o que aconteceu nos últimos dias em relação à atividade física, ao comportamento alimentar e compensatório, à hidratação, entre outros, a fim de que esse paciente entenda que o peso é uma somatória de vários fatores (Fairburn, 2008). Segundo Fairburn (2008), muitas vezes, ao restringir a 
pesagem em pacientes com TAs, o comportamento migra para outra forma de checagem do corpo, como por exemplo, avaliar-se ao espelho.

Outro aspecto da checagem corporal que deve ser destacado é justamente o oposto: a evitação da checagem do corpo. Nesses casos, a hipervigilância sobre o peso e o corpo torna-se altamente aversiva e alguns indivíduos podem, em algum momento, não tolerar mais a repetida automonitoração e começar a evitá-la. Esse repúdio faz com que os indivíduos mantenham seus conceitos sobre o corpo uma vez que não têm mais maneiras de confirmá-los ou não. Sem o controle do "sucesso", frequentemente mantêm a insatisfação corporal e, consequentemente, as restrições alimentares (Fairburn et al. 1999; Fairburn, 2008). Exemplos de evitação de checagem do corpo seriam a recusa absoluta em se pesar, cobrir espelhos da casa, evitar se olhar quando passa por vidros e vestir roupas largas para disfarçar o corpo (Shafran et al., 2004; Walker et al., 2009). É importante salientar que a evitação da checagem corporal pode ser tão obsessiva a ponto de alguns autores acreditarem que a base do estímulo do comportamento seja fóbico (Vocks et al., 2008). Essa fobia pode ser tão intensa que certos pacientes chegam a evitar situações em que seu corpo poderia ser colocado à prova e a checagem corporal fosse necessária (por exemplo, em consultas médicas em que ocorre a pesagem, passeios na praia, onde existe a comparação) (Reas et al., 2002; De Berardis et al., 2007).

Existem ainda formas mistas de checagem e evitação da checagem do corpo, ou seja, coexistência dos dois comportamentos em que os indivíduos checam algumas partes do corpo e evitam outras (Fairburn, 2008). 
Os comportamentos de checagem corporal podem ser associados a uma baixa autoestima, superavaliação do corpo, restrições alimentares, fracasso em dietas e preocupação excessiva com perda de peso (Garner e Garfinkel, 1997; Walker et al., 2009). Estão também sujeitos a um leque de influências, entre elas o humor, o consumo alimentar hipercalórico e a imagem corporal (Taylor e Cooper, 1993; Shafran et al, 2004). São comuns em pacientes com TAs e estão associados ao constructo central da doença: superavaliação do corpo, do peso e do que se ingere (Fairburn et al., 2003; Shafran et al., 2004). Estudos prévios demonstraram que, apesar da checagem ser normativa entre as mulheres, naquelas com TAs alcança patamares diferentes (Reas et al., 2002; Shafran et al., 2004). Segundo Shafran et al. (2004), mais da metade dos pacientes com TAs relatam que a checagem afeta seu modo de ser e comer, mas que esse comportamento é alternado com o repúdio ao hábito.

As cognições relacionadas à checagem do peso permitem diferenciar a população clínica da não clínica, e a gravidade da doença está diretamente ligada à frequência da checagem de peso e/ ou sua aversão (Shafran et al., 2004; Mountford et al., 2006). Para pacientes com TAs, checar o corpo promove a percepção de imperfeição, servindo de reforço para manter a preocupação com o peso e o sentimento de perda de controle, ajudando-os, assim, a manter a restrição dietética (Reas et al., 2002; Waller et al., 2008). Na pesquisa de Shafran et al. (2004), somente 5\% da amostra relataram melhora do humor após checagem do peso. Para as outras pacientes, a checagem do corpo aumentou suas preocupações com o corpo. O problema 
é que a checagem do corpo (e especialmente a pesagem corporal) pode ser comparada a uma máquina de caça-níqueis, na qual o indivíduo tem a esperança de encontrar mudanças consideráveis no seu corpo e fica à mercê do acaso das flutuações de peso, repercutindo no reforço da checagem - que pode se tornar obsessivo - e de difícil extinção (Alfano et al., 2011).

É interessante perceber que o hábito de checar o corpo pode ser um controle para a segurança pessoal, uma vez que reduz a ansiedade a curto prazo. Por outro lado, o comportamento aumenta a ansiedade a longo prazo, pois o indivíduo fica dependente da aferição do corpo para reforçar crenças que serão responsáveis por assegurar o corpo idealizado (Fairburn et al., 1998; Haase et al., 2007; Waller et al., 2008).

Em pesquisa com 292 mulheres universitárias, Haase et al. (2007) perceberam que as cognições relacionadas à verificação objetiva do corpo envolvem a checagem do corpo como um todo, mas também partes isoladas como beliscar a barriga para verificar se há gordura. As cognições relativas à segurança e controle do corpo, além de envolverem a checagem do corpo todo (e de partes isoladas também), incluem idiossincrasias de checagem, como por exemplo, saber se o anel cabe no dedo da forma que deveria caber. Já as cognições relativas ao conforto emotivo estão associadas a partes isoladas do corpo.

Em pacientes com TAs, as cognições relacionadas à checagem do corpo estão associadas às atitudes, tais como ideias que dizem respeito à dieta, restrições alimentares e tamanho corporal, mas são mais específicas aos comportamentos - por exemplo compulsões e purgações (Haase et al., 2011). 
Entre os subgrupos dos TAs, pacientes com BN parecem checar mais o peso numa tentativa objetiva de verificar se a forma de purgação está sendo eficiente. Segundo Calugi et al. (2006), o fato de as pacientes com AN checarem menos seu peso pode estar relacionado com o sucesso visível de um peso muito baixo, reduzindo a necessidade de checagem. Porém essa hipótese não é consensual, já que seria incompatível com a eterna insatisfação corporal e a importante distorção de imagem corporal encontrada nessas pacientes com AN (Mountford et al., 2007). Seria incompatível também com a teoria comportamental da $\mathrm{AN}$, na qual se postula que essas pacientes seriam extremamente controladas pela família, e o peso, ao contrário de outras variáveis da vida (p.ex: trabalho, família, esportes, entre outros), poderia ser controlado por elas, garantindo então a sensação de sucesso (Fairburn et al., 1999). Nesse sentido, a checagem do corpo seria uma forma de controlar pequenas flutuações (e/ou manutenção) do peso de modo a incentivar ainda mais a restrição alimentar (Fairburn et al., 1999); porém, até o final desta revisão, não foram encontrados trabalhos que explicassem objetivamente a menor frequência de checagem corporal por pacientes com AN do que por pacientes com BN.

Trabalho de Waller et al. (2008) com 68 mulheres com transtornos alimentares verificou que aquelas com traços de personalidade narcísico tinham maior propensão em verificar seus corpos. Se levarmos em consideração que o narcisismo se refere ao amor que um indivíduo tem pela sua imagem, então esse indivíduo busca constantemente preservar uma imagem que julga adequada, e desta será escravo (Tavares, 2003). Nas 
culturas ocidentais, ser magro confere um senso de specialness e por isso reforçaria a checagem do corpo em indivíduos com características narcísicas (Beck et al., 2004).

O fato é que checar o corpo é comparar-se com normas culturais préestabelecidas. As implicações da checagem corporal e das tabelas de referência de peso/ altura vão além dos esperados direcionamentos para um tratamento de sobrepeso e obesidade e passam a ser determinantes nas intervenções comportamentais, tais como a mudança de dieta. São vistos como "motivadores" e "fornecedores de feedback" na mudança de peso e na restrição dietética (Ogden e Evans, 1996). É por isso que tratamentos modernos de imagem corporal investem no nondieting approach e incluem modificações nos pensamentos sobre corpo, mudança de estereótipos sobre a obesidade e importância da imagem e aparência física, exposição a situações relacionadas à imagem corporal, e eliminação dos comportamentos de checagem do corpo (Foster e Matz, 2004).

Imagem corporal, checagem do corpo e comorbidades nos transtornos alimentares

Ao falarmos de autoestima e de satisfação corporal nos TAs, é importante considerar os transtornos de humor. A incidência ao longo da vida de sintomas de transtornos do humor em pacientes com BN varia de $38 \%$ a $63 \%$ (Herzog et al., 1996). No que diz respeito à $A N$, a prevalência de transtornos do humor é quase universal, chegando a até $98 \%$ em alguns estudos (Ratsam et al., 1995). Porém, estudos de seguimento mostram que 
após seis a sete anos de tratamento, apenas 14\% dessas pacientes mantêm o diagnóstico de transtorno depressivo unipolar (Ratsam et al., 1995).

Atualmente, algumas possibilidades explicariam essa alta prevalência: a) os TAs poderiam levar a um quadro depressivo secundário; b) alguns pacientes com quadros depressivos desenvolveriam TAs como parte da síndrome depressiva; c) esses transtornos poderiam simplesmente coexistir sem nenhuma relação de causa e efeito (Fontenelle et al., 2002).

Segundo alguns autores (White et al., 1992; Craske e Pontillo, 2001; Rapaport, 2001; Spindler e Milos, 2007), o transtorno do humor bem como os transtornos ansiosos tendem a ser acompanhados por distorções de cognições relacionadas à percepção que esses pacientes têm de si mesmos e do meio em que estão, e podem ser estendidos para o domínio do "comer, parecer, pesar" independentemente de qual transtorno é primário.

Não são poucos os trabalhos na literatura que relacionam peso, imagem corporal e baixa autoestima (Rosen e Ross, 1968; Ogden e Evans 1996), e imagem corporal e humor deprimido (Taylor e Cooper, 1986; Kaplan et al., 1988). Uma vez estabelecida a relação imagem corporal e humor deprimido bem como insatisfação corporal com comportamentos de checagem diferentes (Reas et al., 2002; Rosen et al., 1991; Shafran e Robinson, 2004), Shafran e Robinson (2004) puderam observar a relação entre checagem corporal e humor. A evitação da checagem corporal, um dos subtipos da checagem corporal, pode estar também relacionada com o humor e seria uma forma de pacientes deprimidos não confirmarem seus piores sentimentos e medos (Salkovskis, 1991). 
Outra comorbidade frequente que influencia a checagem corporal é o transtorno obsessivo-compulsivo (TOC). Parece haver uma ligação entre o TOC e os TAs, principalmente na AN. Estudos recentes postulam que alguns casos de TAs sejam incluídos num suposto espectro obsessivo-compulsivo (Fontenelle et al., 2002; Blinder et al., 2006). Alguns autores observam que os pacientes com TAs referem pensamentos obsessivos desagradáveis e indesejados que os conduzem a comportamentos compulsivos, com vivências de incompletude, tomando tempo e causando sofrimento, vergonha, baixa autoestima e, em casos mais graves, isolamento social e incapacidade funcional (Castilho, 1999; Torres et al., 2005). No caso de indivíduos com TAs, seus pensamentos são frequentemente atormentados por ruminações incessantes e intrusivas sobre comida e forma corporal, além de diversos comportamentos ritualizados, como a restrição alimentar, a contagem de calorias, muitas verificações ao espelho e atividade física compulsiva (Yaryuara-Tobias, 2001; Torres et al., 2005). Nesse contexto, a checagem corporal poderia ser considerada uma forma de comportamento compulsivo, uma vez que, por meio da checagem do corpo, os pacientes poderiam reduzir temporariamente a ansiedade derivada de pensamentos negativos a respeito do peso e forma corporal (Rosen, 1997; De Berardis, 2007). Corroborando essa afirmação, alguns autores definem a checagem do corpo como "a monitoração repetitiva e ritualística dos inúmeros aspectos do corpo" (Smeets et al., 2011).

Vários estudos já tentaram definir a prevalência de TOC em pacientes com TAs. Revisões recentes têm apontado que $10 \%$ a $60 \%$ dos pacientes 
com AN e até $40 \%$ dos pacientes com BN têm TOC. Nos casos de pacientes primariamente diagnosticados com TOC, a prevalência de TAs varia de $13 \%$ a $42 \%$, resultado diferente daquele encontrado no Brasil, onde foi observada uma prevalência de $11,3 \%$ de TAs numa amostra de 815 pacientes com TOC (Halmi et al., 2005; Wu, 2008; Sallet et al., 2010).

Segundo Speranza et al. (2001), a prevalência da comorbidade em AN pode chegar a $22,4 \%$ (principalmente no subtipo purgativo) e a $12,9 \%$ na BN. Em 2002, Milos et al., relataram uma prevalência de $9 \%$ a $66 \%$ em pacientes com $\mathrm{AN}$ e $0 \%$ a $43 \%$ em pacientes com BN. Num trabalho mais recente, porém, que não distinguia pacientes com $\mathrm{AN}$ e BN, Brouwer et al. (2009) verificaram uma prevalência de $30 \%$ de TOC em pacientes com TAs, e observaram também que $60 \%$ deles apresentavam sintomas obsessivocompulsivos.

Esses pensamentos obsessivos podem estar relacionados a uma característica de personalidade: o perfeccionismo, implicado na etiologia e manutenção dos TAs, especialmente naqueles em que prevalecem o jejum e a purgação, ou seja, na AN e BN (Bulik et al., 2003; Halmi et al., 2005; Forbush et al., 2007). O perfeccionismo pode ser ainda um importante componente na insatisfação corporal e na decorrente baixa autoestima (Bulik et al., 2003), uma vez que essa característica pode criar expectativas corporais nem sempre realistas. Em uma meta-análise a respeito da personalidade de pacientes com TAs elaborada por Lilenfeld et al. (2006), das 26 pesquisas estudadas, oito delas indicavam o perfeccionismo como um traço marcante da personalidade do indivíduo com TAs. 
Embora a checagem do corpo e sua repulsa sejam expressões da superavaliação do corpo e do peso características de indivíduos com TAs (Fairburn et al., 2003), a literatura ainda é carente de trabalhos que discutam se esses comportamentos seriam preventivos ou uma forma de alívio de preocupações com a forma e com o peso. Outros autores acreditam que, diferentemente do TOC, a checagem compulsiva do corpo nos pacientes com TAs não é ansiolítica e o comportamento é motivado por crenças e não por obsessões (Shafran et al., 2004). 
3 JUSTIFICATIVA 
Os fatores cognitivos parecem ter um papel decisivo na etiologia e manutenção dos TAs. As distorções de imagem corporal ocorridas nas pacientes preocupam, uma vez que são estruturadas, inverídicas e descontextualizadas (Shafran e Robinson, 2004). A literatura acerca do tratamento de TAs aponta frequentemente a necessidade de trabalhar crenças pouco saudáveis que levem a comportamentos destrutivos em pacientes com esses quadros clínicos (Cooper et al., 1987; Thompson et al., 1987; Garner e Garfinkel, 1997).

A frequente checagem do peso está entre os comportamentos que podem sustentar cognições errôneas que foquem o alcance do peso perfeito e do corpo ideal (Mountford et al., 2006). A frequência da checagem de peso e seu repúdio variam de um indivíduo para o outro, e as razões para isso são ainda desconhecidas (Waller et al., 2008). Já é estabelecida na literatura a diferença de comportamentos de checagem corporal entre a população clínica e não clínica (Reas et al., 2002; Shafran et al., 2004; Mountford et al, 2006; Mountford et al., 2007), e até onde se sabe somente um trabalho foi realizado para diferenciar os subgrupos de TAs, porém com amostras bem menores do que este trabalho se propõe a fazer (Mountford et al., 2007).

Dada a importância do hábito de checar-se constantemente na etiologia e manutenção dos TAs, é importante que os clínicos conheçam e 
observem esse comportamento nos diferentes subtipos da doença, bem como os fatores que levam à checagem/ evitação da checagem corporal, pois esses aspectos poderiam estar associados a mudanças no modelo de tratamento. 
4 HIPÓTESES 
1. Pacientes com AN checam o corpo como verificação objetiva e forma de manutenção do controle;

2. Pacientes com BN checam o corpo como forma objetiva de verificação do peso, mas também por controle das estratégias de manutenção do peso;

3. Pacientes em dietas restritivas costumam checar mais o corpo;

4. Pacientes com comportamentos bulímicos purgativos costumam checar mais o corpo;

5. Pacientes com grande insatisfação corporal costumam evitar a checagem corporal;

6. Pacientes com sintomas depressivos costumam evitar a checagem do corpo;

7. Pacientes com sintomas obssessivos-compulsivos costumam checar mais o corpo. 
5 OBJETIVOS 


\section{Geral:}

Comparar comportamentos de checagem corporal e cognições relacionados a esses comportamentos em pacientes com anorexia nervosa (AN), bulimia nervosa (BN) e controles.

\section{Específicos:}

1. Verificar as áreas corporais e as formas de checagem mais utilizadas em cada grupo;

2. Verificar que cognições associadas ao comportamento de checagem são mais influentes em cada grupo;

3. Verificar se o tempo de tratamento influencia na quantidade de checagem corporal e cognições associadas;

4. Verificar possíveis associações entre atitudes alimentares e checagem corporal;

5. Verificar possíveis associações entre sintomas bulímicos e checagem corporal;

6. Verificar possíveis associações entre insatisfação corporal e checagem corporal; 
7. Verificar possíveis associações entre sintomas depressivos e checagem corporal;

8. Verificar possíveis associações entre sintomas obssessivo-compulsivos e checagem corporal. 


\section{MÉTODOS}




\subsection{Delineamento do estudo}

Estudo transversal, descritivo, que caracteriza um sinal/ sintoma, sem a intenção imediata de classificação.

\subsection{Local}

O projeto foi desenvolvido durante os anos de 2009 e 2010 no Programa de Transtornos Alimentares do Instituto de Psiquiatria do Hospital das Clínicas da Faculdade de Medicina da Universidade de São Paulo (AMBULIM - IPq - HC - FMUSP). A carta de anuência para realização do trabalho encontra-se no Anexo 1.

As pacientes foram encaminhadas ao AMBULIM por meio da triagem geral do Instituto de Psiquiatria, hospital público universitário que atende a população geral. Os pacientes que procuram a triagem geral podem fazê-lo espontaneamente, ou por encaminhamento de outras unidades do Hospital das Clínicas. 


\subsection{Casuística}

\subsubsection{Pacientes}

Todas as pacientes do sexo feminino tratadas no AMBULIM durante os anos de 2009 e 2010. Para inclusão no referido ambulatório, as pacientes foram avaliadas clinicamente por psiquiatras da equipe, e diagnosticadas a partir de critérios diagnósticos do Manual Diagnóstico e Estatístico de Transtornos Mentais - DSM-IV (APA, 1994) (Anexo 2). As pacientes foram divididas em dois grupos: $A N(n=44)$ e $B N(n=41)$. Para homogenizar os grupos, foram evitadas as pacientes com síndromes parciais ou TANE.

\section{Critérios de inclusão das pacientes:}

- Estar em tratamento no AMBULIM;

- Idade maior que 18 anos;

- Assinatura do termo de consentimento livre e esclarecido (Anexo 3);

- Condições educacionais que permitissem a compreensão das escalas utilizadas.

\section{Critérios de exclusão das pacientes:}

- Doença clínica ou psiquiátrica que impossibilitasse a compreensão dos questionários.

- Dependência de álcool e/ ou outras drogas com abstinência menor do que um mês (exceto nicotina e cafeína). 
As pacientes em tratamento no AMBULIM que se encaixavam nos critérios de inclusão foram convidadas a participar da pesquisa, o mesmo ocorrendo para as ingressantes no programa. No momento do convite, foram explicados todos os itens do Termo de Consentimento Livre e Esclarecido (Anexo 3), que foi assinado por aquelas que concordaram em participar da pesquisa. Em seguida, a paciente preencheu a ficha de dados sociodemográficos (Anexo 4), salvo os dados antropométricos, que foram preenchidos pela pesquisadora (peso atual, altura, altura ${ }^{2}=\mathrm{H}^{2}$ e IMC). Todas as escalas foram preenchidas também neste momento. Quatro pacientes com BN se recusaram a participar da pesquisa e uma paciente com AN estava muito desnutrida, a ponto de não conseguir se concentrar para preencher as escalas.

\section{Cálculo do tamanho amostral}

Uma vez que não foram encontrados trabalhos deste tipo na literatura, o tamanho amostral foi calculado com base no eta square $\left(\eta^{2}\right)$ (Kirk, 1995), tipo de effect size (Kraemer e Kupfer, 2005), a fim de se verificar a qualidade do ajuste. Para tanto, considerou-se $\eta^{2}=0,18$, valor exigente, pois supõe que apenas $18 \%$ da variância das variáveis de interesse (escores) serão explicados pelas variáveis independentes. Fixando-se, ainda, um nível de significância $\alpha \leq 0,05$ e um poder estatístico desejado de $1-\beta=0,95$, temos um tamanho mínimo de amostra representativa de 75 indivíduos (25 pacientes com AN, 25 pacientes com BN e 25 controles). 


\subsubsection{Grupo controle}

O Serviço de Ginecologia do HC-FMUSP concordou em participar deste projeto, permitindo que suas pacientes formassem um terceiro grupo (grupo controle), submetido às mesmas escalas aplicadas aos grupos de AN e BN (Anexo 5).

Para garantir a homogeneidade dos grupos, foi realizado um "balanceamento" por categorias de idade e de escolaridade das participantes (Fisher, 1922). Após já ter sido coletada a maioria dos dados das pacientes com transtorno alimentar $(n=73)$ e ser observada a distribuição das mesmas nas categorias de idade (18 a 20 anos, 21 a 30 anos, 31 a 40 anos, 41 anos ou mais) e de escolaridade (Ensino Fundamental completo - EF completo, Ensino Médio completo - EM completo, Ensino Médio incompleto - EM incompleto, Superior completo e Superior incompleto), foi realizada a técnica de alocação proporcional do grupo controle. Assim, são formados grupos homogêneos que diminuem ou anulam o confundimento, ou seja, é selecionado um grupo controle com características semelhantes aos casos a não ser pelo fato de não apresentar os distúrbios alimentares. A alocação proporcional do grupo controle foi realizada em três etapas: a) balanceamento por idade; b) balanceamento por nível educacional; e c) balanceamento final.

\section{a) Balanceamento por idade}

As pacientes foram categorizadas em quatro faixas etárias, e se mostraram grupos homogêneos em relação a essa categoria, ou seja, possuem frequências próximas em cada classe de idade, o que pode ser 
verificado pelo Teste Exato de Fisher ( $p$-valor= 0,304) (Vieira, 1998; Neter et al., 2004) (Tabela 1).

Tabela 1: Frequências de pacientes com anorexia nervosa e bulimia nervosa em relação às categorias de idade

\begin{tabular}{|c|c|c|c|c|c|c|c|c|c|}
\hline \multirow{3}{*}{ Idade } & \multicolumn{6}{|c|}{ Grupo } & \multirow{2}{*}{\multicolumn{3}{|c|}{ Total }} \\
\hline & \multicolumn{3}{|c|}{ Anorexia } & \multicolumn{3}{|c|}{ Bulimia } & & & \\
\hline & $\mathbf{N}$ & $\begin{array}{c}\% \\
\text { Idade }\end{array}$ & $\begin{array}{c}\% \\
\text { Grupo }\end{array}$ & $\mathbf{N}$ & $\begin{array}{c}\% \\
\text { Idade }\end{array}$ & $\begin{array}{c}\% \\
\text { Grupo }\end{array}$ & $\mathbf{N}$ & $\begin{array}{c}\% \\
\text { Idade }\end{array}$ & $\begin{array}{c}\% \\
\text { Grupo }\end{array}$ \\
\hline 18 a 20 anos & 5 & 38,5 & 12,8 & 8 & 61,5 & 23,5 & 13 & 100,0 & 17,8 \\
\hline 21 a 30 anos & 20 & 57,1 & 51,3 & 15 & 42,9 & 44,1 & 35 & 100,0 & 47,9 \\
\hline 31 a 40 anos & 9 & 47,4 & 23,1 & 10 & 52,6 & 29,4 & 19 & 100,0 & 26,0 \\
\hline 41 anos ou mais & 5 & 83,3 & 12,8 & 1 & 16,7 & 2,9 & 6 & 100,0 & 8,2 \\
\hline Total & 39 & 53,4 & 100,0 & 34 & 46,6 & 100,0 & 73 & 100,0 & 100,0 \\
\hline
\end{tabular}

Dessa forma, mostrou-se razoável a utilização das frequências dos grupos em relação às classes de idade para definir as frequências de indivíduos controle que estarão em cada classe de idade. A Tabela 2 mostra a frequência de pacientes e indivíduos-controle em relação às categorias de idade.

Tabela 2: Frequências de pacientes e controles em relação às categorias de idade

\begin{tabular}{lcccc}
\hline \multirow{2}{*}{ Idade } & \multicolumn{2}{c}{ Pacientes } & \multicolumn{2}{c}{ Controles } \\
\cline { 2 - 5 } & $\mathbf{N}$ & $\%$ & $\mathbf{N}$ & $\%$ \\
\hline 18 a 20 anos & 13 & 17,8 & $\mathbf{7}$ & 17,5 \\
21 a 30 anos & 35 & 47,9 & $\mathbf{1 9}$ & 47,5 \\
31 a 40 anos & 19 & 26,0 & $\mathbf{1 1}$ & 27,5 \\
41 anos ou mais & 6 & 8,2 & $\mathbf{3}$ & 7,5 \\
\hline Total & $\mathbf{7 3}$ & $\mathbf{1 0 0 , 0}$ & $\mathbf{4 0}$ & $\mathbf{1 0 0 , 0}$ \\
\hline
\end{tabular}




\section{b) Balanceamento por nível educacional}

A amostra também foi categorizada em níveis educacionais (Tabela 3) e, por meio do Teste Exato de Fisher ( $p$-valor $=0,080$ ), foi observado que a amostra também se distribui de forma homogênea em relação a essa variável (Vieira, 1998; Neter et al., 2004).

Tabela 3: Frequências de pacientes com anorexia nervosa e bulimia nervosa em relação às categorias de educação

\begin{tabular}{|c|c|c|c|c|c|c|c|c|c|}
\hline \multirow{3}{*}{ Educação } & \multicolumn{6}{|c|}{ Grupo } & \multirow{2}{*}{\multicolumn{3}{|c|}{ Total }} \\
\hline & \multicolumn{3}{|c|}{ Anorexia } & \multicolumn{3}{|c|}{ Bulimia } & & & \\
\hline & $\mathbf{N}$ & $\begin{array}{c}\% \\
\text { Educação }\end{array}$ & $\begin{array}{c}\% \\
\text { Grupo }\end{array}$ & $\mathbf{N}$ & $\begin{array}{c}\% \\
\text { Educação }\end{array}$ & $\begin{array}{c}\% \\
\text { Grupo }\end{array}$ & $\mathbf{N}$ & $\begin{array}{c}\% \\
\text { Educação }\end{array}$ & $\begin{array}{c}\% \\
\text { Grupo }\end{array}$ \\
\hline EF completo & 2 & 100,0 & 5,1 & 0 & 00,0 & 00,0 & 2 & 100,0 & 2,7 \\
\hline EM incompleto & 1 & 16,7 & 2,6 & 5 & 83,3 & 14,7 & 6 & 100,0 & 8,2 \\
\hline EM completo & 18 & 69,2 & 46,2 & 8 & 30,8 & 23,5 & 26 & 100,0 & 35,6 \\
\hline Superior incompleto & 10 & 45,5 & 25,6 & 12 & 54,5 & 35,3 & 22 & 100,0 & 30,1 \\
\hline Superior completo & 8 & 47,1 & 20,5 & 9 & 52,9 & 26,5 & 17 & 100,0 & 23,3 \\
\hline Total & 39 & 53,4 & 100,0 & 34 & 46,6 & 100,0 & 73 & 100,0 & 100,0 \\
\hline
\end{tabular}

Uma vez que ambas as variáveis se distribuem de forma homogênea na amostra, foi possível correlacioná-las e verificar um perfil da amostra de pacientes (Tabela 4). 
Tabela 4: Frequências de pacientes com anorexia nervosa e bulimia nervosa em relação às categorias de idade e educação

\begin{tabular}{|c|c|c|c|c|c|c|c|c|c|c|}
\hline \multirow{3}{*}{ Educação } & \multicolumn{8}{|c|}{ Idade } & & \\
\hline & \multicolumn{2}{|c|}{$\begin{array}{c}18 \text { a } 20 \\
\text { anos }\end{array}$} & \multicolumn{2}{|c|}{$\begin{array}{c}21 \text { a } 30 \\
\text { anos }\end{array}$} & \multicolumn{2}{|c|}{$\begin{array}{c}31 \text { a } 40 \\
\text { anos }\end{array}$} & \multicolumn{2}{|c|}{$\begin{array}{l}41 \text { anos ou } \\
\text { mais }\end{array}$} & \multicolumn{2}{|c|}{ Total } \\
\hline & $\mathbf{N}$ & $\%$ & $\mathbf{N}$ & $\%$ & $\mathbf{N}$ & $\%$ & $\mathbf{N}$ & $\%$ & $\mathbf{N}$ & $\%$ \\
\hline EF completo & 0 & 0,0 & 0 & 0,0 & 2 & 2,7 & 0 & 0,0 & 2 & 2,7 \\
\hline EM incompleto & 2 & 2,7 & 2 & 2,7 & 2 & 2,7 & 0 & 0,0 & 6 & 8,2 \\
\hline EM completo & 6 & 8,2 & 12 & 16,4 & 6 & 8,2 & 2 & 2,7 & 26 & 35,6 \\
\hline Superior incompleto & 5 & 6,8 & 12 & 16,4 & 3 & 4,1 & 2 & 2,7 & 22 & 30,1 \\
\hline Superior completo & 0 & 0,0 & 9 & 12,3 & 6 & 8,2 & 2 & 2,7 & 17 & 23,3 \\
\hline Total & 13 & 17,8 & 35 & 47,9 & 19 & 26,0 & 6 & 8,2 & 73 & 100,0 \\
\hline
\end{tabular}

c) Balanceamento final

Finalmente, foi possível parear os grupos a fim de se definir as frequências de indivíduos controle que estarão em cada classe (Tabela 5).

Tabela 5: Frequências de indivíduos controle em relação às categorias de idade e educação

\begin{tabular}{|c|c|c|c|c|c|c|c|c|c|c|}
\hline \multirow{3}{*}{ Educação } & \multicolumn{8}{|c|}{ Idade } & & \\
\hline & \multicolumn{2}{|c|}{$\begin{array}{c}18 \text { a } 20 \\
\text { anos }\end{array}$} & \multicolumn{2}{|c|}{$\begin{array}{c}21 \text { a } 30 \\
\text { anos }\end{array}$} & \multicolumn{2}{|c|}{$\begin{array}{c}31 \text { a } 40 \\
\text { anos }\end{array}$} & \multicolumn{2}{|c|}{$\begin{array}{l}41 \text { anos } \\
\text { ou mais }\end{array}$} & \multicolumn{2}{|c|}{ Total } \\
\hline & $\mathbf{N}$ & $\%$ & $\mathbf{N}$ & $\%$ & $\mathbf{N}$ & $\%$ & $\mathbf{N}$ & $\%$ & $\mathbf{N}$ & $\%$ \\
\hline EF completo & 0 & 0,0 & 0 & 0 & 1 & 2,5 & 0 & 0,0 & 1 & 2,5 \\
\hline EF incompleto & 1 & 2,5 & 1 & 2,5 & 1 & 2,5 & 0 & 0,0 & 3 & 7,5 \\
\hline EM completo & 3 & 7,5 & 7 & 17,5 & 4 & 7,5 & 1 & 2,5 & 15 & 35,0 \\
\hline Superior incompleto & 3 & 7,5 & 6 & 15 & 2 & 5,0 & 1 & 2,5 & 12 & 30,0 \\
\hline Superior completo & 0 & 0,0 & 5 & 12,5 & 3 & 7,5 & 1 & 2,5 & 10 & 25,0 \\
\hline Total & 7 & 17,8 & 19 & 47,9 & 11 & 26 & 3 & 8,2 & 40 & 100,0 \\
\hline
\end{tabular}


Alguns critérios de inclusão e exclusão também foram considerados para os indivíduos controle:

\section{Critérios de inclusão para o grupo controle:}

- Ser paciente do ambulatório ginecológico do HC-FMUSP;

- Estar na faixa etária e educacional exigida pelo resultado do pareamento da amostra;

- Assinar termo de consentimento livre e esclarecido (Anexo 3).

\section{Critérios de exclusão do grupo controle:}

- Presença de morbidade psiquiátrica;

- Fazer uso de medicação psicoativa;

- Estar grávida;

- Não ter condições clínicas de participar da pesquisa, por exemplo, estar em situação pós-cirúrgica ou ter muita dor.

Para verificação desses critérios de inclusão e exclusão para o grupo controle, foram utilizados os prontuários médicos das mulheres participantes, bem como questionamentos realizados a essas pacientes durante a própria entrevista de coleta de dados. 


\subsection{Instrumentos de avaliação}

\subsubsection{Questionário de Checagem Corporal (Body Checking and Avoidance Questionnaire - BCAQ) (Anexo 6)}

Escala Likert que permite avaliar a presença e a gravidade do sintoma checagem corporal em pacientes com e sem TAs. Possui 22 itens que avaliam sistematicamente a frequência de comportamentos de checagem corporal nas partes específicas do corpo, por exemplo: beliscou suas coxas/ barriga/ bumbum/ rosto (Shafran et al., 2004). A escala prevê também uma entrevista aberta sobre as respostas emocionais relativas à checagem do corpo e o impacto da checagem no controle do peso e da alimentação. Porém esta segunda parte não foi utilizada neste trabalho, pois se optou por fazer estas perguntas de uma forma fechada, utilizando-se outro questionário.

O BCAQ foi adaptado culturalmente e validado por Kachani et al. (no prelo), mostrando ser de fácil compreensão tanto por profissionais que trabalham com TAs como para a população (valores médios superiores a 3,4 - valor máximo 5,0) e excelente concordância (a de Crombach: 0,94). A escala se mostrou competente em discriminar populações clínicas das não clínicas $(p<0,001)$, ao correlacionar positivamente os escores do Teste de Atitudes Alimentares (EAT) $(r=0,50)$, Questionário de Imagem Corporal (BSQ) $(r=0,68)$ e Inventário de Depressão de Beck (BDI) $(0,51)$.

Para a pontuação, os autores (Shafran et al., 2004a; Kachani et al., no prelo) propõem: 
$>$ Nenhuma vez - não me interesso $=0$ ponto

$>$ Pelo menos uma vez na semana $=1$ ponto

$>$ Todos os dias $=2$ pontos

$>1-2$ vezes por dia $=3$ pontos

$>$ Mais de 3 vezes ao dia $=4$ pontos

$>$ Nenhuma vez - evito para não me chatear $=5$ pontos

É importante salientar que, para poder avaliar a frequência da evitação da checagem, após a análise normal dos resultados, foi creditado 5 (cinco) pontos a cada resposta número 5 ("nenhuma vez - evito para não me chatear"), cuja somatória foi dividida pelo número de questões presentes na escala (22 questões). Assim, foi elaborado o escore de evitação (EV), que pode variar de 0-5 em cada paciente.

Na apresentação dos resultados será utilizada também a mediana da checagem de cada área corporal a fim de saber qual parte do corpo é mais checada em cada grupo. Neste caso, a mediana é interessante, visto que os resultados não são números absolutos, mas sim classificações.

\subsubsection{Escala de Checagem Corporal e Cognições (Body Checking Cognitions Scale - BCCS) (Anexo 7)}

Escala Likert com 19 questões que objetivam verificar cognições acerca de comportamentos de checagem corporal. Cada questão deve ser assinalada no número que corresponde à intensidade do pensamento ao checar o corpo, sendo a opção de menor intensidade (nunca) $=1$, evoluindo 
até 5 (muito frequentemente) (Mountford et al., 2006). A escala foi adaptada culturalmente por Kachani et al. (2011), e demonstrou ser de fácil compreensão (valores médios superiores a 4,22 - valor máximo 5,0) e excelente concordância ( $\alpha$ de Crombach: 0,80 a 0,95). Os constructos verificação objetiva, segurança sobre o corpo, consequências de não checar e controle da dieta e do peso foram identificados pelos especialistas e o nível de concordância correspondeu a 48,6\%. A avaliação psicométrica do BCCS indicou confirmação dos quatro componentes na análise fatorial, com valores acima de 1. A escala se mostrou competente em discriminar populações clínicas das não clínicas ( $p<0,001)$, ao correlacionar positivamente os escores do $\operatorname{EAT}(r=0,630)$ e BSQ $(r=0,706)$ (Kachani et al., submetido).

O BCCS divide-se em quatro subescalas:

a) verificação objetiva: intenciona saber o tamanho do corpo, por exemplo, "ao checar meu corpo, eu sei o quanto engordei";

b) segurança e garantia: intenciona assegurar a manutenção do peso e boa forma a fim de se sentir melhor, por exemplo, "checar o corpo me faz sentir melhor";

c) consequências de não checar o corpo: intenciona mostrar 0 que pode acontecer caso o corpo não seja checado, por exemplo, "não consigo me lembrar como eu sou se eu não me checar";

d) controle da dieta e ganho de peso: intenciona saber, a partir da checagem corporal, o quanto será permitido comer, por exemplo, "checar o corpo hoje me dá uma noção para decidir o quanto eu posso comer amanhã" (Mountford et al., 2006). 
O Quadro 1 apresenta as subescalas e suas respectivas questões (Mountford et al., 2006).

Quadro 1: Conteúdo das subescalas do BCCS

\begin{tabular}{|c|c|}
\hline Subescala & Questões \\
\hline Verificação objetiva & $8,9,10,11,13,19$ \\
\hline Segurança e garantia & $2,3,5,7$ \\
\hline Consequências de não checar o corpo & $14,15,16,17,18$ \\
\hline Controle da dieta e ganho de peso & $1,4,6,12$ \\
\hline
\end{tabular}

Para verificar, em cada grupo, qual a subescala mais importante, será somada a pontuação de cada subescala e dividida pelo número de questões que a compõe. Essa medida será tomada a fim de que se mantenha a proporcionalidade entre as subescalas, visto que o número de questões que as compõe é diferente entre elas.

\subsubsection{Teste de Atitude Alimentar - (Eating Atitudes Questionnaire - EAT) (Anexo 8)}

Escala Likert de autopreenchimento elaborada por Garner e Garfinkel (1979) e traduzida para o português por Nunes et al. (1994), que utiliza respostas do tipo "sempre", "muito frequentemente", "frequentemente", "às vezes", "raramente", "nunca". Desenvolvida para avaliar comportamento alimentar inadequado sugestivo de anorexia nervosa, pode ser usada como índice de gravidade de indivíduos com TA, particularmente intenção de emagrecer e medo de ganhar peso (Cordás e Neves, 2000). Neste trabalho 
foi utilizada sua versão reduzida, conhecida como EAT-26, por ter 26 itens. O EAT-26 é mais utilizado do que sua versão completa (composta por 40 itens) em virtude de sua praticidade e objetividade (Kotait et al., 2009). Os comportamentos de dieta já haviam sido confirmados no diagnóstico das pacientes, porém o teste foi utilizado para relacionar algumas respostas com o comportamento de checagem de peso nas pacientes.

Foi considerado um escore igual ou maior do que 20 sugestivo de comportamento alimentar de risco para transtornos alimentares. A pontuação sugerida pelos autores (Garner e Garfinkel, 1979; Alvarenga, 2001) é:
$>$ sempre $=3$ pontos
$>$ muito frequentemente $=2$ pontos
$>$ frequentemente $=1$ ponto
$>$ às vezes, raramente, nunca $=0$ pontos

\subsubsection{Teste de Investigação Bulímica de Edinburg (BITE) (Anexo 9)}

Desenvolvido por Henderson e Freeman (1987), foi traduzido por Cordás e Hochgraf (1993). É um questionário de autopreenchimento com 33 questões, que identifica indivíduos com sintomatologia de bulimia nervosa. Não é um instrumento diagnóstico e é formado por duas subescalas: sintomática, que avalia o grau dos sintomas alimentares presentes, e gravidade, que fornece índice de gravidade do comportamento compulsivo e purgativo (Cordás e Hochgraf, 1993). Como trabalhamos com uma amostra de pacientes já diagnosticadas com $\mathrm{BN}$, o questionário foi 
utilizado para avaliar o grau de gravidade nas pacientes e excluir na amostra controle indivíduos com sintomas bulímicos.

Os critérios utilizados foram aqueles apontados por Cordás e Hochgraf (1993) e Alvarenga (2001). Todas as questões constituem a escala de sintomas, exceto as de número 6, 7 e 27. As questões 1, 13, 21, 23 e 31 recebem 1 ponto para a resposta NÃO. Todas as outras questões recebem 1 ponto para a resposta SIM. A máxima pontuação possível é 30 pontos. A pontuação deve ser avaliada da seguinte forma:

$>$ Escore igual ou maior que 20: presença de comportamento alimentar compulsivo e grande possibilidade de preencher critérios diagnósticos para BN, segundo o DSM-IV;

$>$ Escores de 10 a 19: sugere padrão alimentar não usual. No caso de escore entre 15-19, a paciente deve ser avaliada. Pode também indicar paciente com $\mathrm{BN}$ em recuperação

$>$ Escore menor que 10: limite da normalidade.

As questões 6, 7 e 27 (assinaladas no questionário por um asterisco) valem o total da pontuação correspondente ao número da alternativa assinalada e indicam o grau de gravidade da doença. São questões sobre frequência de jejum, uso de moderadores de apetite, diuréticos, laxantes e vômitos para auxiliar a perda de peso, bem como questões sobre frequência de episódios exagerados de alimentação.

$>$ Escore 0 a 4: insignificante

$>$ Escore 5 a 9: clinicamente significativo

$>$ Escore igual ou maior que 10: alto grau de severidade 
Apesar do objetivo deste instrumento não ser diagnosticar a bulimia nervosa, mas, sim, fazer um screening do problema, indivíduos controle que pontuaram acima de 14 foram retirados da amostra.

\subsubsection{Escala de Figuras de Stuntkard (Anexo 10)}

Desenvolvido por Stunkard et al. (1983), possui uma série de nove figuras humanas organizadas crescentemente em relação ao peso corporal, variando da desnutrição até obesidade, permitindo avaliar o grau de insatisfação corporal das entrevistadas (Gardner et al., 1998). A escala foi validada para a população brasileira por Scagliusi et al. (2006).

Para efeitos deste trabalho, solicitou-se às participantes que anotassem a silhueta que mais se aproximasse com a delas próprias e a silhueta que gostariam de ter. A existência de diferença entre o corpo percebido e o corpo desejado é considerada insatisfação corporal (Bulik et al., 2001; Scagliusi et al., 2006). Neste trabalho computamos as medidas "com insatisfação" e "sem insatisfação". Paralelamente, anotar uma silhueta maior ou menor que seu Índice de Massa Corpórea (IMC) indica uma distorção da imagem corporal e, neste trabalho, consideramos "com distorção" e "sem distorção". O Quadro 2 indica as silhuetas e seus respectivos IMCs.

Quadro 2: Silhuetas de Stunkard e seus respectivos IMCs *

\begin{tabular}{|c|c|c|c|c|c|c|c|c|c|}
\hline IMC & 1 & 2 & 3 & 4 & 5 & 6 & 7 & 8 & 9 \\
\hline Min & 17,5 & 18,9 & 19,9 & 21,6 & 23,7 & 26,5 & 30,7 & 36,8 & 41,5 \\
Max & 18,9 & 19,8 & 21,5 & 23,6 & 26,4 & 30,6 & 36,7 & 41,4 & 48,4 \\
\hline
\end{tabular}

Adaptado de: Bulik et al., 2001. 
Este questionário não é excludente para o grupo controle, visto a existência da insatisfação normativa existente na maioria das mulheres (Ogden e Evans, 1996).

\subsubsection{Questionário de Imagem Corporal (Body Shape Questionnaire - BSQ) (Anexo 11)}

Desenvolvida por Cooper et al. (1987) mede as preocupações com a forma do corpo, a autodepreciação devido à aparência física e a sensação de estar "gorda" (Cordás e Neves, 2000). Escala Likert autoaplicável, com 34 questões relativas ao estado do entrevistado nas últimas quatro semanas, foi adaptada para uso da população brasileira por Di Pietro e Silveira (2009).

Cada questão possui seis alternativas numeradas: "nunca" (1 ponto), "raramente" (2 pontos); "às vezes" (3 pontos), "frequentemente" (4 pontos), "muito frequentemente" (5 pontos) e "sempre" (6 pontos). Considerando a somatória das alternativas assinaladas, foram categorizados para este trabalho os seguintes resultados (Alvarenga, 2001; Brasiliano, 2005; Di Pietro e Silveira, 2009):

$>$ Escore maior que 167: insatisfação corporal grave;

$>$ Escore entre 138 e 167: insatisfação corporal moderada;

$>$ Escore entre 110 e 138: insatisfação corporal leve;

$>$ Escore menor ou igual a 110: sem insatisfação corporal.

Pelos mesmos motivos que a Escala de Figuras de Stunkard, este questionário não foi eliminatório para o grupo controle. 


\subsubsection{O Inventário de Depressão de Beck (BDI) (Beck et al., 1961) (Anexo 12)}

É a medida de autoavaliação da presença de sintomas depressivos mais amplamente usada. A escala não tem pretensão diagnóstica e foi desenvolvida para avaliação de sintomas pela ótica do próprio paciente, podendo ser utilizada também para amostras não clínicas (Gorenstein e Andrade, 2000). O BDI foi validado para o português por Gorenstein e Andrade (1996) e tem valor preditivo de aproximadamente $90 \%$.

Seu tempo de autoaplicação gira em torno de 10 minutos e é composto por 21 itens que avaliam sintomas depressivos que refletem o estado atual (última semana) do indivíduo: tristeza, pessimismo, sensação de fracasso, falta ou perda de satisfação, sentimento de culpa, sensação de punição, autodepreciação, autoacusação, ideação suicida, crises de choro, irritabilidade, isolamento ou retração social, indecisão, distorção de imagem corporal, inibição para o trabalho, distúrbios no sono, fadiga, perda de apetite, perda de peso, preocupação somática e diminuição de libido. Cada item engloba quatro afirmativas $(0,1,2$ ou 3$)$. Pode-se ter mais de uma resposta em cada questão, levando-se em consideração a alternativa de maior valor. Segundo Gorentein e Andrade (1998), deve-se adotar os seguintes pontos de corte para amostras psiquiátricas:

$>$ Escore menor que 10 - sem depressão ou depressão mínima;

D Escore entre 10 e 18 - depressão leve a moderada;

> Escore entre 19 e 29 - depressão moderada a grave;

Dscore entre 30 e 63 - depressão grave. 
Para amostras não diagnosticadas as diretrizes são diferentes, devendo considerar "depressão" somente acima de 20 pontos (Kendall et al., 1987). Dessa forma, mulheres entrevistadas para participar do grupo controle que apresentaram escores maiores ou iguais a 20 foram retiradas da amostra.

\subsubsection{Escala de Yale-Brown de Sintomas Obsessivo-Compulsivos (Yale Brown Obsessive-Compulsive Scale - YBOCS) (Anexo 13)}

Desenvolvida por Goodman et al. (1989 a, b), esta escala foi construída como uma forma de avaliar e detectar sintomas obsessivocompulsivos (Araújo, 2000).

O primeiro passo na sua aplicação é fornecer uma definição precisa do que são obsessões e compulsões. Após essa explicação inicial, é apresentada uma lista de sintomas-alvo que servirão de objeto de avaliação. São exemplos de obsessões e rituais mais comuns, organizados em 15 categorias ou temas diferentes: agressividade, contaminação, sexualidade, armazenagem, religiosidade, simetria, entre outras (Araújo, 1998).

Para este trabalho, foi usada somente a primeira parte do YBOCS, na qual as obsessões e compulsões são rastreadas. A segunda parte, que avalia a intensidade dos sintomas foi descartada, visto que diagnosticar o TOC não é escopo desta pesquisa, mas, sim, relacionar sintomas obsessivo-compulsivos com a checagem corporal, principalmente obsessões somáticas relacionadas ao corpo e compulsões de verificação, 
controle, contagem, de comportamentos ritualizados para comer, comportamentos automutilantes, entre outros.

\subsection{Variáveis estudadas}

- Variáveis sociodemográficas: idade, estado civil (solteira, casada, divorciada, viúva), paridade $(1,2,3,4$ ou mais filhos), opção sexual (heterossexual, homossexual ou bissexual), educação (EF completo, EM completo, EM incompleto, Superior completo, Superior incompleto), situação ocupacional (empregada, desempregada, aposentada, em licença médica; dona de casa).

- Variáveis relacionadas a medidas antropométricas: IMC (desnutrição, baixo peso, eutrofia, sobrepeso, obesidade).

É importante esclarecer que o IMC, também conhecido como "Índice de Quetelet" é um indicador simples do estado nutricional calculado a partir da seguinte fórmula (Kamimura et al., 2002):

$$
I M C=\frac{\operatorname{PESO}(\mathrm{kg})}{\operatorname{ALTURA}^{2}(\mathrm{~m})}
$$

Por ser este um índice que relaciona as variáveis peso e altura, estas duas medidas foram consideradas dispensáveis. 
Seus valores são classificados de acordo com o Quadro 3.

Quadro 3: Classificação nutricional para os intervalos de IMC, segundo World Health Organization, 1997

\begin{tabular}{|c|c|}
\hline Valor de referência & Classificação \\
\hline$<16,0$ & Baixo peso severo \\
\hline $16,0-16,99$ & Baixo peso moderado \\
\hline $17,0-18,49$ & Baixo peso suave \\
\hline$<18,5$ & Desnutrição \\
\hline $18,5-24,99$ & Eutrofia \\
\hline $25,0-29,99$ & Pré-obeso \\
\hline $30,0-34,99$ & Obesidade grave I \\
\hline $35,0-39,99$ & Obesidade grave II \\
\hline$>40,0$ & Obesidade grave III \\
\hline
\end{tabular}

Fonte: WHO, 1997.

- Variáveis relacionadas ao tratamento: tempo de tratamento em meses contados a partir da primeira consulta após triagem do paciente.

- Variáveis relacionadas ao quadro clínico: diagnóstico atual (anorexia nervosa, bulimia nervosa), presença de atitudes alimentares com intenção de emagrecer e medo de ganhar peso (escore do EAT), presença e gravidade de sintomas bulímicos (escore do BITE), insatisfação e/ ou distorção corporal (figuras de Stunkard e escore de BSQ), presença de sintomas depressivos (escore do BDI), presença de sintomas obsessivo-compulsivos (YBOCKS).

- Variáveis relacionadas à checagem do corpo: checagem do corpo (não se interessa em checar, costuma checar, evita checar), forma 
de checagem do corpo (beliscos no corpo, observação no espelho, apalpação, uso de fita métrica, uso de roupas-alvo, observação do "esparramento" das coxas, medida de pulso, pesagem), partes do corpo mais medidas (coxas, rosto, estômago, quadris, região glútea, ossos da clavícula), motivos de checagem do corpo (segurança e garantia da manutenção do peso e boa forma, consequências de não checar o corpo, uso do controle da dieta e ganho de peso), evitação da checagem corporal.

\subsection{Análise estatística}

\subsubsection{Análise descritiva}

Para caracterização da amostra, as variáveis quantitativas foram apresentadas por meio de médias e desvios padrões (d.p.), medianas, mínimas e máximas. As variáveis qualitativas foram apresentadas como frequências absolutas (n) e porcentagens (\%) das características presentes na amostra para cada um dos grupos estudados (Vieira, 1998; Pereira, 2001).

A avaliação da homogeneidade dos grupos em relação à paridade, opção sexual, educação, ocupação e dieta, foi realizada a partir do teste Qui-quadrado de Pearson (Armitage e Berry, 1994), ou o Teste Exato de 
Fisher (Armitage e Berry, 1994), caso houvesse frequências menores que cinco pacientes.

Para verificar a homogeneidade quanto à idade, IMC, peso atual, peso desejado, tempo de tratamento (apenas para os grupos AN e BN), utilizou-se o Teste de Análise de Variância - ANOVA (Magalhães e Lima, 2000), ou o Teste de Kruskal-Wallis (Siegel e Castellan, 1988), caso os dados não se mostrassem ajustáveis a distribuição normal pelo Teste de Kolmogorov-Smirnov (Siegel e Castellan, 1988).

Para identificar as áreas mais checadas por cada grupo e os principais motivos de checagem pela escala BCCS foi utilizado o teste de Friedman (Conover, 1998). Para verificar se existiam comportamentos diferentes em cada grupo e no geral utilizamos o teste de Cochran (Conover, 1999) sobre as prevalências de comportamento de checagem. E ainda, para identificar tipos de checagem mais utilizados em cada grupo foi realizada análise de resíduos nas tabelas (Pereira, 2001). As associações entre as variáveis de checagem do corpo e suas diferenças para os grupos foram verificadas por Teste Qui-quadrado ou Teste Exato de Fisher, dependendo do caso (Pereira, 2001).

\subsubsection{Análise inferencial}

Para verificar possíveis associações entre as variáveis de interesse (escores das escalas) e outras variáveis (sociodemográficas, antropométricas, de tratamento e de quadro clínico) que pudessem gerar 
confusão nas conclusões, foram realizadas modelagens. Nos casos em que ambas as variáveis eram quantitativas, todas as variáveis foram submetidas ao teste de Kolmogorov-Smirnov (Siegel e Castelan, 1988) para verificação de ajuste à distribuição normal. Posteriormente, foi utilizado o Teste de Correlação de Pearson/ Spearman (Cohen e Cohen, 2003), de acordo com a adequação à distribuição. Nos casos em que ambas as variáveis eram qualitativas foram utilizados testes de associação, como, por exemplo, o Teste Qui-quadrado e o teste Exato de Fisher (Pereira, 2001). Para comparar médias/medianas de variáveis quantitativas para diferentes grupos (definidos por variáveis qualitativas) foram utilizados o Teste t de Student ou o Teste de Mann-Whitney (Conover, 1998; Bussab e Morettin, 2009).

A análise principal das variáveis quantitativas (escores) para verificar diferença entre os três grupos foi realizada a partir da análise de variância ANOVA (Bussab e Morenttin, 2009) ou Teste T-student (Bussab e Morettin, 2009). Nos casos em que a diferença entre os grupos foi estatisticamente significante foi realizada uma análise post hoc via correção de Bonferroni (Abdi, 2007), a fim de identificar as diferenças entre os grupos. Caso as variáveis não atendessem as pressuposições da ANOVA, o referido teste foi substituído pelo teste de Kruskal-Wallis (Conover, 1998). Para a análise post hoc foram então utilizadas as comparações múltiplas próprias do teste com correção do nível de significância.

As análises foram realizadas no programa SPSS versão 16,0, e foram consideradas significativas as diferenças com $p$-valores $\leq 0,05$. 


\subsection{Análise de risco}

Por tratar-se de aplicação de questionários, a metodologia desta pesquisa não envolveu riscos para a população estudada.

O presente estudo está de acordo com as normas ํo 196 de 10/10/1996 do Conselho Nacional de Saúde e foi aprovado pelo Comitê de Ética e Pesquisa do Hospital das Clínicas da Faculdade de Medicina da Universidade de São Paulo - Protocolo: 0029/09 (Anexo 14). 


\section{RESULTADOS}




\subsection{Descrição das variáveis}

\subsubsection{Características sociodemográficas}

A Tabela 6 apresenta características qualitativas relacionadas aos dados sociodemográficos dos três grupos. É importante destacar que os grupos foram balanceados estatisticamente por idade e grau de escolaridade, dessa forma não houve diferenças em relação a essas variáveis. Em relação às outras categorias, de uma forma geral, os três grupos se mostraram homogêneos (Tabelas 6 e 7).

Tabela 6: Comparação das características sociodemográficas dos grupos estudados - 2009 a 2010

\begin{tabular}{|c|c|c|c|c|c|c|c|c|}
\hline & & \multicolumn{6}{|c|}{ Grupo } & \multirow{3}{*}{ p-valor } \\
\hline & & \multicolumn{2}{|c|}{ AN } & \multicolumn{2}{|c|}{ BN } & \multicolumn{2}{|c|}{ Controle } & \\
\hline & & $(n=44)$ & $\%$ & $(n=41)$ & $\%$ & $(n=40)$ & $\%$ & \\
\hline \multirow[t]{2}{*}{ Estado Civil } & Solteira & 40 & 90,90 & 29,00 & 70,70 & 30 & 75,00 & \multirow{2}{*}{$0,053^{*}$} \\
\hline & Casada & 4 & 9,10 & 12 & 29,30 & 10 & 25,00 & \\
\hline \multirow[t]{2}{*}{ Paridade } & Sem filhos & 36 & 81,80 & 31 & 75,60 & 30 & 75,00 & \multirow{2}{*}{$0,705^{*}$} \\
\hline & Com filhos & 8 & 18,20 & 10 & 24,40 & 10 & 25,00 & \\
\hline \multirow{3}{*}{ Opção Sexual } & Heterossexual & 38 & 86,40 & 39 & 95,10 & 40 & 100,00 & \multirow{3}{*}{$0,139^{*}$} \\
\hline & Homossexual & 4 & 9,10 & 1 & 2,40 & - & - & \\
\hline & Bissexual & 2 & 4,50 & 1 & 2,40 & - & - & \\
\hline \multirow{5}{*}{ Educação } & EF completo & 2 & 4,50 & - & - & - & - & \multirow{5}{*}{$0,239^{*}$} \\
\hline & EM completo & 20 & 45,50 & 10 & 24,40 & 15 & 37,50 & \\
\hline & EM incompleto & 1 & 2,30 & 5 & 12,20 & 4 & 10,00 & \\
\hline & Superior completo & 10 & 22,70 & 11 & 26,80 & 9 & 22,50 & \\
\hline & Superior incompleto & 11 & 25,00 & 15 & 36,60 & 12 & 30,00 & \\
\hline \multirow{6}{*}{ Ocupação } & Estudante & 11 & 25,00 & 11 & 26,80 & 9 & 22,50 & \multirow{6}{*}{$0,776^{*}$} \\
\hline & Funcionária registrada & 14 & 31,80 & 9 & 22,00 & 16 & 40,00 & \\
\hline & Funcionária s/ registro & 4 & 9,10 & 4 & 9,80 & 2 & 5,00 & \\
\hline & Dona de Casa & 3 & 6,80 & 4 & 9,80 & 4 & 10,00 & \\
\hline & Desempregada & 12 & 27,30 & 13 & 31,70 & 8 & 20,00 & \\
\hline & Licença médica & - & - & - & - & 1 & 2,5 & \\
\hline
\end{tabular}

*Teste Qui-quadrado de Pearson 
Tabela 7: Comparação da idade dos grupos estudados - 2009 a 2010

\begin{tabular}{llcccc}
\hline & & \multicolumn{3}{c}{ Grupo } & \\
\cline { 3 - 5 } & & AN & BN & Controle & p-valor \\
& Média & 28,20 & 27,50 & 29,20 & \\
\hline \multirow{3}{*}{ Idade } & Mediana & 26 & 28 & 27 & \\
(anos) & Desvio padrão & 8,50 & 7,30 & 9,10 & $0,674^{*}$ \\
& Mínimo & 18 & 18 & 18 & \\
& Máximo & 55 & 45 & 62 & \\
\hline
\end{tabular}

*ANOVA

\subsubsection{Características antropométricas}

Os resultados da análise de variância indicaram que houve diferença estatística entre os grupos em relação ao IMC (Tabela 8). Dessa forma, foram realizadas comparações múltiplas para identificar que categorias diferenciavam entre si, constatando-se que:

- O peso do grupo AN é estatisticamente menor do que os outros dois grupos;

- O grupo AN apresenta em média menor peso desejado; por outro lado, os grupos BN e controle não apresentaram diferença estatisticamente significante em relação ao peso desejado;

- O grupo BN apresenta em média maior perda de peso desejada; por outro lado, os grupos AN e controle não apresentaram diferença estatisticamente significante em relação à perda de peso desejado; 
- o grupo AN apresenta em média IMC menor do que os demais grupos;

- o grupo BN apresenta em média IMC maior que os demais grupos.

Tabela 8: Comparação do IMC e peso desejado entre os grupos estudados 2009 a 2010

\begin{tabular}{|c|c|c|c|c|c|}
\hline & Grupo & $\begin{array}{c}\text { AN } \\
(n=44)\end{array}$ & $\begin{array}{c}\text { BN } \\
(n=41)\end{array}$ & $\begin{array}{c}\text { Controle } \\
(n=40)\end{array}$ & p-valor \\
\hline & Média & 46,68 & 67,50 & 61,39 & \\
\hline & Desvio padrão & 7,93 & 14,74 & 12,33 & \\
\hline \multirow[t]{5}{*}{ Peso atual $(\mathrm{kg})$} & Mediana & 45,10 & 64,30 & 58,00 & $<0,001^{\star \star}$ \\
\hline & Mínimo & 32,00 & 43,50 & 45,00 & \\
\hline & Máximo & 72,70 & 106,00 & 104,30 & \\
\hline & Média & 43,97 & 53,70 & 57,39 & \\
\hline & Desvio padrão & 7,65 & 9,80 & 6,65 & \\
\hline \multirow[t]{5}{*}{ Peso desejado (kg) } & Mediana & 45,00 & 53,50 & 56,00 & $<0,001^{*}$ \\
\hline & Mínimo & 24,00 & 20,00 & 46,00 & \\
\hline & Máximo & 64,00 & 80,00 & 80,00 & \\
\hline & Média & 2,71 & 13,88 & 4,01 & \\
\hline & Desvio padrão & 8,78 & 12,89 & 7,76 & \\
\hline \multirow[t]{5}{*}{ Perda de peso desejada $(\mathrm{kg})$} & Mediana & 2,90 & 11,20 & 3,00 & $<0,001^{\star \star}$ \\
\hline & Mínimo & $-14,50$ & $-16,50$ & $-9,00$ & \\
\hline & Máximo & 30,70 & 46,05 & 24,30 & \\
\hline & Média & 18,27 & 24,95 & 23,10 & \\
\hline & Desvio padrão & 2,91 & 5,57 & 4,22 & \\
\hline \multirow[t]{3}{*}{$\mathrm{IMC}\left(\mathrm{kg} / \mathrm{m}^{2}\right)$} & Mediana & 18,10 & 24,40 & 22,10 & $<0,001^{\star *}$ \\
\hline & Mínimo & 11,90 & 15,20 & 15,90 & \\
\hline & Máximo & 26,40 & 40,50 & 37,50 & \\
\hline
\end{tabular}

*ANOVA. ${ }^{*}$ Teste de Kruskal-Wallis 


\subsubsection{Variáveis relacionadas ao tratamento: tempo de tratamento}

Não houve diferença estatística entre o tempo de tratamento das pacientes, com $p=0,689$.

A média do tempo de tratamento se mostrou semelhante entre os grupos (22,3 meses para o grupo AN e 20,2 meses para o grupo BN), com $p=0,689$. Essas médias foram aquém dos tempos máximos de ambos os grupos ( $\mathrm{AN}=96$ meses e $\mathrm{BN}=120$ meses), indicando uma heterogeneidade muito grande na variável tempo de tratamento.

Tabela 9: Comparação do tempo de tratamento entre os grupos AN e BN - 2009 a 2010

\begin{tabular}{llccl}
\hline & & \multicolumn{2}{c}{ Grupo } & \\
\cline { 3 - 4 } & & AN & BN & p-valor \\
& Média & 22,30 & 20,20 & \\
& Mediana & 12 & 14 & \\
Tempo de tratamento (meses) & Desvio padrão & 23,20 & 25,00 & $0,689^{*}$ \\
& Mínimo & 0 & 0 & \\
& Máximo & 96 & 120 & \\
\hline
\end{tabular}

*Teste $\mathrm{t}$-Student

\subsubsection{Variáveis relacionadas ao quadro clinico}

Houve diferença estatística entre os grupos em todas as escalas apresentadas (Tabela 10): 
- EAT: menor comportamento alimentar de risco no grupo controle $(92,5 \%, n=37)$ e maior comportamento alimentar de risco nos grupos AN $(70,5 \%, n=31)$ e BN $(82,9 \%, n=34)$.

- BITE: em relação à escala de sintomas, foi notado maior percentual de comportamento alimentar compulsivo no grupo BN $(68,3 \%$, $\mathrm{n}=28$ ); em relação à escala de gravidade de sintomas, foi percebido maior percentual de indivíduos com alto grau de gravidade no grupo BN (61\%, n=25); é interessante notar que duas pacientes (5\%) do grupo controle pontuaram, na escala de gravidade de sintomas, como clinicamente significativo.

- Figuras de Stunkard: em relação à insatisfação corporal, existe um maior percentual de indivíduos sem insatisfação corporal no grupo controle $(27,5 \%, n=11)$ e maior insatisfação corporal no grupo BN $(97,6 \%, n=40)$; em relação à distorção da imagem corporal, ela foi notada de forma mais marcante no grupo AN $(86,4 \%, n=38)$ e BN $(75,6 \%, \mathrm{n}=31)$. É interessante notar que alguns indivíduos do grupo controle têm imagem corporal distorcida, porém, ao contrário das pacientes, acreditam ser de um tamanho menor do que realmente são $(47,5 \%, n=19)$.

- BSQ: o grupo controle tem um maior percentual de indivíduos sem insatisfação corporal $(67,5 \%, n=27)$ enquanto o grupo $B N$ possui maior percentual de insatisfação corporal grave $(51,2 \%, n=21)$.

- BDI: o grupo AN possui maior percentual de pacientes com sintomas depressivos moderados $(34,1 \%, n=15)$, enquanto o grupo BN possui maior percentual de pacientes com sintomas depressivos graves $(48,8 \%, \mathrm{n}=20) .1$ 
- Tabela 10: $\quad$ Comparação dos escores do EAT, BITE, Figuras de Stunkard, BSQ e BDI entre os grupos estudados - 2009 a 2010

\begin{tabular}{|c|c|c|c|c|c|c|c|c|}
\hline & & \multicolumn{6}{|c|}{ Grupo } & \multirow{3}{*}{ p-valor } \\
\hline & & \multicolumn{2}{|c|}{$\begin{array}{c}\text { AN } \\
(n=44)\end{array}$} & \multicolumn{2}{|c|}{$\begin{array}{c}\text { BN } \\
(n=41)\end{array}$} & \multicolumn{2}{|c|}{$\begin{array}{c}\text { Controle } \\
(n=40)\end{array}$} & \\
\hline & & $\mathbf{n}$ & $\%$ & $\mathbf{n}$ & $\%$ & $\mathbf{N}$ & $\%$ & \\
\hline \multirow{2}{*}{$\begin{array}{l}\text { Resultado } \\
\text { EAT }\end{array}$} & $\begin{array}{l}\text { Sem comportamento alimentar } \\
\text { de risco }\end{array}$ & 13 & 29,50 & 7 & 17,10 & 37 & 92,50 & \multirow{2}{*}{$<0,001^{\star}$} \\
\hline & $\begin{array}{l}\text { Com comportamento alimentar } \\
\text { de risco }\end{array}$ & 31 & 70,50 & 34 & 82,90 & 3 & 7,50 & \\
\hline \multirow{3}{*}{$\begin{array}{l}\text { BITE } \\
\text { Sintomática }\end{array}$} & $\begin{array}{l}\text { Escore < 10: limite da } \\
\text { normalidade }\end{array}$ & 13 & 29,50 & 1 & 2,40 & 40 & 100,00 & \multirow{3}{*}{$<0,001^{\star}$} \\
\hline & $\begin{array}{l}\text { Escores de } 10 \text { a 19: sugere } \\
\text { padrão alimentar não usual. }\end{array}$ & 17 & 38,60 & 12 & 29,30 & - & - & \\
\hline & $\begin{array}{l}\text { Escore igual ou }>20 \text { : } \\
\text { comportamento alimentar } \\
\text { compulsivo }\end{array}$ & 14 & 31,80 & 28 & 68,30 & - & - & \\
\hline \multirow{3}{*}{$\begin{array}{l}\text { BITE } \\
\text { Gravidade }\end{array}$} & Escore 0 a 4: insignificante & 12 & 27,30 & 7 & 17,10 & 38 & 95,00 & \multirow{3}{*}{$<0,001^{\star}$} \\
\hline & $\begin{array}{l}\text { Escore } 5 \text { a 9: clinicamente } \\
\text { significativo }\end{array}$ & 13 & 29,50 & 9 & 22,00 & 2 & 5,00 & \\
\hline & $\begin{array}{l}\text { Escore igual ou > 10: alto grau } \\
\text { de severidade }\end{array}$ & 19 & 43,20 & 25 & 61,00 & - & - & \\
\hline \multirow{2}{*}{$\begin{array}{l}\text { Stunkard } \\
\text { Insatisfação } \\
\text { corporal }\end{array}$} & Sem insatisfação corporal & 2 & 4,50 & 1 & 2,40 & 11 & 27,50 & \multirow[b]{2}{*}{$<0,001^{*}$} \\
\hline & Insatisfação corporal & 42 & 95,50 & 40 & 97,60 & 29 & 72,50 & \\
\hline \multirow{3}{*}{$\begin{array}{l}\text { Stunkard } \\
\text { Distorção } \\
\text { imagem } \\
\text { corporal }\end{array}$} & $\begin{array}{l}\text { Sem distorção da imagem } \\
\text { corporal }\end{array}$ & 6 & 13,60 & 10 & 24,40 & 15 & 37,50 & \multirow{3}{*}{$<0,001^{\star}$} \\
\hline & $\begin{array}{l}\text { Com distorção da imagem } \\
\text { (menor do que realmente é) }\end{array}$ & 38 & 86,40 & 31 & 75,60 & 6 & 15,00 & \\
\hline & $\begin{array}{l}\text { Com distorção da imagem } \\
\text { (maior do que realmente é) }\end{array}$ & - & - & - & - & 19 & 47,50 & \\
\hline \multirow{4}{*}{$B S Q$} & $\begin{array}{l}\text { Escore < ou igual a 110: sem } \\
\text { insatisfação corporal }\end{array}$ & 15 & 34,10 & 3 & 7,30 & 27 & 67,50 & \multirow{4}{*}{$<0,001^{*}$} \\
\hline & $\begin{array}{l}\text { Escore entre } 110 \text { e 138: } \\
\text { insatisfação corporal leve }\end{array}$ & 3 & 6,80 & 7 & 17,10 & 9 & 22,50 & \\
\hline & $\begin{array}{l}\text { Escore entre } 138 \text { e 167: } \\
\text { insatisfação corporal moderada }\end{array}$ & 11 & 25,00 & 10 & 24,40 & 4 & 10,00 & \\
\hline & $\begin{array}{l}\text { Escore > 167: insatisfação } \\
\text { corporal grave }\end{array}$ & 15 & 34,10 & 21 & 51,20 & - & - & \\
\hline \multirow{4}{*}{ BDI } & $\begin{array}{l}\text { Escore < 10: sem depressão ou } \\
\text { depressão mínima }\end{array}$ & 8 & 18,20 & 5 & 12,20 & 32 & 80,00 & \multirow{4}{*}{$<0,001^{*}$} \\
\hline & $\begin{array}{l}\text { Escore entre } 10 \text { e 18: com } \\
\text { depressão leve a moderada }\end{array}$ & 8 & 18,20 & 3 & 7,30 & 8 & 20,00 & \\
\hline & $\begin{array}{l}\text { Escore entre } 19 \text { e } 29 \text { : com } \\
\text { depressão moderada a grave }\end{array}$ & 15 & 34,10 & 13 & 31,70 & - & - & \\
\hline & $\begin{array}{l}\text { Escore entre } 30 \text { e } 63: \text { com } \\
\text { depressão grave }\end{array}$ & 13 & 29,50 & 20 & 48,80 & - & - & \\
\hline
\end{tabular}

*Teste do Qui-quadrado com análise de resíduos nas situações com evidência de associação estatística. 
Em relação à escala YBOCS, somente foram comparados os grupos AN e BN visto que o grupo controle não apresentou nenhuma obsessão ou compulsão. Os grupos de pacientes não apresentaram diferenças estatísticas em relação a essas variáveis (Tabela 11).

Tabela 11: Comparação dos resultados do YBOCS entre os grupos AN e BN 2009 a 2010

\begin{tabular}{|c|c|c|c|c|c|c|}
\hline & & \multicolumn{4}{|c|}{ Grupo } & \multirow{3}{*}{ p-valor } \\
\hline & & \multicolumn{2}{|c|}{$\begin{array}{c}A N \\
(n=44)\end{array}$} & \multicolumn{2}{|c|}{$\begin{array}{c}B N \\
(n=41)\end{array}$} & \\
\hline & & $\mathbf{n}$ & $\%$ & $\mathbf{n}$ & $\%$ & \\
\hline \multirow{2}{*}{$\begin{array}{l}\text { Obsessões Somáticas - } \\
\text { partes do corpo }\end{array}$} & Não & 22 & 50,00 & 15 & 36,60 & \multirow{2}{*}{$0,213^{*}$} \\
\hline & Sim & 22 & 50,00 & 26 & 63,40 & \\
\hline \multirow{3}{*}{ Outras Obsessões } & Não & 12 & 27,30 & 7 & 17,10 & \multirow{3}{*}{$0,259^{*}$} \\
\hline & & & & & & \\
\hline & Sim & 32 & 72,70 & 34 & 82,90 & \\
\hline \multirow{2}{*}{ Verificação/ controle } & Não & 27 & 61,40 & 19 & 46,30 & \multirow{2}{*}{$0,195^{*}$} \\
\hline & Sim & 17 & 38,60 & 22 & 53,70 & \\
\hline \multirow{2}{*}{ Repetições } & Não & 29 & 65,90 & 27 & 65,90 & \multirow{2}{*}{$0,996^{*}$} \\
\hline & Sim & 15 & 34,10 & 14 & 34,10 & \\
\hline \multirow{2}{*}{ Contagem } & Não & 37 & 84,10 & 29 & 70,70 & \multirow[b]{2}{*}{$0,140^{*}$} \\
\hline & Sim & 7 & 15,90 & 12 & 29,30 & \\
\hline \multirow{3}{*}{ Rituais para comer } & Não & 34 & 77,30 & 29 & 70,70 & \multirow{3}{*}{$0,491^{*}$} \\
\hline & & & & & & \\
\hline & Sim & 10 & 22,70 & 12 & 29,30 & \\
\hline
\end{tabular}

*Teste Qui-quadrado 


\subsubsection{Variáveis relacionadas à checagem do corpo}

7.1.5.1 Pontuação de checagem de corpo dos três grupos estudados

Conforme podemos observar na Tabela 12, houve diferença estatística na pontuação entre grupos nas escalas BCAQ:

- Grupo BN apresentou maior pontuação de checagem/ evitação corporal, seguido pelo grupo AN e por fim, grupo controle.

- Após as comparações múltiplas, ficou evidenciado que o grupo controle teve menor pontuação no $\mathrm{BCAQ}$ que os outros dois grupos, mostrando ser o grupo que se checa menos.

Tabela 12: Comparação da pontuação da escala BCAQ entre os grupos estudados -2009 a 2010

\begin{tabular}{llcccc}
\hline & & \multicolumn{3}{c}{ Grupo } & \\
\cline { 3 - 5 } & & $\begin{array}{c}\text { AN } \\
(\mathbf{n}=\mathbf{4 4})\end{array}$ & $\begin{array}{c}\text { BN } \\
(\mathbf{n}=\mathbf{4 1})\end{array}$ & $\begin{array}{c}\text { Controle } \\
(\mathrm{n}=\mathbf{4 0})\end{array}$ & p-valor \\
\hline \multirow{4}{*}{ Pontuação BCAQ } & Média & 46,05 & 57,83 & 22,80 & \\
& Mediana & 40,50 & 57,00 & 19,50 & \\
& Desvio padrão & 24,79 & 28,62 & 14,12 & $<\mathbf{0 , 0 0 1}^{*}$ \\
& Mínimo & 8 & 10 & 4 & \\
& Máximo & 100 & 116 & 61 & \\
\hline
\end{tabular}

${ }^{*}$ ANOVA 


\subsubsection{Descrição da forma de checagem/ áreas corporais mais medidas dos três grupos estudados}

De acordo com a Tabela 13, pode-se verificar que houve diferença estatisticamente significante entre os grupos em diversos itens da escala. Entre os resultados, encontramos:

- Grupo AN - maior percentual de pacientes que não se interessam em checar das seguintes formas/ áreas: a) beliscar a barriga; b) apalpar coxas/ barriga.

- Grupo BN - 1) maior percentual de pacientes que se checam mais de três vezes ao dia ou que não se checam para "não se chatearem" nas seguintes áreas: a) beliscar a barriga e rosto; b) olhar no espelho rosto/ coxas;

2) maior percentual de pacientes que não se checam nas seguintes áreas para "não se chatearem": a) beliscar a barriga/ glúteos; b) apalpar as coxas/ barriga/ glúteos; c) não se pesam.

- Grupo controle - há um maior percentual de indivíduos que não faz ou não se interessa em: a) beliscar as coxas/ barriga/ rosto; b) olhar no espelho a barriga; c) apalpar o rosto/ coxas/ barriga/ clavícula; d) usar o tamanho das roupas para julgar o tamanho do corpo; e) comparar o tamanho do seu corpo com o de outras pessoas; f) monitorar a "esparramação" das coxas; g) medir a circunferência do pulso. 
Tabela 13: Formas de checagem e áreas corporais mais medidas dos três grupos estudados -2009 a 2010

\begin{tabular}{|c|c|c|c|c|c|c|c|c|}
\hline & & \multicolumn{6}{|c|}{ Grupo } & \multirow{3}{*}{ p-valor } \\
\hline & & \multicolumn{2}{|c|}{$\begin{array}{c}\text { NA } \\
(n=44)\end{array}$} & \multicolumn{2}{|c|}{$\begin{array}{c}B N \\
(n=41)\end{array}$} & \multicolumn{2}{|c|}{$\begin{array}{l}\text { Controle } \\
(n=40)\end{array}$} & \\
\hline & & $\mathbf{n}$ & $\%$ & $\mathbf{n}$ & $\%$ & $\mathbf{n}$ & $\%$ & \\
\hline \multirow{6}{*}{$\begin{array}{l}\text { Beliscou } \\
\text { coxas }\end{array}$} & Nenhuma vez - não me interesso & 22 & 50,00 & 5 & 12,20 & 29 & 72,50 & \multirow{6}{*}{$<0,001^{\star}$} \\
\hline & Pelo menos uma vez na semana & 9 & 20,50 & 9 & 22,00 & 8 & 20,00 & \\
\hline & Todos os dias & 5 & 11,40 & 7 & 17,10 & 1 & 2,50 & \\
\hline & $1-2$ vezes por dia & 1 & 2,30 & 7 & 17,10 & - & - & \\
\hline & Mais de 3 vezes ao dia & 4 & 9,10 & 5 & 12,20 & - & - & \\
\hline & $\begin{array}{l}\text { Nenhuma vez - evito para não me } \\
\text { chatear }\end{array}$ & 3 & 6,80 & 8 & 19,50 & 2 & 5,00 & \\
\hline \multirow{6}{*}{$\begin{array}{l}\text { Beliscou } \\
\text { barriga }\end{array}$} & Nenhuma vez - não me interesso & 10 & 22,70 & 4 & 9,80 & 16 & 40,00 & \multirow{6}{*}{$0,001^{*}$} \\
\hline & Pelo menos uma vez na semana & 7 & 15,90 & 4 & 9,80 & 10 & 25,00 & \\
\hline & Todos os dias & 16 & 36,40 & 11 & 26,80 & 8 & 20,00 & \\
\hline & $1-2$ vezes por dia & 4 & 9,10 & 2 & 4,90 & 2 & 5,00 & \\
\hline & Mais de 3 vezes ao dia & 7 & 15,90 & 12 & 29,30 & 2 & 5,00 & \\
\hline & $\begin{array}{l}\text { Nenhuma vez - evito para não me } \\
\text { chatear }\end{array}$ & - & - & 8 & 19,50 & 2 & 5,00 & \\
\hline \multirow{6}{*}{$\begin{array}{l}\text { Beliscou } \\
\text { bumbum }\end{array}$} & Nenhuma vez - não me interesso & 26 & 59,10 & 11 & 26,80 & 22 & 55,00 & \multirow{6}{*}{$0,001^{*}$} \\
\hline & Pelo menos uma vez na semana & 6 & 13,60 & 4 & 9,80 & 12 & 30,00 & \\
\hline & Todos os dias & 6 & 13,60 & 10 & 24,40 & 5 & 12,50 & \\
\hline & 1-2 vezes por dia & 2 & 4,50 & 3 & 7,30 & - & - & \\
\hline & Mais de 3 vezes ao dia & 3 & 6,80 & 5 & 12,20 & - & - & \\
\hline & $\begin{array}{l}\text { Nenhuma vez - evito para não me } \\
\text { chatear }\end{array}$ & 1 & 2,30 & 8 & 19,50 & 1 & 2,50 & \\
\hline \multirow{6}{*}{ Beliscou rosto } & Nenhuma vez - não me interesso & 21 & 47,70 & 9 & 22,00 & 25 & 62,50 & \multirow{6}{*}{$0,003^{*}$} \\
\hline & Pelo menos uma vez na semana & 6 & 13,60 & 7 & 17,10 & 6 & 15,00 & \\
\hline & Todos os dias & 8 & 18,20 & 5 & 12,20 & 5 & 12,50 & \\
\hline & $1-2$ vezes por dia & 1 & 2,30 & 4 & 9,80 & 3 & 7,50 & \\
\hline & Mais de 3 vezes ao dia & 7 & 15,90 & 9 & 22,00 & - & - & \\
\hline & $\begin{array}{l}\text { Nenhuma vez - evito para não me } \\
\text { chatear }\end{array}$ & 1 & 2,30 & 7 & 17,10 & 1 & 2,50 & \\
\hline \multirow{6}{*}{$\begin{array}{l}\text { Olhou no } \\
\text { espelho a } \\
\text { aparência } \\
\text { geral }\end{array}$} & Nenhuma vez - não me interesso & 1 & 2,30 & 3 & 7,30 & 4 & 10,00 & \multirow{6}{*}{$0,065^{\star}$} \\
\hline & Pelo menos uma vez na semana & 1 & 2,30 & 3 & 7,30 & 3 & 7,50 & \\
\hline & Todos os dias & 26 & 59,10 & 12 & 29,30 & 21 & 52,50 & \\
\hline & 1-2 vezes por dia & 5 & 11,40 & 6 & 14,60 & 7 & 17,50 & \\
\hline & Mais de 3 vezes ao dia & 7 & 15,90 & 9 & 22,00 & 5 & 12,50 & \\
\hline & $\begin{array}{l}\text { Nenhuma vez - evito para não me } \\
\text { chatear }\end{array}$ & 4 & 9,10 & 8 & 19,50 & - & - & \\
\hline
\end{tabular}




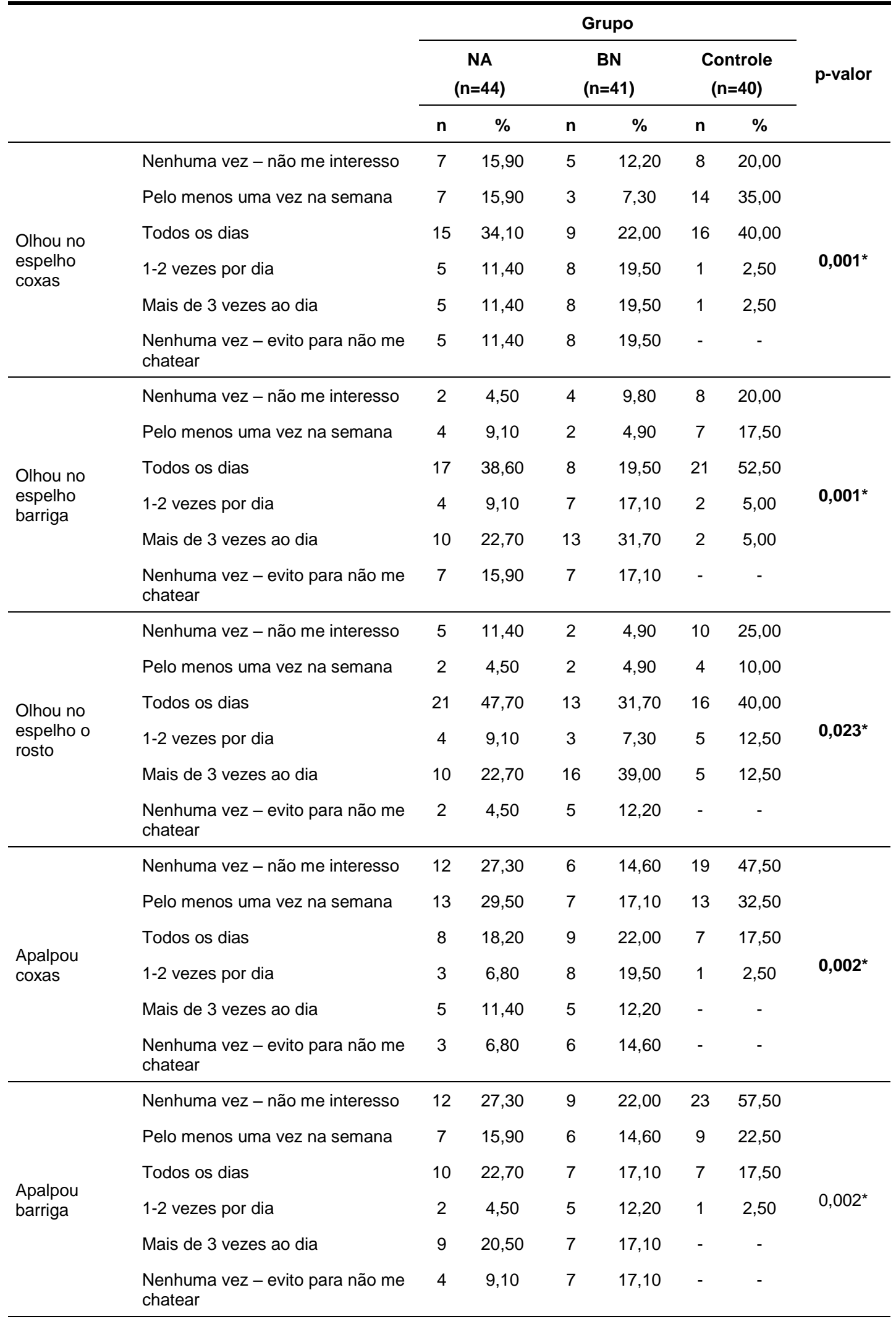




\section{Continuação Tabela 13}

\begin{tabular}{|c|c|c|c|c|c|c|c|c|}
\hline & & \multicolumn{6}{|c|}{ Grupo } & \multirow{3}{*}{ p-valor } \\
\hline & & \multicolumn{2}{|c|}{$\begin{array}{c}\text { NA } \\
(n=44)\end{array}$} & \multicolumn{2}{|c|}{$\begin{array}{c}\text { BN } \\
(n=41)\end{array}$} & \multicolumn{2}{|c|}{$\begin{array}{l}\text { Controle } \\
(n=40)\end{array}$} & \\
\hline & & $\mathbf{n}$ & $\%$ & $\mathbf{n}$ & $\%$ & $\mathbf{n}$ & $\%$ & \\
\hline \multirow{6}{*}{$\begin{array}{l}\text { Apalpou } \\
\text { bumbum }\end{array}$} & Nenhuma vez - não me interesso & 16 & 36,40 & 10 & 24,40 & 17 & 42,50 & \multirow{6}{*}{$0,014^{*}$} \\
\hline & Pelo menos uma vez na semana & 5 & 11,40 & 3 & 7,30 & 12 & 30,00 & \\
\hline & Todos os dias & 13 & 29,50 & 13 & 31,70 & 9 & 22,50 & \\
\hline & $1-2$ vezes por dia & 4 & 9,10 & 5 & 12,20 & 2 & 5,00 & \\
\hline & Mais de 3 vezes ao dia & 4 & 9,10 & 4 & 9,80 & - & - & \\
\hline & $\begin{array}{l}\text { Nenhuma vez - evito para não me } \\
\text { chatear }\end{array}$ & 2 & 4,50 & 6 & 14,60 & - & - & \\
\hline \multirow{6}{*}{$\begin{array}{l}\text { Apalpou } \\
\text { Rosto }\end{array}$} & Nenhuma vez - não me interesso & 12 & 27,30 & 3 & 7,30 & 16 & 40,00 & \multirow{6}{*}{$0,007^{*}$} \\
\hline & Pelo menos uma vez na semana & 6 & 13,60 & 7 & 17,10 & 7 & 17,50 & \\
\hline & Todos os dias & 14 & 31,80 & 11 & 26,80 & 13 & 32,50 & \\
\hline & $1-2$ vezes por dia & 3 & 6,80 & 3 & 7,30 & 2 & 5,00 & \\
\hline & Mais de 3 vezes ao dia & 6 & 13,60 & 12 & 29,30 & 1 & 2,50 & \\
\hline & $\begin{array}{l}\text { Nenhuma vez - evito para não me } \\
\text { chatear }\end{array}$ & 3 & 6,80 & 5 & 12,20 & - & - & \\
\hline \multirow{6}{*}{$\begin{array}{l}\text { Apalpou } \\
\text { costelas }\end{array}$} & Nenhuma vez - não me interesso & 12 & 27,3 & 6 & 14,60 & 27 & 67,50 & \multirow{6}{*}{$<0,001^{*}$} \\
\hline & Pelo menos uma vez na semana & 7 & 15,9 & 9 & 22,00 & 10 & 25,00 & \\
\hline & Todos os dias & 11 & 25,0 & 11 & 26,80 & 1 & 2,50 & \\
\hline & $1-2$ vezes por dia & 3 & 6,8 & 2 & 4,90 & - & - & \\
\hline & Mais de 3 vezes ao dia & 9 & 20,5 & 6 & 14,60 & 1 & 2,50 & \\
\hline & $\begin{array}{l}\text { Nenhuma vez - evito para não me } \\
\text { chatear }\end{array}$ & 2 & 4,5 & 7 & 17,10 & 1 & 2,50 & \\
\hline \multirow{6}{*}{$\begin{array}{l}\text { Apalpou } \\
\text { clavícula }\end{array}$} & Nenhuma vez - não me interesso & 9 & 20,5 & 14 & 34,10 & 26 & 65,00 & \multirow{6}{*}{$0,001^{*}$} \\
\hline & Pelo menos uma vez na semana & 12 & 27,3 & 6 & 14,60 & 11 & 27,50 & \\
\hline & Todos os dias & 7 & 15,9 & 8 & 19,50 & 1 & 2,50 & \\
\hline & $1-2$ vezes por dia & 2 & 4,5 & 3 & 7,30 & - & - & \\
\hline & Mais de 3 vezes ao dia & 9 & 20,5 & 5 & 12,20 & 1 & 2,50 & \\
\hline & $\begin{array}{l}\text { Nenhuma vez - evito para não me } \\
\text { chatear }\end{array}$ & 5 & 11,4 & 5 & 12,20 & 1 & 2,50 & \\
\hline \multirow{6}{*}{$\begin{array}{l}\text { Usou fita } \\
\text { métrica para } \\
\text { coxas }\end{array}$} & Nenhuma vez - não me interesso & 32 & 72,7 & 25 & 61,00 & 32 & 80,00 & \multirow{6}{*}{$0,571^{*}$} \\
\hline & Pelo menos uma vez na semana & 3 & 6,8 & 2 & 4,90 & 3 & 7,50 & \\
\hline & Todos os dias & 2 & 4,5 & 1 & 2,40 & 1 & 2,50 & \\
\hline & $1-2$ vezes por dia & 1 & 2,3 & 2 & 4,90 & - & - & \\
\hline & Mais de 3 vezes ao dia & - & - & 1 & 2,40 & - & - & \\
\hline & $\begin{array}{l}\text { Nenhuma vez - evito para não me } \\
\text { chatear }\end{array}$ & 6 & 13,6 & 10 & 24,40 & 4 & 10,00 & \\
\hline \multirow{6}{*}{$\begin{array}{l}\text { Usou fita } \\
\text { métrica para } \\
\text { barriga }\end{array}$} & Nenhuma vez - não me interesso & 30 & 68,2 & 23 & 56,10 & 32 & 80,00 & \multirow{6}{*}{$0,724^{*}$} \\
\hline & Pelo menos uma vez na semana & 5 & 11,4 & 5 & 12,20 & 2 & 5,00 & \\
\hline & Todos os dias & 1 & 2,3 & 1 & 2,40 & 1 & 2,50 & \\
\hline & $1-2$ vezes por dia & 1 & 2,3 & 1 & 2,40 & - & - & \\
\hline & Mais de 3 vezes ao dia & 1 & 2,3 & 1 & 2,40 & - & - & \\
\hline & $\begin{array}{l}\text { Nenhuma vez - evito para não me } \\
\text { chatear }\end{array}$ & 6 & 13,6 & 10 & 24,40 & 5 & 12,50 & \\
\hline
\end{tabular}




\begin{tabular}{|c|c|c|c|c|c|c|c|c|}
\hline & & \multicolumn{6}{|c|}{ Grupo } & \multirow{3}{*}{ p-valor } \\
\hline & & \multicolumn{2}{|c|}{$\begin{array}{c}\text { AN } \\
(n=44)\end{array}$} & \multicolumn{2}{|c|}{$\begin{array}{c}B N \\
(n=41)\end{array}$} & \multicolumn{2}{|c|}{$\begin{array}{l}\text { Controle } \\
(n=40)\end{array}$} & \\
\hline & & $\mathbf{n}$ & $\%$ & $\mathbf{n}$ & $\%$ & $\mathbf{n}$ & $\%$ & \\
\hline \multirow{6}{*}{$\begin{array}{l}\text { Usou fita } \\
\text { métrica para } \\
\text { quadril }\end{array}$} & Nenhuma vez - não me interesso & 28 & 63,6 & 25 & 61,00 & 29 & 72,50 & \multirow{6}{*}{$0,617^{*}$} \\
\hline & Pelo menos uma vez na semana & 7 & 15,9 & 3 & 7,30 & 6 & 15,00 & \\
\hline & Todos os dias & 2 & 4,5 & 2 & 4,90 & 1 & 2,50 & \\
\hline & $1-2$ vezes por dia & 2 & 4,5 & 1 & 2,40 & - & - & \\
\hline & Mais de 3 vezes ao dia & 1 & 2,3 & 1 & 2,40 & - & - & \\
\hline & $\begin{array}{l}\text { Nenhuma vez - evito para não me } \\
\text { chatear }\end{array}$ & 4 & 9,1 & 9 & 22,00 & 4 & 10,00 & \\
\hline \multirow{6}{*}{$\begin{array}{l}\text { Usou o } \\
\text { número de } \\
\text { suas roupas } \\
\text { para julgar o } \\
\text { tamanho do } \\
\text { corpo }\end{array}$} & Nenhuma vez - não me interesso & 8 & 18,2 & 3 & 7,30 & 19 & 47,50 & \multirow{6}{*}{$0,007^{*}$} \\
\hline & Pelo menos uma vez na semana & 11 & 25,0 & 14 & 34,10 & 12 & 30,00 & \\
\hline & Todos os dias & 13 & 29,5 & 14 & 34,10 & 5 & 12,50 & \\
\hline & $1-2$ vezes por dia & 3 & 6,8 & 1 & 2,40 & 1 & 2,50 & \\
\hline & Mais de 3 vezes ao dia & 6 & 13,6 & 6 & 14,60 & 1 & 2,50 & \\
\hline & $\begin{array}{l}\text { Nenhuma vez - evito para não me } \\
\text { chatear }\end{array}$ & 3 & 6,8 & 3 & 7,30 & 2 & 5,00 & \\
\hline \multirow{6}{*}{$\begin{array}{l}\text { Comparou o } \\
\text { tamanho do } \\
\text { corpo com } \\
\text { outras } \\
\text { pessoas }\end{array}$} & Nenhuma vez - não me interesso & 5 & 11,4 & 2 & 4,90 & 13 & 32,50 & \multirow{6}{*}{$0,002^{\star}$} \\
\hline & Pelo menos uma vez na semana & 10 & 22,7 & 10 & 24,40 & 17 & 42,50 & \\
\hline & Todos os dias & 14 & 31,8 & 17 & 41,50 & 6 & 15,00 & \\
\hline & $1-2$ vezes por dia & 3 & 6,8 & 1 & 2,40 & 1 & 2,50 & \\
\hline & Mais de 3 vezes ao dia & 11 & 25,0 & 10 & 24,40 & 1 & 2,50 & \\
\hline & $\begin{array}{l}\text { Nenhuma vez - evito para não me } \\
\text { chatear }\end{array}$ & 1 & 2,3 & 1 & 2,40 & 2 & 5,00 & \\
\hline \multirow{6}{*}{$\begin{array}{l}\text { Monitorou o } \\
\text { quanto suas } \\
\text { coxas } \\
\text { esparramaram } \\
\text { ao sentar }\end{array}$} & Nenhuma vez - não me interesso & 10 & 22,7 & 4 & 9,80 & 21 & 52,50 & \multirow{6}{*}{$0,001^{*}$} \\
\hline & Pelo menos uma vez na semana & 9 & 20,5 & 5 & 12,20 & 9 & 22,50 & \\
\hline & Todos os dias & 10 & 22,7 & 15 & 36,60 & 7 & 17,50 & \\
\hline & $1-2$ vezes por dia & 3 & 6,8 & 3 & 7,30 & - & - & \\
\hline & Mais de 3 vezes ao dia & 10 & 22,7 & 12 & 29,30 & 1 & 2,50 & \\
\hline & $\begin{array}{l}\text { Nenhuma vez - evito para não me } \\
\text { chatear }\end{array}$ & 2 & 4,5 & 2 & 4,90 & 2 & 5,00 & \\
\hline \multirow{6}{*}{$\begin{array}{l}\text { Mediu a } \\
\text { circunferência } \\
\text { do pulso }\end{array}$} & Nenhuma vez - não me interesso & 16 & 36,4 & 16 & 39,00 & 29 & 72,50 & \multirow{6}{*}{$0,007^{*}$} \\
\hline & Pelo menos uma vez na semana & 7 & 15,9 & 7 & 17,10 & 7 & 17,50 & \\
\hline & Todos os dias & 8 & 18,2 & 3 & 7,30 & 2 & 5,00 & \\
\hline & $1-2$ vezes por dia & 3 & 6,8 & 1 & 2,40 & - & - & \\
\hline & Mais de 3 vezes ao dia & 6 & 13,6 & 10 & 24,40 & - & - & \\
\hline & $\begin{array}{l}\text { Nenhuma vez - evito para não me } \\
\text { chatear }\end{array}$ & 4 & 9,1 & 4 & 9,80 & 2 & 5,00 & \\
\hline \multirow{6}{*}{ Pesou-se } & Nenhuma vez - não me interesso & 6 & 13,6 & 8 & 19,50 & 10 & 25,00 & \multirow{6}{*}{$0,017^{*}$} \\
\hline & Pelo menos uma vez na semana & 13 & 29,5 & 13 & 31,70 & 22 & 55,00 & \\
\hline & Todos os dias & 8 & 18,2 & 3 & 7,30 & 3 & 7,50 & \\
\hline & $1-2$ vezes por dia & 2 & 4,5 & 1 & 2,40 & 2 & 5,00 & \\
\hline & Mais de 3 vezes ao dia & 6 & 13,6 & 2 & 4,90 & 1 & 2,50 & \\
\hline & $\begin{array}{l}\text { Nenhuma vez - evito para não me } \\
\text { chatear }\end{array}$ & 9 & 20,5 & 14 & 34,10 & 2 & 5,00 & \\
\hline
\end{tabular}

*Teste qui-quadrado 
Em relação às formas de checar o corpo, podemos notar que:

- Olhar-se no espelho é forma de checagem mais comum entre os três grupos;

- No grupo BN, apalpar-se também se destacou em relação às outras formas de checagem (Tabela 14).

Tabela 14: Formas de checagem mais prevalentes em cada um dos grupos estudados - 2009 a 2010

\begin{tabular}{|c|c|c|c|c|c|c|c|c|}
\hline \multirow[b]{3}{*}{ Comportamentos } & \multicolumn{6}{|c|}{ Grupo } & \multirow{2}{*}{\multicolumn{2}{|c|}{ Total }} \\
\hline & \multicolumn{2}{|c|}{ AN } & \multicolumn{2}{|c|}{ BN } & \multicolumn{2}{|c|}{ Controle } & & \\
\hline & $\mathbf{N}$ & $\%$ & $\mathbf{n}$ & $\%$ & $\mathbf{n}$ & $\%$ & $\mathbf{n}$ & $\%$ \\
\hline Beliscou-se & 34 & 77,3 & 38 & 92,7 & 28 & 70,0 & 100 & 80,0 \\
\hline Olhou-se no espelho & 44 & 100,0 & 41 & 100,0 & 38 & 95,0 & 123 & 98,4 \\
\hline Apalpou-se & 41 & 93,2 & 41 & 100,0 & 30 & 75,0 & 112 & 89,6 \\
\hline Usou uma fita métrica & 17 & 38,6 & 18 & 43,9 & 12 & 30,0 & 47 & 37,6 \\
\hline $\begin{array}{l}\text { Usou o tamanho das roupas para } \\
\text { julgar o tamanho de seu corpo }\end{array}$ & 36 & 81,8 & 38 & 92,7 & 21 & 52,5 & 95 & 76,0 \\
\hline $\begin{array}{l}\text { Comparou o tamanho do corpo } \\
\text { com o de outras pessoas }\end{array}$ & 39 & 88,6 & 39 & 95,1 & 27 & 67,5 & 105 & 84,0 \\
\hline $\begin{array}{l}\text { Monitorou a "esparramação" das } \\
\text { coxas ao sentar-se }\end{array}$ & 34 & 77,3 & 37 & 90,2 & 19 & 47,5 & 90 & 72,0 \\
\hline Mediu a circunferência do pulso & 28 & 63,6 & 25 & 61,0 & 11 & 27,5 & 64 & 51,2 \\
\hline Pesou-se & 38 & 86,4 & 33 & 80,5 & 30 & 75,0 & 101 & 80,8 \\
\hline p-valor* & \multicolumn{2}{|c|}{$<0,001^{*}$} & \multicolumn{2}{|c|}{$<0,001^{\star}$} & \multicolumn{2}{|c|}{$<0,001^{\star}$} & \multicolumn{2}{|c|}{$<0,001^{\star}$} \\
\hline
\end{tabular}

${ }^{*}$ Teste de Cochran 
Ao avaliar as áreas corporais mais checadas pelos grupos estudados, podemos observar que (Tabela 15):

- A área corporal mais checada é a barriga;

- Metade do grupo BN checa a barriga 1-2 vezes ao dia $($ mediana $=3,00)$;

- Metade do grupo AN checa a barriga pelo menos uma vez ao dia (mediana $=2,25)$

- A área menos checada pelos grupos AN e BN são os glúteos.

Deve-se salientar que, por motivos estatísticos, a área "glúteos" foi agrupada juntamente com a área "quadril".

Tabela 15: Comparação das áreas corporais mais checadas pelos grupos estudados - 2009 a 2010

\begin{tabular}{lccc}
\hline Medianas & $\begin{array}{c}\text { AN } \\
(\mathrm{n}=44)\end{array}$ & $\begin{array}{c}\mathrm{BN} \\
(\mathrm{n}=41)\end{array}$ & $\begin{array}{c}\text { Controle } \\
(\mathrm{n}=40)\end{array}$ \\
\hline Checagem das coxas & 1,30 & 2,20 & 0,70 \\
Checagem da barriga & 2,25 & 3,00 & 1,25 \\
Checagem dos glúteos/ quadril & 0,67 & 1,67 & 0,50 \\
Checagem do rosto & 1,33 & 2,67 & 1,00 \\
Checagem das costelas & 2,00 & 2,00 & 0,00 \\
\hline $\mathbf{p}^{- \text {valor }^{*}}$ & $<\mathbf{0 , 0 0 1 ^ { * }}$ & $<\mathbf{0 , 0 0 1 ^ { * }}$ & $<0,001^{*}$ \\
\hline
\end{tabular}

* Teste de Friedman 


\subsubsection{Evitação da checagem}

A escala BCAQ apresenta, na sua escala Likert, o item "Nenhuma vez - evito checar para não me chatear", responsável pela pontuação mais elevada (pontuação $=5$ ). Assim, foi formado um escore de evitação (EV), relativo à somatória das respostas de evitação da checagem do próprio corpo. Dessa forma, podemos notar que (Tabela 16):

- o comportamento mais evitado é o ato de pesar-se $(20 \%$ das entrevistadas, $n=25)$;

- as áreas mais evitadas são a barriga $(n=21)$, as coxas $(n=20)$ e os quadris ( $\mathrm{n}=17$ ), quando aferidas com a fita métrica;

- Na maioria das categorias de checagem corporal, o grupo BN é o que apresenta maior porcentagem de evitação, porém empata com o grupo AN nas seguintes categorias: olhar no espelho para a barriga; apalpar os ossos da clavícula, medir a circunferência do pulso, usar o tamanho das roupas para julgar o corpo, monitorar a "esparramação" das coxas ao sentar-se, comparar o próprio corpo com o de outras pessoas.

Tabela 16: Comparação dos escores de evitação de checagem entre os grupos estudados - 2009 a 2010

\begin{tabular}{lcccc}
\hline Grupo & $\begin{array}{c}\text { AN } \\
(\mathbf{n}=\mathbf{4 4})\end{array}$ & $\begin{array}{c}\text { BN } \\
(\mathbf{n}=\mathbf{4 1 )}\end{array}$ & $\begin{array}{c}\text { Controle } \\
(\mathbf{n}=\mathbf{4 0})\end{array}$ & p-valor \\
\hline $\mathrm{N}$ & 44 & 41 & 40 & \\
Média & 1,91 & 4,05 & 0,80 & $\mathbf{0 0 , 0 0 1}^{*}$ \\
Desvio padrão & 3,21 & 5,84 & 2,13 & \\
Mediana & 0,00 & 1,00 & 0,00 & \\
\hline
\end{tabular}

* Teste de Kruskal-Wallis 


\subsubsection{Motivos de checagem dos três grupos}

A Tabela 17 mostra os escores do BCCS, deixando claro que o grupo controle apresentou, em média, menor pontuação no BCCS, ou seja, para este grupo, existe uma menor motivação para a checagem corporal.

Tabela 17: Comparação da pontuação da escala BCCS entre os grupos estudados -2009 a 2010

\begin{tabular}{|c|c|c|c|c|c|}
\hline & & \multicolumn{3}{|c|}{ Grupo } & \multirow[b]{2}{*}{ p-valor } \\
\hline & & $\begin{array}{c}\text { AN } \\
(n=44)\end{array}$ & $\begin{array}{c}\text { BN } \\
(n=41)\end{array}$ & $\begin{array}{c}\text { Controle } \\
(n=40)\end{array}$ & \\
\hline \multirow{5}{*}{ Pontuação BCCS } & Media & 65,11 & 62,71 & 43,38 & \multirow{5}{*}{$<0,001^{*}$} \\
\hline & Mediana & 71,00 & 59,00 & 41,50 & \\
\hline & Desvio padrão & 20,79 & 20,41 & 19,42 & \\
\hline & Mínimo & 20 & 23 & 19 & \\
\hline & Máximo & 97 & 122 & 95 & \\
\hline
\end{tabular}

*ANOVA

Porém, se considerarmos as quatro subescalas oferecidas pelo BCCS - verificação objetiva; segurança e garantia; consequências de não checar e controle da dieta e do ganho de peso -, podemos verificar que houve diferença estatística entre os três grupos acerca dos motivos que os levam a checar o corpo (Tabela 18):

- Grupo AN: o principal motivo de checagem é a verificação objetiva empatada estatisticamente com controle da dieta e ganho de peso. Em terceiro lugar apareceu a segurança e 
garantia ( $p$-valores $>0,05)$ e o menor motivo é consequências de não checar.

- Grupo BN: o principal motivo é segurança e garantia, estatisticamente empatado com consequências de não checar ( $p$-valores $>0,05)$, seguidos por verificação objetiva e, como menos importante, controle da dieta e do peso ( $p$-valores $>0,05)$.

- Grupo controle: três motivos empataram - verificação objetiva, segurança e garantia e controle da dieta e do peso ( $p$-valores > 0,05). O grupo controle considerou como menos importante as consequências de não checar.

É importante salientar que na Tabela 18 os três grupos não foram comparados. Esta tabela é diferente de todas as outras deste trabalho, pois evidencia o comportamento de cada grupo. 
Tabela 18: Motivos que levam os três grupos estudados à checagem corporal, segundo o BCCS - 2009 a 2010

\begin{tabular}{|c|c|c|c|c|c|c|}
\hline Grupo & & $\begin{array}{c}\text { Verificação } \\
\text { objetiva }\end{array}$ & $\begin{array}{l}\text { Segurança } \\
\text { e garantia }\end{array}$ & Consequências & $\begin{array}{c}\text { Controle da } \\
\text { dieta e } \\
\text { ganho de } \\
\text { peso }\end{array}$ & p-valor* \\
\hline \multirow[t]{8}{*}{ NA } & $\mathrm{N}$ & 44 & 44 & 44 & 44 & $<0,001$ \\
\hline & Média & 3,80 & 3,20 & 3,00 & 3,70 & \\
\hline & Desvio padrão & 1,06 & 1,23 & 1,28 & 1,39 & \\
\hline & Erro padrão & 0,16 & 0,19 & 0,19 & 0,21 & \\
\hline & Mediana & 4,00 & 3,30 & 2,90 & 4,00 & \\
\hline & Mínimo & 1 & 1 & 1 & 1 & \\
\hline & Máximo & 5 & 5 & 5 & 5 & \\
\hline & Intervalo interquartílico & $3-5$ & $2--4$ & $2-4$ & $3-5$ & \\
\hline \multirow[t]{8}{*}{$\mathrm{BN}$} & $\mathrm{N}$ & 41 & 41 & 41 & 41 & $<0,001$ \\
\hline & Média & 3,00 & 3,60 & 3,50 & 2,90 & \\
\hline & Desvio padrão & 1,14 & 1,11 & 1,04 & 1,03 & \\
\hline & Erro padrão & 0,18 & 0,17 & 0,16 & 0,16 & \\
\hline & Mediana & 3,20 & 3,80 & 3,40 & 3,00 & \\
\hline & Mínimo & 1 & 1 & 1 & 1 & \\
\hline & Máximo & 5 & 5 & 5 & 5 & \\
\hline & Intervalo interquartílico & $2-4$ & $3--4$ & $3--4$ & $2-4$ & \\
\hline \multirow[t]{8}{*}{ Controle } & $\mathrm{N}$ & 40 & 40 & 40 & 40 & $<0,001$ \\
\hline & Média & 2,50 & 2,50 & 1,70 & 2,30 & \\
\hline & Desvio padrão & 1,08 & 1,23 & 0,81 & 1,18 & \\
\hline & Erro padrão & 0,17 & 0,19 & 0,13 & 0,19 & \\
\hline & Mediana & 2,7 & 2,55 & 1,3 & 2,15 & \\
\hline & Mínimo & 1 & 1 & 1 & 1 & \\
\hline & Máximo & 4 & 5 & 4 & 5 & \\
\hline & Intervalo interquartílico & $2-3$ & $1--3$ & $1-2$ & $1-3$ & \\
\hline
\end{tabular}

*Teste de Friedman 


\subsection{Análise inferencial dos resultados}

7.2.1 Relação entre idade, medidas antropométricas, tempo de tratamento e checagem/ evitação corporal

Ao relacionar as variáveis idade, medidas antropométricas, tempo de tratamento e checagem/ evitação corporal, podemos observar que:

- a idade e o IMC não se relacionaram com os escores de BCAQ (Tabela 19);

- o peso desejado se relacionou negativamente com a checagem/ evitação corporal, ou seja, quanto menor o peso desejado, maior a pontuação no $B C A Q$, nos grupos de pacientes. Apesar de 0 peso desejado não se relacionar com a pontuação de BCAQ no grupo controle, se considerarmos os três grupos como um só, peso desejado e BCAQ se relacionaram (Tabela 19);

- ao analisarmos o grupo de forma geral, o tempo de tratamento se relacionou positivamente com a checagem corporal, ou seja, quanto maior o tempo de tratamento, maior a checagem corporal. 
Tabela 19: Relação entre idade, medidas antropométricas, tempo de tratamento e checagem corporal - 2009 a 2010

\begin{tabular}{llcccc}
\hline & & $\begin{array}{c}\text { AN } \\
(\mathbf{n}=\mathbf{4 4})\end{array}$ & $\begin{array}{c}\text { BN } \\
(\mathbf{n}=\mathbf{4 1})\end{array}$ & $\begin{array}{c}\text { Controle } \\
(\mathbf{n}=\mathbf{4 0})\end{array}$ & $\begin{array}{c}\text { Geral } \\
(\mathbf{n}=\mathbf{1 2 5})\end{array}$ \\
\hline Idade & Correlação de Pearson & 0,045 & $-0,115$ & $-0,231$ & $-0,103$ \\
& p-valor & 0,772 & 0,474 & 0,152 & 0,253 \\
\hline IMC & Correlação de Pearson & 0,277 & 0,240 & 0,113 & 0,174 \\
& p-valor & 0,069 & 0,131 & 0,489 & 0,052 \\
\hline Peso desejado & Correlação de Pearson & $-0,446$ & $-0,331$ & 0,180 & $-0,340$ \\
& p-valor & 0,002 & 0,037 & 0,266 & $<0,001$ \\
\hline Tempo de tratamento & Correlação de Pearson & $0,317^{*}$ & 0,307 & - & 0,294 \\
& p-valor & 0,036 & 0,051 & - & $<0,001$ \\
\hline
\end{tabular}

Uma vez que a variável tempo de tratamento não alterou a checagem/ evitação corporal, foi realizada uma correlação de Pearson para verificar se ao longo do tratamento os motivos para checagem corporal são alterados. Na Tabela 20 podemos observar que, nos grupos AN e BN, os motivos que levam as pacientes a se checarem não se alteram ao longo do tratamento. Porém, ao avaliarmos os dois grupos juntos, a correlação se torna positiva, indicando que, numa população maior, talvez seja detectada uma alteração de cognição ao longo do tratamento.

Tabela 20: Relação entre tempo de tratamento e pontuação de BCCS nos grupos AN e BN - 2009 a 2010

\begin{tabular}{lccc}
\hline BCCS Pontuação & $\begin{array}{c}\text { AN } \\
(\mathbf{n}=\mathbf{4 4})\end{array}$ & $\begin{array}{c}\text { BN } \\
(\mathbf{n}=\mathbf{4 1 )}\end{array}$ & $\begin{array}{c}\text { Geral } \\
(\mathbf{n}=\mathbf{8 5})\end{array}$ \\
\hline Correlação de Pearson & 0,287 & 0,201 & 0,360 \\
p-valor & 0,059 & 0,207 & $<\mathbf{0 , 0 0 1}$ \\
\hline
\end{tabular}




\subsubsection{Relação entre atitude alimentar e checagem corporal}

Antes de iniciar todas as relações entre escalas, é importante lembrar que o grupo controle não teve pontuação importante em nenhuma das escalas rastreadoras de TAs (EAT, BITE e BSQ), depressão (BDI) ou comportamentos obsessivo-compulsivos (Y-BOCKS), uma vez que foi escolhido de forma a ser isento de problemas psiquiátricos.

Se considerarmos a relação geral (dos três grupos) entre a atitude alimentar (pela pontuação total do EAT) e a checagem corporal (pela pontuação total do BCAQ), podemos notar que ela é estatisticamente significante (Tabela 21). Ou seja, quanto pior a atitude alimentar, maior o comportamento de checagem corporal.

Ao verificarmos separadamente cada um dos grupos, em nenhum deles a relação foi estatisticamente significante, apesar de a relação ter sido mais forte no grupo de AN (Tabela 21).

Tabela 21: Correlação entre atitude alimentar (pontuação do EAT) e a checagem corporal (pontuação do BCAQ) entre os três grupos estudados - 2009 a 2010

\begin{tabular}{llcccc}
\hline BCAQ Pontuação & & $\begin{array}{c}\text { AN } \\
(\mathbf{n}=44)\end{array}$ & $\begin{array}{c}\text { BN } \\
(\mathbf{n}=\mathbf{4 1})\end{array}$ & $\begin{array}{c}\text { Controle } \\
(\mathbf{n}=\mathbf{4 0 )}\end{array}$ & $\begin{array}{c}\text { Geral } \\
(\mathbf{n}=\mathbf{1 2 5})\end{array}$ \\
\hline EAT & Correlação Pearson & $0,370^{*}$ & 0,222 & 0,109 & $0,501^{*}$ \\
& p-valor & 0,013 & 0,163 & 0,501 & $<\mathbf{0 , 0 0 1}$ \\
\hline
\end{tabular}




\subsubsection{Relação entre sintomas e gravidade de bulimia nervosa e checagem corporal}

A Tabela 22 relaciona resultados do BITE e a checagem corporal. Nela, podemos notar que:

- Pela escala de sintomatologia, não houve relação significativa com a checagem corporal tanto no grupo AN como no grupo BN;

- O alto grau de severidade de bulimia nervosa repercute positivamente na pontuação de checagem corporal do grupo BN. Isso significa que, quanto maior a gravidade de $\mathrm{BN}$, maior a checagem/ evitação da checagem corporal.

Tabela 22: Relação entre sintomas e gravidade de bulimia nervosa com a checagem corporal nos três grupos estudados - 2009 a 2010

\begin{tabular}{|c|c|c|c|c|c|c|c|c|c|}
\hline \multirow[b]{3}{*}{ BITE Sintomática } & \multicolumn{9}{|c|}{ Escores de BCAQ } \\
\hline & \multicolumn{3}{|c|}{$\begin{array}{c}\text { AN } \\
(n=44)\end{array}$} & \multicolumn{3}{|c|}{$\begin{array}{c}\text { BN } \\
(n=41)\end{array}$} & \multicolumn{3}{|c|}{$\begin{array}{c}\text { Controle } \\
(n=40)\end{array}$} \\
\hline & $\mathbf{n}$ & Média & d.p. & $\mathbf{n}$ & Média & d.p. & $\mathbf{N}$ & Média & d.p. \\
\hline Limite da normalidade & 13 & 37,31 & 25,92 & - & - & - & - & - & - \\
\hline Padrão alimentar não usual & 17 & 50,82 & 26,02 & 12 & 65,67 & 31,55 & - & - & - \\
\hline $\begin{array}{l}\text { Presença de comportamento } \\
\text { alimentar compulsivo }\end{array}$ & 14 & 48,36 & 21,60 & 28 & 54,14 & 27,62 & - & - & - \\
\hline Total & 44 & 46,05 & 24,79 & 41 & 57,83 & 28,62 & - & - & - \\
\hline p-valor & \multicolumn{3}{|c|}{0,240} & \multicolumn{3}{|c|}{0,516} & \multicolumn{3}{|c|}{-} \\
\hline BITE Gravidade & $\mathbf{n}$ & Média & d.p. & $\mathbf{n}$ & Média & d.p. & $\mathbf{N}$ & Média & d.p. \\
\hline Insignificante & 12 & 42,75 & 30,75 & 7 & 44,71 & 38,67 & 38 & 22,71 & 14,32 \\
\hline Clinicamente significativo & 13 & 36,15 & 20,69 & 9 & 42,33 & 21,17 & 2 & 24,50 & 13,44 \\
\hline Alto grau de severidade & 19 & 54,89 & 21,07 & 25 & 67,08 & 24,74 & - & - & - \\
\hline Total & 44 & 46,05 & 24,79 & 41 & 57,83 & 28,62 & 40 & 22,80 & 14,12 \\
\hline p-valor & \multicolumn{3}{|c|}{0,058} & \multicolumn{3}{|c|}{0,021} & \multicolumn{3}{|c|}{0,864} \\
\hline
\end{tabular}

*Teste de Kruskal-Wallis 


\subsubsection{Relação entre imagem corporal e checagem corporal}

Ao relacionarmos a checagem corporal com os resultados de satisfação/ insatisfação corporal propiciados pela escala BSQ (Tabela 23), podemos notar que tanto no grupo $\mathrm{AN}$ como no grupo $\mathrm{BN}$, quanto maior quanto maior a insatisfação corporal, maior a pontuação no BCAQ.

Tabela 23: Relação entre satisfação/ insatisfação corporal e checagem corporal nos três grupos estudados - 2009 a 2010

\begin{tabular}{|c|c|c|c|c|c|c|c|c|c|}
\hline \multirow[b]{3}{*}{ BSQ Resultado } & \multicolumn{9}{|c|}{ Escores de BCAQ } \\
\hline & \multicolumn{3}{|c|}{$\begin{array}{c}\text { AN } \\
(n=44)\end{array}$} & \multicolumn{3}{|c|}{$\begin{array}{c}\text { BN } \\
(n=41)\end{array}$} & \multicolumn{3}{|c|}{$\begin{array}{l}\text { Controle } \\
(n=40)\end{array}$} \\
\hline & $\mathbf{n}$ & Média & d.p. & $\mathbf{n}$ & Média & d.p. & $\mathbf{n}$ & Média & d.p. \\
\hline Sem insatisfação corporal & 15 & 28,93 & 21,70 & 3 & 37,33 & 25,74 & 27 & 20,19 & 13,75 \\
\hline Insatisfação corporal leve & 3 & 43,00 & 13,08 & 7 & 35,43 & 18,67 & 9 & 31,67 & 10,97 \\
\hline Insatisfação corporal moderada & 11 & 48,82 & 25,32 & 10 & 57,40 & 27,12 & 4 & 20,50 & 18,08 \\
\hline Insatisfação corporal grave & 15 & 61,73 & 18,66 & 21 & 68,43 & 27,91 & - & - & - \\
\hline Total & 44 & 46,05 & 24,79 & 41 & 57,83 & 28,62 & 40 & 22,80 & 14,12 \\
\hline$p$-valor & \multicolumn{3}{|c|}{$0,001^{*}$} & \multicolumn{3}{|c|}{$0,022^{\star}$} & \multicolumn{3}{|c|}{$0,051^{*}$} \\
\hline
\end{tabular}

*Teste de Kruskal-Wallis

Porém, ao usarmos a Escala de Silhuetas de Stunkard para relacionarmos imagem corporal e checagem corporal, os resultados são um pouco diferentes:

- Em nenhum dos grupos estudados houve diferença estatística na relação entre checagem corporal e satisfação com o próprio corpo (Tabela 24);

- Em relação à distorção da imagem corporal, pôde-se perceber que aquelas que acreditam ser maiores do que realmente são, pontuam mais no $B C A Q$, especialmente no grupo BN (Tabela 24). 
Tabela 24: Relação entre imagem corporal e checagem corporal nos três grupos estudados - 2009 a 2010

\begin{tabular}{|c|c|c|c|c|c|c|c|c|c|}
\hline \multirow[b]{3}{*}{$\begin{array}{l}\text { Insatisfação corporal } \\
\text { (Stunkard) }\end{array}$} & \multicolumn{9}{|c|}{ Escores de BCAQ } \\
\hline & \multicolumn{3}{|c|}{$\begin{array}{c}\text { AN } \\
(n=44)\end{array}$} & \multicolumn{3}{|c|}{$\begin{array}{c}\text { BN } \\
(n=41)\end{array}$} & \multicolumn{3}{|c|}{$\begin{array}{l}\text { Controle } \\
(n=40)\end{array}$} \\
\hline & $\mathbf{n}$ & Média & d.p. & $\mathbf{N}$ & Média & d.p. & $\mathbf{n}$ & Média & d.p. \\
\hline Sem insatisfação corporal & 2 & 51,00 & 55,15 & 1 & 21,00 & . & 11 & 24,18 & 17,53 \\
\hline Insatisfação corporal & 42 & 45,81 & 23,85 & 40 & 58,75 & 28,36 & 29 & 22,28 & 12,91 \\
\hline Total & 44 & 46,05 & 24,79 & 41 & 57,83 & 28,62 & 40 & 22,80 & 14,12 \\
\hline p-valor & \multicolumn{3}{|c|}{0,933} & \multicolumn{3}{|c|}{0,176} & \multicolumn{3}{|c|}{0,916} \\
\hline $\begin{array}{l}\text { Distorção da imagem } \\
\text { corporal (Stunkard) }\end{array}$ & $\mathbf{n}$ & Média & d.p. & $\mathbf{N}$ & Média & d.p. & $\mathbf{n}$ & Média & d.p. \\
\hline $\begin{array}{l}\text { Com distorção da imagem } \\
\text { corporal } \\
\text { Acredita ser menor do que } \\
\text { realmente é }\end{array}$ & - & - & - & - & - & - & 19 & 21,79 & 12,92 \\
\hline $\begin{array}{l}\text { Sem distorção da imagem } \\
\text { corporal }\end{array}$ & 6 & 48,33 & 25,62 & 10 & 40,70 & 22,29 & 15 & 24,80 & 14,65 \\
\hline $\begin{array}{l}\text { Com distorção da imagem } \\
\text { corporal }\end{array}$ & & & & & & & & & \\
\hline $\begin{array}{l}\text { Acredita ser maior do que } \\
\text { realmente é }\end{array}$ & 38 & 45,68 & 24,99 & 31 & 63,35 & 28,52 & 6 & 21,00 & 18,25 \\
\hline Total & 44 & 46,05 & 24,79 & 41 & 57,83 & 28,62 & 40 & 22,80 & 14,12 \\
\hline$p$-valor & \multicolumn{3}{|c|}{0,758} & \multicolumn{3}{|c|}{0,030} & \multicolumn{3}{|c|}{0,698} \\
\hline
\end{tabular}

*Teste de Kruskal-Wallis

\subsubsection{Relação entre sintomas depressivos e checagem corporal}

Se considerarmos a relação geral (dos três grupos) entre sintomas depressivos (pela pontuação total do BDI) e a checagem corporal (pela pontuação total do BCAQ), podemos notar que ela é estatisticamente 
significante (Tabela 25). Ou seja, quanto mais sintomas depressivos, maior o comportamento de checagem corporal.

Ao verificarmos separadamente cada um dos grupos, podemos observar que essa relação é mais forte no grupo BN (Tabela 25).

Tabela 25: Correlação entre sintomas depressivos (pontuação do BDI) e a checagem corporal (pontuação do BCAQ) entre os três grupos estudados - 2009 a 2010

\begin{tabular}{|c|c|c|c|c|c|}
\hline \multicolumn{2}{|c|}{ BCAQ Pontuação } & \multirow{2}{*}{$\begin{array}{c}\begin{array}{c}\text { AN } \\
(n=44)\end{array} \\
0,190\end{array}$} & \multirow{2}{*}{$\begin{array}{c}\begin{array}{c}\text { BN } \\
(n=41)\end{array} \\
0,397^{*}\end{array}$} & \multirow{2}{*}{$\begin{array}{c}\begin{array}{c}\text { Controle } \\
(\mathbf{n}=40)\end{array} \\
0,210\end{array}$} & \multirow{2}{*}{$\begin{array}{c}\begin{array}{c}\text { Geral } \\
(n=125)\end{array} \\
0,509^{*}\end{array}$} \\
\hline BDI Pontuação & Correlação de Pearson & & & & \\
\hline & $p$-valor & 0,218 & 0,010 & 0,194 & $<0,001$ \\
\hline
\end{tabular}

\subsubsection{Relação entre sintomas obsessivo-compulsivos e checagem corporal}

Ao avaliarmos a relação entre obsessões, compulsões e checagem/ evitação corporal, podemos observar que:

- O grupo AN com obsessões somáticas relacionadas ao corpo, bem como o grupo AN com rituais compulsivos para comer e aquele com outras compulsões apresentaram diferença significante na checagem corporal com pontuação maior no BCAQ (Tabela 26).

É importante lembrar que nesta avaliação não participou o grupo controle, uma vez que nenhuma das entrevistadas apresentou sintomas obsessivo-compulsivos. 
Tabela 26: Relação entre sintomas obsessivo-compulsivos e a checagem corporal dos grupos AN e BN - 2009 a 2010

\begin{tabular}{|c|c|c|c|c|c|c|c|c|c|}
\hline \multirow[b]{3}{*}{$\begin{array}{c}\text { Obsessões } \\
\text { somáticas/partes do corpo } \\
\text { (YBOCS) }\end{array}$} & \multicolumn{9}{|c|}{ Escores de BCAQ } \\
\hline & \multicolumn{3}{|c|}{$\begin{array}{c}\text { AN } \\
(n=44)\end{array}$} & \multicolumn{3}{|c|}{$\begin{array}{c}\text { BN } \\
(n=41)\end{array}$} & \multicolumn{3}{|c|}{$\begin{array}{c}\text { Controle } \\
(n=40)\end{array}$} \\
\hline & $\mathbf{n}$ & Média & d.p. & $\mathbf{n}$ & Média & d.p. & $\mathbf{N}$ & Média & d.p. \\
\hline Sem obsessão & 23 & 35,70 & 20,13 & 15 & 50,53 & 23,30 & - & - & - \\
\hline Com obsessão & 21 & 57,38 & 24,84 & 26 & 62,04 & 30,92 & - & - & - \\
\hline Total & 44 & 46,05 & 24,79 & 41 & 57,83 & 28,62 & - & - & - \\
\hline p-valor & \multicolumn{3}{|c|}{0,004} & \multicolumn{3}{|c|}{0,256} & & & \\
\hline Outras obsessões (YBOCS) & $\mathbf{n}$ & Média & d.p. & $\mathbf{n}$ & Média & d.p. & $\mathbf{N}$ & Média & d.p. \\
\hline Sem obsessão & 12 & 43,92 & 23,97 & 6 & 39,67 & 22,22 & - & - & - \\
\hline Com obsessão & 32 & 46,84 & 25,41 & 35 & 60,94 & 28,68 & - & - & - \\
\hline Total & 44 & 46,05 & 24,79 & 41 & 57,83 & 28,62 & - & - & - \\
\hline $\mathrm{p}$-valor & \multicolumn{3}{|c|}{0,693} & \multicolumn{3}{|c|}{0,097} & & & \\
\hline $\begin{array}{c}\text { Compulsões } \\
\text { verificação/controle } \\
\text { (YBOCS) }\end{array}$ & $\mathbf{n}$ & Média & d.p. & $\mathbf{n}$ & Média & d.p. & $\mathbf{N}$ & Média & d.p. \\
\hline Sem compulsão & 28 & 43,25 & 24,00 & 19 & 57,58 & 30,09 & - & - & - \\
\hline Com compulsão & 16 & 50,94 & 26,16 & 22 & 58,05 & 27,99 & - & - & - \\
\hline Total & 44 & 46,05 & 24,79 & 41 & 57,83 & 28,62 & - & - & - \\
\hline p-valor & \multicolumn{3}{|c|}{0,311} & \multicolumn{3}{|c|}{0,927} & & & \\
\hline $\begin{array}{c}\text { Compulsão repetições } \\
\text { (YBOCS) }\end{array}$ & $\mathbf{n}$ & Média & d.p. & $\mathbf{n}$ & Média & d.p. & $\mathbf{N}$ & Média & d.p. \\
\hline Sem compulsão & 28 & 44,50 & 26,59 & 27 & 57,44 & 30,44 & - & - & - \\
\hline Com compulsão & 16 & 48,75 & 21,83 & 14 & 58,57 & 25,79 & - & - & - \\
\hline Total & 44 & 46,05 & 24,79 & 41 & 57,83 & 28,62 & - & - & - \\
\hline $\mathrm{p}$-valor & \multicolumn{3}{|c|}{0,367} & \multicolumn{3}{|c|}{0,762} & & & \\
\hline $\begin{array}{c}\text { Compulsão contagem } \\
\text { (YBOCS) }\end{array}$ & $\mathbf{n}$ & Média & d.p. & $\mathbf{n}$ & Média & d.p. & $\mathbf{N}$ & Média & d.p. \\
\hline Sem compulsão & 36 & 45,17 & 25,61 & 29 & 53,83 & 30,33 & - & - & - \\
\hline Com compulsão & 8 & 50,00 & 21,73 & 12 & 67,50 & 22,18 & - & - & - \\
\hline Total & 44 & 46,05 & 24,79 & 41 & 57,83 & 28,62 & - & - & - \\
\hline p-valor & \multicolumn{3}{|c|}{0,420} & \multicolumn{3}{|c|}{0,112} & & & \\
\hline $\begin{array}{c}\text { Compulsão rituais para } \\
\text { comer (YBOCS) }\end{array}$ & $\mathbf{n}$ & Média & d.p. & $\mathbf{n}$ & Média & d.p. & $\mathbf{N}$ & Média & d.p. \\
\hline Sem compulsão & 32 & 41,44 & 25,26 & 30 & 55,73 & 27,21 & - & - & - \\
\hline Com compulsão & 12 & 58,33 & 19,41 & 11 & 63,55 & 32,86 & - & - & - \\
\hline Total & 44 & 46,05 & 24,79 & 41 & 57,83 & 28,62 & - & - & - \\
\hline $\mathrm{p}$-valor & \multicolumn{3}{|c|}{0,043} & \multicolumn{3}{|c|}{0,446} & & & \\
\hline Outras Compulsão (YBOCS) & $\mathbf{n}$ & Média & d.p. & $\mathbf{n}$ & Média & d.p. & $\mathbf{N}$ & Média & d.p. \\
\hline Sem compulsão & 25 & 43,32 & 25,61 & 15 & 54,80 & 27,27 & - & - & - \\
\hline Com compulsão & 19 & 49,63 & 23,86 & 26 & 59,58 & 29,75 & - & - & - \\
\hline Total & 44 & 46,05 & 24,79 & 41 & 57,83 & 28,62 & - & - & - \\
\hline p-valor & \multicolumn{3}{|c|}{0,018} & \multicolumn{3}{|c|}{0,418} & & & \\
\hline
\end{tabular}

*Teste de Kruskal-Wallis 


\subsubsection{Relação entre as escalas usadas no trabalho}

A Tabela 27 apresenta a relação entre os resultados de todas as escalas utilizadas neste trabalho. Ao se correlacionarem as escalas rastreadoras de TAs e o BDI com BCAQ e BCCS, verificou-se que:

- as escalas BCCS, EAT, BSQ, BDI, e a autoavaliação na escala de Silhuetas de Stunkard se relacionam positivamente com o BCAQ;

- o BCCS se relaciona positivamente com BCAQ, EAT e BSQ;

- o BITE não participou desta correlação, visto que seus resultados são categoriais, ao contrário das outras escalas, em que a pontuação é por meio de escores. Idem para o YBOCS.

Tabela 27: Correlação entre as escalas BCAQ, BCCS, EAT, BSQ, BDI e autoavaliação (EU) na escala de Silhuetas de Stunkard - 2009 a 2010

\begin{tabular}{lcccccc}
\hline & $\begin{array}{c}\text { Pontuação } \\
\text { BCAQ }\end{array}$ & $\begin{array}{c}\text { Pontuação } \\
\text { BCCS }\end{array}$ & $\begin{array}{c}\text { Pontuação } \\
\text { BDI }\end{array}$ & $\begin{array}{c}\text { Pontuação } \\
\text { BSQ }\end{array}$ & $\begin{array}{c}\text { Pontuação } \\
\text { EAT }\end{array}$ & EU \\
\hline Pontuação BCAQ & 1 & & & & & \\
Pontuação BCCS & 0,53 & 1 & & & & \\
Pontuação BDI & 0,51 & 0,39 & 1 & & 1 & \\
Pontuação BSQ & 0,66 & 0,69 & 0,66 & 1 & & \\
Pontuação EAT & 0,50 & 0,57 & 0,57 & 0,82 & 1 \\
Eu & 0,55 & 0,35 & 0,41 & 0,61 & 0,40 & 1 \\
\hline
\end{tabular}

*Correlação de Pearson 


\section{DISCUSSÃO}


Até onde se conhece, este é o primeiro trabalho brasileiro que compara a checagem em pacientes com TAs, bem como a relação desses comportamentos com as cognições que os impulsionam. O trabalho não desenvolve modelos de tratamento, mas busca as motivações deste hábito tão comum e pouco estudado, e sua magnitude se restringe a levantar alguns indicadores que poderiam contribuir para o tratamento dos distúrbios de imagem corporal, tão frequentes nestas pacientes.

Os resultados encontrados mostraram haver diferença entre pacientes com TAs e indivíduos controle, no que se refere à checagem corporal e sua evitação. Entre as pacientes, aquelas com BN tenderam a se checar e a evitar a checagem corporal de forma mais intensa do que aquelas com AN. Em relação aos objetivos da checagem, todos os grupos estudados parecem buscar uma verificação objetiva do seu peso e de sua forma corporal quando checam seus corpos, porém, no grupo controle, o aspecto cognitivo é menos acionado, ou seja, as crenças que os levam à checagem são mais fracas. Os dados indicaram também que a restrição alimentar, a gravidade da BN e a imagem corporal parecem influenciar a checagem corporal. Outro resultado que exige atenção é a influência dos sintomas depressivos na checagem e na evitação da checagem corporal, principalmente em pacientes com BN. Já os sintomas obsessivo-compulsivos não parecem ter tido grande influência no comportamento, apesar de que, em pacientes com 
AN, eles pareceram atuar mais intensamente, especialmente naquelas com obsessões somáticas relacionadas ao corpo, rituais compulsivos para comer e com outras compulsões diversas.

Antes do aprofundamento na discussão dos resultados encontrados, seria interessante discutir a análise descritiva da amostra, que, de um modo geral, se mostrou bastante homogênea, provavelmente pelo balanceamento estatístico por idade e grau de escolaridade. Esses dois itens foram escolhidos por serem cruciais no entendimento dos questionários aplicados, mas podem ter influenciado também na homogeneidade de outras variáveis, como estado civil, paridade e ocupação. Apesar de não ser critério diagnóstico para nenhum tipo de TA, a não funcionalidade social é marcante nessas pacientes, embora não tenha havido diferença estatística entre os grupos, relacionada a essas variáveis. Por exemplo, por conta de alterações na fertilidade (Cordás et al., 2004; Moya e Cominato, 2008) - comuns nos TAs - poderia se esperar que as pacientes apresentassem paridade diferente do grupo controle. Sabe-se que mulheres com TAs apresentam amenorreia secundária decorrente de deficiência estrogênica, causada por baixos níveis dos hormônios hipofisários luteinizantes (LH) e folículo-estimulante (FSH), que, em níveis normais, estimulam os ovários. Fatores emocionais também poderiam estar relacionados à não paridade ou até ao não relacionamento conjugal. Trabalho qualitativo realizado por Jones et al. (2008) com 32 pacientes em tratamento num hospital-dia para TAs encontrou somente $6,25 \%(n=2)$ pacientes com companheiros, ambas com relacionamentos insatisfatórios sexualmente. Dentre as solteiras, algumas relataram evitar 
contato físico; outras, falta de confiança em se mostrarem nuas; mas muitas delas mostraram esperança de terem um companheiro (a) assim que estivessem "melhores de saúde". Talvez o fato de as pacientes deste trabalho estarem sendo tratadas de forma ambulatorial indique que no momento da entrevista estivessem menos graves do que aquelas da pesquisa de Jones et al. (2008), permitindo, então, uma maior funcionalidade, e repercutindo na diferença de resultados entre as duas pesquisas.

Outro fator que poderia ter influenciado numa diferença significativa do estado civil, paridade e ocupação são os resultados encontrados no BDI, a escala utilizada para avaliar sintomas depressivos. O grupo controle apresentou $80 \%(n=30)$ de indivíduos sem sintomas depressivos, enquanto o grupo AN apresentou maior percentual de pacientes com sintomas depressivos moderados $(34,1 \%, n=15)$ e o grupo BN apresentou maior percentual de pacientes com sintomas depressivos graves $(48,8 \%, n=20)$. Dessa forma, seria de se esperar que fosse comum encontrar mais entrevistadas desempregadas ou em licença médica entre as pacientes do que nos controles - o que não ocorreu. No trabalho de Jones et al. (2008) acima citado, $75 \%$ das pacientes reportaram que não estavam aptas a trabalhar ou concluir algum curso, sempre relacionando essa incapacidade a impedimentos físicos, tais como falta de energia e de concentração, bem como a fatores emocionais. Mais uma vez, é importante atentar ao fato de que as entrevistadas para este trabalho estavam em tratamento ambulatorial, o que poderia indicar que seu estado fosse menos grave do que as pacientes de Jones et al. (2008), atendidas num hospital-dia. 
A opção sexual das pacientes também chama a atenção. Apesar de não haver diferença estatística entre os grupos, o grupo controle não tinha nenhum indivíduo homossexual ou bissexual, enquanto o grupo AN tinha quatro pacientes homossexuais $(9,1 \%)$ e duas pacientes bissexuais $(4,5 \%)$, e o grupo $\mathrm{BN}$, uma paciente homossexual $(2,4 \%)$ e uma paciente bissexual $(2,4 \%)$. Evidências indicam que mulheres homossexuais, comparadas às heterossexuais, têm risco elevado de problemas psicológicos, que são atribuídos à pressão da discriminação (Cochran et al., 2007). No caso específico dos TAs, os estudos são contraditórios. Cochran (2007) e French et al. (1996) identificaram uma taxa maior de comportamentos purgativos em mulheres heterossexuais do que nas homossexuais. Já Heffernan (1996), num dos mais detalhados trabalhos publicados sobre o assunto, não encontrou diferenças entre mulheres homossexuais e heterossexuais na prevalência de TAs. Uma hipótese seria o fato de que as mulheres que crescem em uma mesma sociedade estão expostas aos mesmos ideais de beleza, independentemente de sua orientação sexual (Heffernan, 1996; Moore e Keel, 2003). A afirmação é congruente com estudos que demonstram não existir diferenças também nos níveis de insatisfação corporal entre essas mulheres (Beren et al., 1996; Heffernan, 1996), tampouco sobre os conceitos de dieta e peso (Heffernan, 1996).

Analisando as características antropométricas da amostra, é esperado que o grupo AN apresente IMC estatisticamente menor do que os outros (média AN = 46,68 kg/m², média $B N=67,50 \mathrm{~kg} / \mathrm{m}^{2}$, média controle $=$ $61,39 \mathrm{~kg} / \mathrm{m}^{2}$ ), visto que o baixo peso é critério diagnóstico para a doença 
(APA, 1994) e o IMC é uma das formas de avaliá-lo. O fato do grupo com BN apresentar média de IMC mais elevada do que o grupo controle é congruente com os resultados do BITE, que indicaram diferença estatística no comportamento alimentar compulsivo $(68,3 \%, n=28)$ e alto grau de gravidade da doença $(61 \%, n=25)$, evidenciando o diagnóstico nestas pacientes. Assim, o alto IMC no grupo BN se explica pela frequência e intensidade de compulsões alimentares. Sabe-se que os valores energéticos das compulsões podem variar muito, mesmo na literatura. A variedade se deve em decorrência da amplitude do conceito de compulsão alimentar: "ingestão, em um curto espaço de tempo, de uma quantidade de alimento definitivamente superior ao que a maioria das pessoas conseguiria comer durante um período de tempo igual e sob circunstâncias similares" (APA, 1994). Isso significa que o conceito pode abranger quantidades e qualidades de alimentos muito variadas (Romano, 2002). Dessa forma, podemos encontrar na literatura compulsões de 1.436 a $8.585 \mathrm{kcal}$ (Mitchell e Laine, 1985) e de 5.700 a $6.680 \mathrm{kcal}$ (Gendall et al., 1997). No Brasil, foram encontradas compulsões menores, de 459,9 a $2.689 \mathrm{kcal}$ (Alvarenga, 2001) e 196,4 a 1.030 kcal (Romano, 2002). De qualquer forma, independentemente do valor calórico, com certeza o valor energético de uma compulsão tem impacto no ganho de peso dessas pacientes, que, mesmo com comportamentos purgativos, não conseguem eliminar todas as calorias ingeridas.

Em relação ao peso desejado, faz sentido o fato de a média almejada pelo grupo AN $(43,97 \mathrm{~kg})$ ser estatisticamente menor do que os grupos BN $(53,7 \mathrm{~kg})$ e controle $(57,39)$, visto que seu IMC também é menor. 
Quando notamos a mediana do peso desejado entre os grupos BN e controle (53,6 kg e $56 \mathrm{~kg}$ respectivamente) as metas são muito parecidas, e o maior peso citado como peso desejado é idêntico $(80 \mathrm{~kg})$ para os dois grupos. Já o peso mínimo desejado citado no grupo BN (20 kg) é menor do que o grupo AN $(24 \mathrm{~kg})$ e ambos chamam a atenção, visto serem esses pesos normalmente encontrados em crianças. Já o peso mínimo citado pelo grupo controle é $46 \mathrm{~kg}$, um peso que, dependendo da altura do adulto, poderia ser saudável. A meta almejada pelas pacientes pode ser explicada pela perda de noção em relação à forma do corpo que normalmente os indivíduos com TAs têm (Claudino e Borges, 2002; Saikali et al., 2004). Segundo Garner (2004), em pacientes com TAs, a autoestima é inversamente relacionada a seu peso e estar magra é um sinal de autocontrole - dessa forma, um peso menor poderia significar ser mais disciplinada. Nas pacientes com BN, a meta pode estar também relacionada à sua personalidade, muitas vezes exagerada e histriônica, como foi observado por Lobera et al. (2009), ao avaliar 147 pacientes com TAs. Em sua pesquisa, $46,6 \%$ das pacientes com BN apresentaram transtorno de personalidade histriônica $(n=21)$, ou seja um padrão de excessiva emotividade e busca de atenção, que entre outros sintomas, costumam ter um excesso de teatralidade e dramaticidade (APA, 1994) que coincidiriam com esse baixo peso mencionado.

Apesar das medianas do tempo de tratamento demonstrarem que $50 \%$ das pacientes dos grupos AN e BN estavam se tratando há pelo menos um ano no momento da pesquisa, algumas delas eram recém-ingressas no 
tratamento. A média do tempo de tratamento se mostrou semelhante entre os grupos (22,3 meses para o grupo AN e 20,2 meses para o grupo BN), com médias muito aquém dos tempos máximos de ambos os grupos $(A N=$ 96 meses, $\mathrm{BN}=120$ meses), indicando uma heterogeneidade muito grande nessa variável.

Nas características do quadro clínico dos grupos, os resultados foram os esperados. Considerando que o comportamento alimentar inadequado e a insatisfação corporal são questões centrais dos TAs (Bruch, 1962; APA, 1994; Claudino e Borges, 2002), e mais especificamente, as compulsões alimentares seguidas de métodos purgativos são sintomas característicos da BN (Russel, 1979; APA, 1994), as escalas que identificam esses comportamentos podem ser utilizadas como rastreadoras dos TAs (Garner e Garfinkel, 1979; Cooper et al., 1987; Henderson e Freeman, 1987; Cordás e Hochgraf, 1993; Nunes et al., 1994; Cordás e Neves, 2000; Di Pietro e Silveira, 2009; Kotait et al., 2009). Portanto, não surpreende que diferenças estatisticamente significantes tenham sido encontradas entre os grupos de pacientes e o grupo controle nas escalas EAT, BITE e BSQ. Um exemplo que ilustra bem o rastreamento é a não diferença estatística entre as médias de IMCs do grupo BN $\left(24,95 \mathrm{~kg} / \mathrm{m}^{2}\right)$ e controle $\left(23,10 \mathrm{~kg} / \mathrm{m}^{2}\right)$. Mesmo assim, o grupo BN apresentou - segundo o BSQ - maior percentual de indivíduos com insatisfação corporal grave $(51,2 \%, n=21)$ enquanto 0 grupo controle apresentou um maior percentual de indivíduos sem insatisfação corporal $(67,5 \%, n=27)$. Trabalho qualitativo realizado por Novaes (2010) nas camadas mais simples da nossa sociedade tem, na fala 
de uma de suas entrevistadas, a representação de que nem sempre a beleza está associada à magreza e, sim, à fartura ou a curvas bem delineadas, segundo modelos difundidos pela mídia: "Eu sei que sou gorda, mas nem por isso deixo de ir à praia, ao forró ou ao baile (funk). Meto meu uniforme: short, top e gorro e ouço gostosa em todas as quebradas que passo" (pág. 167), ou ainda "sei que estou gorda, mas o Nego (referindo-se ao marido) comparece sem erro, não me dá sossego e me chama de gostosa" (pág.170) e "Passo o rodo geral quando vou ao baile (...) sou a mulher churrasco, aqui tem carne pra matar a fome de todo mundo!" (pág. 170). Ou seja, para grande parte da população brasileira, não é correto afirmar que a gordura é a forma mais representativa de feiúra (Novaes, 2010).

A Escala de Figuras de Stunkard apresentou resultados semelhantes àqueles do $\mathrm{BSQ}$ no que concerne à insatisfação corporal: um maior percentual de indivíduos sem insatisfação corporal no grupo controle $(27,5 \%$, $\mathrm{n}=11)$ e maior insatisfação corporal no grupo $\mathrm{BN}(97,6 \%, \mathrm{n}=40)$. Como já discutido anteriormente, a insatisfação corporal é marcante na $\mathrm{BN}$, e muito maior do que na AN, visto que, nesse caso, no pior estágio da doença, muitas das pacientes costumam estar satisfeitas e/ou orgulhosas de seus corpos (Garner, 2004). Por outro lado, a porcentagem de indivíduos-controle insatisfeitas com a forma corporal $(72 \%, n=29)$ foi bem maior do que os resultados publicados por Alvarenga et al. (2010), cuja pesquisa recente com 2.402 estudantes universitárias brasileiras também utilizou a Escala de Figuras de Stunkard. As autoras encontraram 64,4\% ( $n=1314)$ de insatisfação 
corporal entre as entrevistadas e correlacionaram positivamente - entre outras variáveis - com a idade (média de 23,5 anos). Alvarenga et al. (2010) afirmam que o padrão de beleza vigente é restrito e pouco democrático, favorecendo mulheres mais jovens. Sendo assim, é plausível que uma maior carga de exigências estéticas possa incidir sobre mulheres mais velhas, justificando a maior quantidade de insatisfação corporal no nosso grupo, cuja média etária foi de 29,2 anos. Três trabalhos regionais foram realizados com estudantes universitárias e, em dois deles, a porcentagem de insatisfação corporal foi bem menor que a encontrada por esta pesquisa: $28 \%$ no Ceará (Souza, 2006) e 50\% na Bahia (Moreira et al., 2005). Poderíamos justificar a maior insatisfação corporal no presente trabalho pelo mesmo motivo: nestes trabalhos com estudantes, a faixa etária foi bem menor do que na presente pesquisa. Somente o trabalho realizado em São Paulo, encontrou uma porcentagem de $80 \%$ de insatisfação nas entrevistadas (Kakeshita e Almeida, 2006). A questão da idade na influência da insatisfação corporal se torna visível principalmente em estudos com adolescentes, outra faixa etária crítica para a insatisfaçào corporal. Na adolescência, costuma-se ter uma percepção de sobrepeso que se correlaciona de forma fraca com os parâmetros da OMS (1997), que são hoje internacionalmente usados. Assim, adolescentes com peso normal costumam classificar a si mesmas como sobrepeso quando muitas vezes são eutróficas.

A Escala de Figuras de Stunkard oferece também parâmetros de distorção de imagem corporal, que, como já foi explicado na revisão da literatura, é muito acentuada em indivíduos com AN, podendo também 
ocorrer em indivíduos com BN (Garner, 2004). Assim, foram encontrados $86,4 \%(n=38)$ de pacientes com distorção da imagem corporal no grupo AN, e $75,6 \%(n=31)$ de pacientes com distorção da imagem corporal no grupo $\mathrm{BN}$, dados muito diferentes daqueles encontrados no trabalho publicado por Timerman et al. (2010), em que foram avaliadas 14 pacientes também tratadas no AMBULIM com diagnóstico de BN. Os resultados apontaram que, no início do tratamento, 6 mulheres (42,9\%) superestimaram seus corpos, enquanto ao final do tratamento de 18 semanas preconizado pelo Ambulatório, apenas $3(27,3 \%)$ superestimaram seus corpos. Comparandose esses dados com a presente pesquisa, provavelmente a diferença tenha ocorrido no tamanho da amostra de pacientes com BN ou ainda no tempo de tratamento: enquanto este trabalho apresentou heterogeneidade quanto a essa variável, no trabalho de Timerman et al. (2010) a variável tempo de tratamento estava controlada.

Voltando a esta pesquisa, um dado deve ser destacado: a prevalência de $47,5 \%(n=19)$ de mulheres do grupo controle com distorção da imagem corporal "positiva" - que acreditam ter uma forma corporal menor do que realmente têm -, ou seja, acreditam ser mais magras do que realmente são, o que se imagina ser incomum na nossa sociedade. Especula-se que a ilusão possa ser um fator de proteção contra a baixa autoestima em indivíduos saudáveis (Taylor \& Brown, 1988; Taylor \& Brown, 1994). Essa teoria é conhecida como Teoria da llusão de Taylor \& Brown (1988), e se baseia no fato de que os indivíduos costumam exibir ilusões positivas em três domínios, sendo um deles a forma que se veem - essa ilusão 
garantiria o bem-estar pessoal e seria um protetor em relação à saúde mental. Um trabalho recente que também pôde observar esse fenômeno foi o de Shi et al. (2007), que numa amostra de 824 adolescentes, verificaram que $15 \%$ das meninas se consideravam com baixo peso, apesar de somente $5,6 \%$ delas estarem objetivamente com baixo peso, ou seja, com distorção de imagem corporal "positiva", e corroborando com o fato de que esse tipo de imagem corporal pode existir.

Em relação à Escala de Figuras de Stunkard, é importante salientar que a silhueta número 1 equivale a um IMC de 17,5 a 18,9 kg/m² (Bulik et al., 2001). Provavelmente, muitas das pacientes com AN podem ter marcado como corpo atual ou corpo desejado esta figura simplesmente por não haver nenhuma outra menor disponível - o que pode ter influenciado na porcentagem de insatisfação e distorção corporal nesta população.

No que diz respeito a sintomas depressivos, o grupo controle apresentou médias abaixo do ponto de corte para depressão (segundo o BDI), compatível com os critérios que excluíam do grupo controle indivíduos com quadros psiquiátricos. Desta forma, $80 \%(n=32)$ dos indivíduos-controle não apresentaram sintomas de depressão e 20\% (n=8) apresentaram sintomas leves. Por outro lado, as pacientes mostraram, na sua maioria, sintomas depressivos importantes: o grupo AN com 34,10\% ( $n=15)$ de depressão moderada a grave e 29,50\% $(n=13)$ de depressão grave. Já o grupo BN, apresentou $31,70 \%(n=13)$ de pacientes com depressão moderada a grave e 48,80\% $(n=20)$ de pacientes com depressão grave segundo o BDI. A diferença estatística foi significante entre os grupos, com 
$p<0,001$. Esses resultados também não são inesperados. $A$ literatura é rica em afirmar que os transtornos do humor são a comorbidade mais prevalente nos TAs, podendo variar de 20 a 80\% (Bulik, 2002; Fontenelle et al., 2002).

Porém, devemos ficar atentos aos resultados do BDI em pacientes com TAs. Estudos mostram que quadros de desnutrição podem causar sintomas depressivos, bem como alterações neuroquímicas (alterações no sistema serotoninérgico) e neuroendócrinas (hiperatividade dos eixos hipotálamo-hipófise-adrenal e tireóide). Essas alterações podem estar presentes tanto em pacientes com transtornos depressivos como naquelas com TAs (Gwirtsmann e Gerner, 1981; Jimersonet al., 1990; Herzog et al., 1996) e decorreriam de uma desregulação no metabolismo cerebral da glicose, um hipometabolismo (Fontenelle et al., 2002). Assim, a instabilidade nutricional própria dos TAs poderia levar as pacientes a responderem afirmativamente aos itens relacionados a sintomas depressivos em escalas de autoavaliação. Kennedy et al. (1994) avaliou a capacidade do $\mathrm{BDI}$ em distinguir quais pacientes com TAs preenchiam critérios para a depressão maior e quais itens possuíam maior valor preditivo para diagnosticar depressão como comorbidade nestes pacientes. Os autores concluíram que somente escores mais elevados do BDI podem detectar a presença de síndrome depressiva nos pacientes com TAs. É por isso que, neste trabalho, falamos em sintomas depressivos e não em pacientes com depressão.

Já os sintomas obsessivo-compulsivos (inexistentes no grupo controle) foram mais prevalentes nas pacientes com BN, apesar de não ter 
havido diferença estatística entre os dois grupos de pacientes. Mesmo assim, é interessante chamar a atenção para alguns sintomas, tais como obsessões somáticas relacionadas às partes do corpo, compulsões por verificação/ controle, contagem e compulsões de rituais para comer. No grupo AN, 50\% $(n=22)$ das pacientes apresentaram obsessões somáticas, $38,6 \%(n=17)$ apresentaram compulsões relacionadas a verificação e controle, $15,9 \% \quad(n=7)$, compulsões por contagem e 22,7\% $(n=10)$, compulsões por rituais para comer. Já no grupo BN as frequências foram $63,4 \%(n=26), 53,7 \%(n=22), 29,3 \%(n=12)$ e $29,3 \%(n=12)$, respectivamente. Vale descrever as anotações feitas pelas pacientes ao lado das questões no YBOCS. As obsessões de verificação e controle eram muitas vezes definidas como checagem corporal e as compulsões de contagem relacionadas a contagem de calorias. Em alguns casos, os rituais para comer apareciam como "usar sempre os mesmos talheres e pratos" - talvez uma forma de controle do quanto a paciente estava consumindo. Estes sintomas já foram anteriormente descritos por Yaryuara-Tobias (2001), que relatou rituais complexos que incluem a seleção, compra e preparo de alimentos, ornamentação de pratos ou postura na mesa. O autor explica ainda que alguns pacientes contam quantas vezes enchem a boca de comida ou mastigam alimentos visando o controle alimentar. Os primeiros relatos de casos de AN em pacientes com TOC aconteceram em 1939 e foram descritos por Palmer e Jones, que também sugeriram o termo "neurose compulsiva" para a doença. Ou seja, os resultados deste trabalho reforçam a relação entre TAs e TOC e com a hipótese de que a AN pode ser 
um espectro do TOC ou que pelo menos ambos seriam uma expressão do mesmo fenótipo (Fontenelle et al., 2002; Wonderlich, 2002).

Foi observado que pacientes com BN checam seus corpos mais dos que os outros dois grupos avaliados (média $=57,83$ ). $O$ grupo controle foi aquele que apresentou menos comportamentos de checagem corporal (média $=22,80$ ). Esse resultado corrobora trabalho recente de Calugi et al. (2006), que também verificou que pacientes com BN checam mais seus corpos do que aquelas com AN. Apesar de o estudo de Calugi et al. (2006) não ter relacionado Índice de Massa Corpórea (IMC) e idade à checagem/ aversão ao peso, e ter omitido as cognições relacionadas ao hábito, os resultados são parecidos com Mountford et al. (2007): pacientes com BN se checam mais.

Porém, se considerarmos que a escala medidora destes comportamentos - o BCAQ - é uma escala Likert cuja pontuação varia de 0 a 5, sendo a pontuação 0 equivalente a "nenhuma vez - não me interesso" e a pontuação 5 "nenhuma vez - evito para na me chatear", a diferença evidenciada no grupo BN poderia estar relacionada não ao excesso de checagem, mas sim à evitação desse comportamento. E este impasse do resultado é válido também para todas as relações entre o BCAQ e outras escalas. Foi por isso que neste estudo se optou por avaliar separadamente a evitação da checagem corporal. O resultado confirmou a experiência clínica da pesquisadora, cuja rotina inspirou este trabalho. Desta forma, pacientes com $B N$ apresentaram uma média de $E V=4,05$, que comparada às médias do grupo $A N(E V=1,91)$ e do grupo controle $(E V=0,80)$, apresentou 
diferença estatística $(p<0,001)$. $O$ comportamento relatado ser mais evitado foi $o$ ato de pesar-se, ato este normalmente assumido como inofensivo, mas que em certos casos pode ter consequências negativas (Ogden e Evans, 1996; Ogden e Whyman, 1997), especialmente em pacientes com BN. Nessas pacientes, $\mathrm{o}$ ato de pesar-se pode estar relacionado à frequência $\mathrm{e}$ ao volume de episódios de compulsão alimentar, e seria perigoso no controle de purgações, uma vez que mostrariam a necessidade de as purgações serem realizadas (Mountford et al., 2007). Por outro lado, o olhar com que os indivíduos - e especialmente pacientes com TAs - aplicam em seus corpos parece ser uma expressão das suas demandas pessoais por perfeição, e eles passam a ver seus aspectos corporais que não estão no "padrão magro" como fracassos pessoais (Scagliusi e Lourenço, 2010). Assim, a verificação de um peso que Ihes desagrade pode ser vivenciada como uma falha pessoal, o que repercute de forma negativa no humor e na autoestima das pacientes (Ogden e Whyman, 1997). Para evitar esse sentimento negativo, muitas vezes as pacientes evitam a checagem para não se decepcionarem consigo mesmas. Vale ressaltar que duas $(4,87 \%)$ das pacientes com BN pontuaram a evitação da checagem em quase todos os quesitos, ou seja, estas podem ser o tipo de pacientes em que evitar a checagem pode ser tão obsessivo quanto fóbico (Vocks et al., 2008).

Segundo os resultados apresentados, a forma de se checar mais comum é por meio do espelho, nos três grupos estudados $(p<0,001)$. Talvez por ser esta a forma mais comum de checagem, na reduzida literatura científica acerca do tema, a maioria dos experimentos práticos têm sido feito 
com espelhos: cinco trabalhos (Jansen et al., 2005; Delinsky e Wilson, 2006; Jansen et al., 2006; Shafran et al., 2007; Vocks et al., 2007) contra dois, que utilizaram a pesagem (Ogden e Evans, 1996; Ogden e Whyman, 1997). Segundo Nahoum (1987), nossos sentidos receberam uma educação na qual a visão assumiu um papel importante no que diz respeito à representação corporal - o que acabou por constituir um aspecto essencial para a construção moderna das formas de atenção com o corpo, além de forjar a percepção que adquirimos em relação ao mesmo. Associa-se a isso o fato de espelhos serem objetos facilmente encontrados entre os utensílios domésticos, o que facilita deveras a checagem. De qualquer forma, tanto o Mito de Narciso (que, em uma das suas várias versões conta que o belo rapaz se apaixonou por sua própria imagem refletida na água) quanto a história da Branca de Neve (cuja madrasta se olhava no espelho para saber se existiria alguém mais bela do que ela), indicam que a checagem corporal por meio do reflexo/uso de espelho é mais antiga do que se imagina.

No grupo BN, outra forma de checagem também chama a atenção "apalpar-se" - na mesma intensidade do que se olhar no espelho. Já a opção "de usar uma fita métrica" pareceu ser a menos comum no total da amostra, e somente no grupo controle ficou à frente de "medir a circunferência do pulso". Cabe aqui dizer que "medir a circunferência do pulso" é uma forma de checagem mais frequente nos Estados Unidos, onde é comum a avaliação do estado nutricional segundo a tabela da companhia de seguros Metropolitan Life (Hammond, 2002), que exige o conhecimento da compleição física - pequena, média ou grande - para sua utilização. Para 
o cálculo da compleição física é necessária a medida da circunferência do pulso (Grant, 1980).

Avaliando as partes do corpo mais checadas, percebemos uma grande diferença estatística em relação à barriga nos três grupos (mediana $\mathrm{AN}=2,25 ; \mathrm{BN}=3,00 ;$ controle= 1,25$)$. Nos grupos $\mathrm{AN}$ e $\mathrm{BN}$, o local menos checado foram os glúteos/ quadril (mediana $\mathrm{AN}=0,67 ; \mathrm{BN}=1,67$ ), resultado este que pode causar estranhamento, visto que ambas são regiões valorizadas na cultura brasileira. Alguns outros trabalhos observaram as áreas mais checadas em mulheres. Estudando pacientes com transtorno dismórfico corporal, Phillips e Diaz (1997) observaram que a verificação de celulites nas coxas ou o tamanho dos glúteos são as áreas mais checadas por essa população. As pacientes com transtorno dismórfico corporal que apresentaram comorbidade com BN estavam também muito preocupadas com o peso. Já Alfano et al. (2011), entrevistando 465 estudantes, destacaram práticas como se deitar no chão para verificar os ossos da costela e observar os glúteos no espelho. Outros comportamentos também foram relatados, tais como olhar-se no espelho e comparar-se a outras pessoas. Jansen et al. (2006) compararam, por meio da eletroculografia (método que registra o movimento do olho), a atenção visual entre mulheres com e sem TAs. Verificaram que as pacientes relataram como feias as nádegas, quadris, barriga e joelhos, e as controles relataram se incomodar mais com coxas, panturrilhas, quadris e joelhos. Shafran et al. (2004), utilizando também o BCAQ, observaram que pacientes com TAs costumam tocar a barriga e estômago - bem como examiná-los no espelho e se 
comparar com outras pessoas. Já o grupo controle costuma checar mais o rosto. Independentemente da metodologia utilizada, o presente trabalho indicou que, nas mulheres brasileiras, existindo ou não um TA, as preocupações corporais são muito semelhantes entre si e diferentes das de outros países, cujos padrões de beleza e formas de exposição corporal são outros.

Se o primeiro objetivo deste trabalho era verificar de que forma pacientes com TAs checavam seus corpos e quais as áreas corporais mais checadas, o segundo objetivo tinha como meta entender por que os comportamentos de checagem acontecem com tanta frequência nos grupos estudados. A BCCS, escala utilizada para este fim, relaciona o comportamento de checagem em quatro cognições. São elas: verificação objetiva do corpo, segurança e garantia da boa forma - a fim de que se sintam bem e seguras, consequências de não checar o corpo - ou seja, a checagem como forma de proteção contra o sentimento de inferioridade por causa do corpo, e finalmente controle da dieta e do peso. É importante ressaltar que a análise dos resultados do BCCS foi a única parte deste trabalho em que não comparamos os três grupos, mas, sim, os verificamos isoladamente para saber qual o motivo que leva cada uma das modalidades de TAs a checar o corpo, e assim podermos pensar em tratamentos mais específicos.

No trabalho de validação do BCCS original, Mountford et al. (2006) não distinguiram os TAs e observaram que a verificação objetiva foi o principal motivo de checagem entre as pacientes (média=3,32), seguido pelo controle da dieta e do peso (média= 3,13 ), enquanto que os controles obtiveram pontuações muito baixas, significando checar-se quase que 
instintivamente. Mesmo não se importando muito com os motivos da checagem corporal, o grupo controle de Mountford et al. (2006), quando checava seu corpo, era na intenção de uma verificação objetiva (média $=2,33$ ). Já no presente trabalho, observamos que no grupo AN o principal motivo da checagem foi a verificação objetiva ( édia $=3,80$ ), seguido do controle da dieta e ganho de peso ( $\mathrm{média}=3,20$ ). Não podemos esquecer que $38,6 \%$ das pacientes com $A N(n=17)$ apresentaram compulsões relacionadas à verificação e ao controle. Sendo assim, essa população com sintomas obsessivo-compulsivos específicos pode ter influenciado os resultados, visto que checar o corpo buscando verificação objetiva pode ser um objeto de compulsão naqueles que referem compulsão por verificação, bem como checar o corpo a fim de controlar a dieta está relacionado diretamente com a compulsão por controle. $O$ fato de muitas pacientes com AN, nos piores estágios da doença, se sentirem satisfeitas com seus corpos, explica o fato de as pacientes não se preocuparem em checar seus corpos com objetivo de evitarem consequências negativas. Ou seja, quem está bem consigo não precisa se preocupar em se sentir diminuído num ambiente com outras pessoas - o que não acontece com pacientes com BN, por exemplo, cuja insatisfação corporal é um traço marcante e constante (Stice, 2004).

Nesse sentido, esta pesquisa mostrou que se prevenir contra consequências negativas é um grande motivo de checagem corporal entre as pacientes com BN (média $=3,50$ ), só perdendo para a intenção de ter segurança e garantia (média $=3,60$ ) que seu corpo está satisfatório - ou 
seja, ambas são subescalas com constructos muito parecidos e que supostamente deveriam garantir o bem-estar e a autoestima das pacientes. Vale ainda lembrar que o BCCS é uma escala que diferencia populações clínicas das não clínicas; dessa forma, o grupo controle obteve escores bem menores, o que significa uma falta de preocupação a respeito do assunto checagem corporal, o mesmo resultado encontrado por Mountford et al. (2006). O grupo controle apresentou, ainda, a mesma importância nas subescalas da BCCS, com exceção das consequências de não checar, que foi o menos pontuado (média $=1,70$ ), resultado este esperado, visto que, apesar de existir uma insatisfação corporal normativa, o corpo não é o centro de suas vidas (como acontece com indivíduos com Tas); portanto, estar acima do peso pouco vai mudar em relação à forma como se sentem perante as outras pessoas.

Ao iniciarmos a conexão entre os resultados, observamos que as variáveis idade, medidas antropométricas e tempo de tratamento não têm influência na checagem/ evitação da checagem corporal. Em relação à idade, Calugi et al. (2006), observaram relação positiva entre a idade e a checagem de peso, numa tentativa de verificação objetiva, bem como o IMC, que foi relacionado não só à verificação objetiva, mas também ao controle corporal. Mountford et al. (2007) também encontraram entre os seus resultados uma relação positiva entre IMC e verificação objetiva do peso mas, também, como forma de controle da dieta e segurança. No presente trabalho, tivemos uma variável a mais - peso desejado - que se relacionou negativamente com a checagem corporal, indicando que, quanto menor o 
peso desejado, mais a pessoa se checa - ou evita se checar, se lembrarmos mais uma vez que a evitação da checagem corporal é o item que mais pontua no BCAQ. No grupo controle essa relação não foi estatisticamente significante $(p=0,180)$, mas ao avaliarmos os três grupos juntos, a relação se confirmou $(p=-340)$.

Os resultados apontaram que o tempo de tratamento aumentou a checagem corporal, apesar de o tratamento multiprofissional realizado no AMBULIM contemplar atendimento específico para imagem corporal. Ao verificar se os motivos de checagem/ evitação da checagem corporal se alteravam ao longo do tempo, foi observado que nos grupos $A N(p=0,059)$ e BN $(p=0,207)$, separadamente, os motivos não se alteravam. Porém, ao avaliar os dois grupos juntos $(p<0,001)$, os resultados apontaram que, ao longo do tratamento, os motivos de checagem corporal se alteram, indicando que provavelmente numa amostra maior os resultados seriam diferentes.

Se a pesquisa demonstrou que pacientes com AN checam seus corpos para fazer uma verificação objetiva ou ainda para controlar sua dieta e ganho de peso, possivelmente essas cognições se mantenham ao longo do tratamento, visto que um dos objetivos deste grupo é a recuperação de peso. Nesse caso, as pacientes continuariam a se checar para acompanhar o quanto estão - segundo elas - "engordando", e o quanto a dieta recomendada tem sido efetiva ou não.

No caso das pacientes com BN, cuja insatisfação corporal costuma ser alta, foi observado que o grupo tem o hábito de checar o corpo na intenção de se prevenir contra situações negativas e ter segurança e 
garantia que seu corpo está satisfatório. Se considerarmos que seu tratamento habitualmente foca - entre outros aspectos - a interrupção dos métodos purgativos (ADA, 1994; ADA, 2001), métodos estes considerados pelas pacientes importantes para a perda de peso, talvez as cognições relativas à checagem não se alterem, uma vez que as pacientes acreditam que continuarão com um corpo não aceito por elas mesmas.

Ao considerarmos que escores mais altos no EAT (maior comportamento alimentar de risco nos grupos AN: $70,5 \%, n=31$; BN: $82,9 \%, n=34)$ sugerem dietas mais restritivas, confirmamos a nossa hipótese de que indivíduos que restringem mais a dieta também se checam mais. Encontramos uma correlação de 0,501 ( $p<0,001)$ entre BCAQ e EAT nos três grupos analisados conjuntamente; porém a análise individualizada por grupos sugere que o grupo AN tenha essa relação mais forte do que nos outros dois grupos: $0,370(p=0,013)$. Mountford et al. (2006) explicam que pacientes com dietas mais restritivas costumam checar seus corpos principalmente para verificar a efetividade de seus esforços e aqueles com grandes preocupações alimentares têm o hábito de se checar para se garantir contra o sentimento de inferioridade por causa do corpo. É importante salientar que checar o corpo afeta o senso de controle do indivíduo e os pacientes tendem a restringir mais a dieta após a checagem (Shafran et al., 2003), o que se transforma num ciclo vicioso. A contradição está no fato de alguns trabalhos terem observado menor comportamento de checagem em pacientes com $\mathrm{AN}$, o grupo que costuma restringir mais a dieta. É o caso de Mountford et al. (2007), cujos pacientes com esse 
diagnóstico apresentaram menor checagem corporal do que pacientes com $\mathrm{BN}$. Os autores hipotetizam que talvez pacientes com AN evitem mais a checagem, hipótese esta que não se confirma nesta pesquisa, na qual o grupo BN foi o que evitou mais a checagem.

Acerca dos resultados da relação BITE-BCAQ, pudemos notar que os sintomas de BN não se relacionam com a checagem do corpo, com $p=0,240$ no grupo $A N$ e $p=0,516$ no grupo $B N$. Foi ao analisar a relação da gravidade da BN que pudemos perceber uma relação positiva (embora não significativa), ou seja, quanto mais grave a paciente, maior o comportamento de checagem, com $p=0,58$ para $\circ$ grupo $A N$ e $p=0,021$ para $\circ$ grupo $B N$. Isso ocorreu inversamente no grupo controle, em que obviamente as pacientes não pontuaram muito ( $p$-valor $=0,864)$. Esses resultados estão de acordo com Fairburn et al. (2003), que insistem em afirmar que a frequência da checagem/evitação da checagem corporal está diretamente relacionada com a gravidade dos TAs. Sabemos que pacientes com BN tendem a julgar seus corpos de forma muito negativa. Hipotetiza-se que a atenção seletiva para imperfeições reais e subjetivas mantém os pensamentos disfuncionais relacionados ao peso e forma corporal. A checagem/ evitação da checagem corporal teria a função negativa de reforçar estes pensamentos nas pacientes (Delinsky e Wilson, 2006). Poderia também servir para avaliar o quanto seus métodos purgativos têm sido eficazes (Mountford et al., 2007).

Já os resultados do BCAQ também se relacionaram positivamente com a insatisfação corporal (medida por meio do BSQ) nos dois grupos com TAs, com $p=0,001$ para o grupo AN e $p=0,022$ para o grupo BN. No grupo 
controle, a relação não foi tão significativa, com $p=0,051$. Curiosamente, ao observarmos os resultados da relação checagem corporal e insatisfação corporal por meio da Escala de Figuras de Stunkard, à semelhança do grupo controle $(p=0,916)$, os grupos de pacientes não apresentaram relações significativas, com $p=0,933$ para $\circ$ grupo $A N$ e $p=0,176$ para $\circ$ grupo BN. Talvez a diferença nos resultados entre as duas escalas se deva ao fato de o BSQ perguntar especificamente a respeito de cada área corporal, assim como faz o BCAQ. Mas a Escala de Figuras de Stunkard avalia o corpo como um todo, obtendo, assim, resultados mais próximos aos encontrados na relação checagem corporal e IMC - que também avalia o corpo de forma global - ou seja, uma relação fraca, indicando que aquelas mulheres que se atentam mais aos detalhes talvez se chequem mais. Jansen et al. (2007) verificaram que mulheres que observam demais as áreas corporais com as quais não estão satisfeitas costumam ter uma maior insatisfação corporal geral e consequente baixa autoestima, reforçando e/ou mantendo ideias prefixadas em relação ao corpo. Adicionalmente, Shafran et al. (2007) manipularam a checagem corporal a fim de avaliar sua influência sobre a imagem corporal e confirmaram que nos grupos em que a checagem corporal era maior, a insatisfação corporal também era maior, confirmando a hipótese de que a checagem poderia ser um mantenedor das preocupações com o corpo que assolam pacientes com TAs.

Em relação à distorção da imagem corporal, pudemos perceber que dentre as mulheres que se acham maiores do que realmente são de cada grupo estudado, aquelas com BN têm o hábito de checar o corpo (e talvez 
evitá-lo, visto que a evitação está inserida na checagem corporal) com maior intensidade do que as outras $(p=0,030)$. Nos outros grupos $A N(p=0,758)$ e controle $(p=0,698)$ essa linearidade não foi encontrada.

Uma vez bem estabelecida na literatura a relação humor/ insatisfação corporal (Kaplan et al., 1988; Ogden e Evans, 1996; Ogden e Whyman, 1997; De Berardis et al., 2007), a relação positiva entre sintomas depressivos e checagem corporal era esperada. Dessa forma, nossos resultados indicaram que, quanto mais graves os sintomas depressivos (segundo o BDI), mais expressiva é a checagem corporal (e a evitação da checagem corporal), numa correlação de 0,509, com $p<0,001$. Ou seja, se os sintomas depressivos envolvem a baixa autoestima, que repercute na insatisfação corporal, o comportamento de checagem e/ou de evitação da checagem corporal será mais intenso. Segundo Mountford et al. (2006) as cognições que levam indivíduos com baixa autoestima a comportamentos de checagem corporal são aquelas que visam as consequências de não checar o corpo - ou seja, a checagem como forma de proteção contra o sentimento de inferioridade por causa do corpo - justamente o segundo motivo que mais leva as pacientes com BN a checarem seus corpos. Devemos lembrar que pacientes com BN costumam ter sintomas mais graves de depressão e maiores escores de insatisfação corporal, e, assim, tenderiam a evitar mais a checagem corporal. Mas o reverso também deve ser levado em consideração. Trabalho de Ogden e Whyman (1997) que comparou indivíduos que se pesavam ao longo de uma dieta com aqueles que não se pesavam observou que os primeiros tinham alterações importantes no 
humor, bem como piora da autoestima. Dessa forma, os rituais de checagem corporal poderiam confirmar os piores medos relacionados à forma corporal e ao consumo alimentar (Williamson et al., 2004). Vale ressaltar que De Berardis et al. (2007), avaliando mulheres com alexitimia, perceberam que naquelas em que os sintomas depressivos eram mais acentuados, a checagem corporal era mais intensa também.

A relação de pensamentos obsessivo-compulsivos e checagem do corpo foi interessante. Verificamos que pacientes com AN - que tinham obsessões somáticas relacionadas a partes do corpo - praticavam a checagem mais que as outras $(p=0,004)$. O mesmo acontecia com aquelas com rituais para comer $(p=0,043)$ e outros rituais $(p=0,018)$. Excluindo-se os "outros rituais" - que provavelmente mostraram uma significância por conta do volume maior - esses sintomas obsessivo-compulsivos vêm ressaltar a hipótese que a AN poderia ser um dos espectros do TOC, e que poderiam estar também relacionados à personalidade perfeccionista dessas pacientes (Bulik et al., 2003; Lilenfeld et al., 2006; Forbush et al., 2007). Assim, pensamentos obsessivos relacionados a um corpo perfeito, bem como a necessidade de verificação se certos rituais para comer estariam sendo eficientes para alcançar o corpo desejado, poderiam ser diminuídos com o ato de checar o corpo, que, para alguns autores, possui características ritualísticas e/ou compulsivas (Reas et al., 2002; Alfano et al., 2010). O comportamento de checagem diminuiria, assim, a ansiedade dessas pacientes, mas de uma forma irreal, visto que, ao se ter um feedback negativo, a ansiedade pode ser aumentada, bem como os rituais para comer 
(Haase et al., 2007). Não houve diferença estatística na relação entre pacientes com e sem compulsão de verificação e controle e a checagem corporal (grupo $A N, p=0311$; grupo $B N, p=0,927$ ). Se pensarmos nos motivos que levam o grupo AN a se checar - verificação objetiva (média de 3,80, $p<0,001$ ) - e grupo $B N$ - segurança e garantia (média $=3,60, p<0,001$ ), era de se esperar ao menos que no grupo AN essa relação fosse significante.

Após avaliar as escalas utilizadas (BCAQ, BCCS, EAT, BSQ, Figuras de Stunkard e BDI) separadamente, tentamos observar como elas se relacionam entre si. O BITE não participou dessa correlação, pois seus resultados são categoriais, tampouco o YBOCS, cujas respostas são qualitativas, o que impossibilitou a comparação com as outras escalas. Assim, pudemos verificar que todas as escalas avaliadas se relacionam positivamente com o $B C A Q, 0$ que significa que, quanto maior a pontuação do $B C A Q$, maior a pontuação nas outras escalas e vice-versa. Essa relação era esperada no EAT, BSQ, que, por serem também escalas rastreadoras de TAs, deveriam ter resultados que apontassem igualmente para a mesma direção, o mesmo ocorrendo para o $\mathrm{BDI}$, uma vez que a escala mede sintomas da comorbidade mais prevalente dos TAs. É por esse motivo que elas têm sido largamente utilizadas para validação de escalas de TAs (Kachani et al., 2011; Kachani et al., submetido). Foi também por esse motivo que as referidas escalas foram usadas neste trabalho: para confirmar a inter-relação de restrição alimentar (avaliada pelo EAT), sintomas bulímicos (BITE), imagem corporal (avaliada pelo BSQ e Figuras de Stunkard), sintomas depressivos (BDI) e sintomas obsessivocompulsivos (YBOCS) com a checagem corporal. 
Este trabalho possui algumas limitações. A primeira delas é a grande heterogeneidade no tempo de tratamento das pacientes. Esse dado é relevante, visto que se espera que a paciente que esteja em tratamento há mais tempo tenha diminuído a gravidade de vários sintomas, entre eles a checagem corporal, ao contrário da paciente recém-ingressa no tratamento, cujos sintomas se apresentam mais intensos. Dessa forma, a frequência da checagem corporal foi diluída no espaço entre o tempo mínimo (0 meses) e máximo de tratamento $(\mathrm{AN}=96$ meses, $\mathrm{BN}=120$ meses). Paralelamente, apesar de a heterogeneidade do tempo de tratamento ter permitido obter a informação de que as pacientes costumam mudar o motivo da checagem corporal ao longo do tratamento, por outro lado, dificultou saber qual é o motivo exato da checagem corporal em cada um dos grupos de pacientes estudados.

Mas talvez as limitações mais importantes sejam decorrentes do ineditismo do estudo da checagem corporal no Brasil, que repercute na indisponibilidade de escalas e na falta de trabalhos brasileiros com os quais este possa ser comparado. Na verdade, só recentemente os estudiosos de TAs perceberam a importância de observar a checagem corporal de seus pacientes. A razão é simples: poucos clínicos se preocupam com esse fenômeno, visto que ele não é relatado espontaneamente pelas pacientes ao contrário, deve-se perguntar objetivamente (Fairburn, 2008). Assim, em decorrência da falta de escalas de checagem corporal no Brasil, foi necessário adaptar e validar duas delas para viabilizar este trabalho: a BCAQ (Kachani et al., no prelo) e BCCS (Kachani et al. , 2011; Kachani et al, submetido). Por serem escalas nunca antes usadas no nosso país, 
não existem trabalhos nacionais que possam ser comparados com nossos resultados. Trabalho recente (Novaes, 2010) aponta diferenças importantes na imagem corporal relacionadas ao nível social da entrevistada, porém não foi possível incluir esse dado nos questionários o que vemos como uma limitação, pois se a imagem corporal é diferente dependendo do nível socioeconômico, talvez os comportamentos de checagem corporal também o sejam.

Outra limitação diz respeito ao uso de escalas de autopreenchimento, devido ao seu caráter subjetivo. Muitas pessoas não se dão conta do quanto checam seus corpos pelo simples fato de que algumas formas de checagem de corpo são muito naturais no dia a dia, comprometendo resultados de pesquisas com este tipo de escalas (Fairburn, 2008).

Finalizando, devemos lembrar que a checagem corporal pode ser brevemente definida como qualquer comportamento que almeje avaliar globalmente ou especificamente características de um indivíduo, que incluem forma, tamanho, composição e simetria corporal (Alfano et al., 2011). A checagem corporal, como todas as outras atitudes que temos, pode ser vista simplesmente como o produto de uma história de aprendizagem, em que cada pessoa foi recompensada por formular algumas atitudes e punida por expressar outras (Harrison, 1975). Dessa forma, cada um encontra sua maneira de se checar - e talvez este trabalho não tenha contemplado todas elas. 
9 CONCLUSÕES

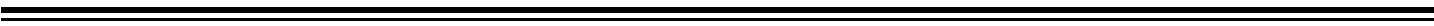


De forma geral, o trabalho mostrou que parece existir diferenças nos comportamentos de checagem corporal e nas cognições relacionadas a estes comportamentos, entre os três grupos estudados: AN, BN e controle. O grupo BN relatou checar mais o corpo do que os outros dois grupos. O grupo que indica se checar menos é o grupo controle. Se analisarmos separadamente a evitação da checagem corporal, notamos que ela é mais acentuada no grupo BN. Em relação aos motivos de checagem corporal, o grupo controle apresentou menor motivação para a checagem do corpo.

Mais especificamente, pôde-se verificar que:

1. A visualização no espelho foi a forma de checagem mais utilizada pelos três grupos. O grupo BN também relatou checar-se bastante por meio das apalpações. A área corporal mais checada pelos três grupos foi a barriga. As áreas corporais menos checadas pelos grupos AN e BN foram os quadris e glúteos. A área corporal menos checada pelo grupo controle foi a região das costelas.

2. Em relação às cognições mais associadas ao comportamento de checagem em cada grupo, encontramos:

- O grupo AN - busca, na checagem corporal, a verificação objetiva e o controle da dieta e ganho de peso; 
- O grupo BN - busca, na checagem corporal, segurança e garantia a respeito do corpo e antecipar as consequências de não checar;

- O grupo controle busca, na checagem corporal, verificação objetiva, segurança e garantia do próprio corpo, porém esses motivos não têm consistência.

3. No modelo de tratamento que as pacientes participantes deste trabalho vêm recebendo, o tempo de tratamento aumenta a checagem corporal; porém, ao longo do tempo, os motivos que levam à checagem corporal são modificados.

4. Em relação às possíveis associações entre atitudes alimentares e checagem corporal foi possível observar que, quanto maior a restrição alimentar, maior o comportamento de checagem corporal, especialmente no grupo AN.

5. Os sintomas bulímicos não se relacionaram com a checagem corporal, ao contrário da gravidade da $\mathrm{BN}$, que parece estar associada positivamente com os comportamentos de checagem do corpo.

6. A insatisfação corporal, medida por meio do $B S Q$, se relacionou positivamente com a checagem corporal, especialmente nos grupos AN e BN. Já esse mesmo sintoma, avaliado por meio da Escala de Figuras de Stunkard, não teve associação com a checagem corporal. A distorção da imagem corporal se relacionou positivamente com a checagem do corpo, especialmente no grupo BN. 
7. Sintomas depressivos, quanto mais frequentes, relacionaram-se positivamente com a checagem corporal, especialmente em pacientes com BN.

8. Sintomas obsessivo-compulsivos relacionaram-se positivamente com maior intensidade no grupo $\mathrm{AN}$, especialmente naquelas pacientes com obsessões somáticas relacionadas ao corpo e rituais compulsivos para comer. 
10 CONSIDERAÇÕES FINAIS 
A aceitação do tamanho corporal consiste em uma posição desafiadora para mulheres com TAs, e a checagem do corpo é a forma mais comum de feedback dessa questão, tornando-se muitas vezes uma prática tão natural que nem mesmo as pacientes se dão conta de sua extensão. Esse assunto tem sido pouco estudado no Brasil, e o presente trabalho se constituiu em uma das possíveis aproximações ao tema, apontando o fato de que pacientes com TAs costumam checar mais seus corpos do que indivíduos controles.

Posto que o conhecimento da dimensão da checagem corporal exagerada realizada pelos pacientes com TAs é de importância para os profissionais da área da saúde, trabalhos futuros devem se dirigir a especificidades do tema. Nesse sentido, novos questionamentos devem aparecer e futuras pesquisas poderão dimensionar a diferença de checagem corporal em subtipos de AN (por exemplo, subtipo restritivo e subtipo purgativo), ou ainda observar diferenças de comportamento de checagem nas diversas características de personalidade (por exemplo, anancástica, ansiosa, entre outras).

O tratamento para a checagem corporal excessiva também deve ser mais bem estabelecido no futuro, e, provavelmente, seja inserido no trabalho de imagem corporal já realizado atualmente com as pacientes. Se checar o corpo é um hábito normal e muitas vezes salutar, qual seria o padrão de checagem corporal ideal para indivíduos com TAs? 
Porém, antes de o assunto ganhar força na comunidade de saúde mental, talvez a questão mais importante a ser debatida seja de que forma o tratamento da checagem corporal excessiva pode influenciar no prognóstico do paciente. Uma vez que os profissionais da saúde envolvidos no tratamento de TAs são responsáveis por auxiliar os pacientes a prover visões realistas do que são formatos e tamanhos corporais adequados, ajudá-los a se libertarem da checagem corporal seria uma forma de auxiliálos a minimizar a aparência como indicativo de valor e enfatizar outras características pessoais. 
11 ANEXOS 


\section{Anexo 1 - Autorização AMBULIM}

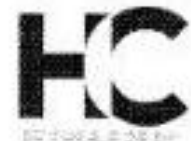

DEPARTAMENTO \& INSTITUTO DE PSIQUIATRIA FACULDADE DE MEDICINA - UNIVERSIDADE DE SÃO PALLO

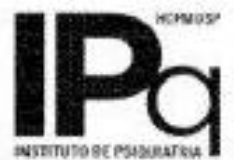

Programa de Transtornos Alimentares (AMBULIM) Coordenador, Prof, Dr. Táki Athanàssios Cordás

1 de abril de 2009

\section{Autorizacāo}

Autorizo a aluna Adriana Trejger Kachani, nutricionista do Programa de Atençăo à Muther Dependente Quimica (PROMUD) do Instituto de Psiquiatria do Hospital das Clinicas da FMUSP, a realizar o seu projeto de pesquisa para defesa de doutorado "Checagern do corpo em transtomos alimentares: relaçđo entre comportamentos e cogniçōes" em nosso Programa. Para tanto, a aluna poderá dispor de nossos recursos bumanos, acesso as pacientes e prontuărios além de oxientaçào tècnica que for necessária.

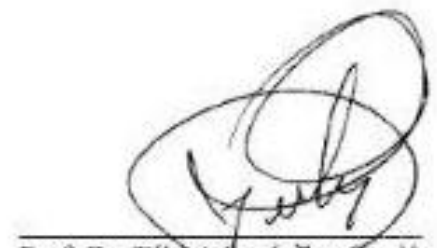

Prof. Dr. Táki Atilanásłore Cordás

Coordenador Geral AMBULIM/PQ/HCFMUSP 


\section{Anexo 2 - Critérios diagnósticos para Anorexia Nervosa e Bulimia Nervosa (APA, 1994)}

\section{Critérios diagnósticos para Anorexia Nervosa}

A. Recusa a manter o peso corporal em um nível igual ou acima do mínimo normal adequado à idade e à altura (p.ex., perda de peso levando à manutenção do peso corporal abaixo de $85 \%$ do esperado; ou incapacidade de atingir o peso esperado durante o período de crescimento, levando a um peso corporal menor que $85 \%$ do esperado).

B. Medo intenso de ganhar peso ou de engordar, mesmo estando com peso abaixo do normal.

C. Perturbação no modo de vivenciar o peso ou a forma do corpo, influência indevida do peso ou da forma do corpo sobre a autoavaliação, ou negação do baixo peso atual.

D. Nas mulheres pós-menarca, amenorreia, isto é, ausência de pelo menos três ciclos menstruais consecutivos. (Considera-se que uma mulher tem amenorreia se seus períodos ocorrem apenas após a administração de hormônio, p.ex., estrógeno).

\section{Especificar tipo:}

Tipo restritivo: durante episódio atual de Anorexia Nervosa, o indivíduo não se envolveu regularmente em um comportamento de comer compulsivamente ou de purgação (i.é, indução de vômito ou uso indevido de laxantes, diuréticos ou enemas).

Tipo Compulsão Periódica/Purgativo: durante o episódio atual de Anorexia Nervosa, o indivíduo envolveu-se regularmente em um comportamento de comer compulsivamente ou de purgação (i.é, indução de vômito ou uso indevido de laxantes, diurético ou enemas). 


\section{Critérios Diagnósticos para Bulimia Nervosa}

A. Crises bulímicas recorrentes. Uma crise bulímica é caracterizada por ambos os seguintes aspectos:

(1) ingestão, em um período limitado de tempo (p.ex., dentro de um período de duas horas) de uma quantidade de alimentos definitivamente maior do que a maioria das pessoas consumiria durante um período similar e sob circunstâncias similares;

(2) um sentimento de falta de controle sobre o comportamento alimentar durante o episódio (p.ex., um sentimento de incapacidade de parar de comer ou de controlar o tipo e a quantidade de alimento).

B. Comportamento compensatório inadequado e recorrente, com o fim de prevenir o aumento de peso, como indução ao vômito, uso indevido de laxantes, diuréticos, enemas ou outros medicamentos, jejuns ou exercícios excessivos.

C. A crise bulímica e os comportamentos compensatórios inadequados ocorrem, em média, pelo menos duas vezes por semana, por três meses.

D. A autoimagem é indevidadmente influenciada pela forma e pelo peso do corpo.

E. O distúrbio não ocorre exclusivamente durante episódios de Anorexia Nervosa.

Especificar tipo:

Tipo purgativo: durante o episódio atual de Bulimia Nervosa, o indivíduo envolveu-se regularmente na indução de vômitos ou no uso indevido de laxantes, diuréticos e enemas.

Tipo Não-Purgativo: durante o episódio atual de Bulimia Nervosa, o indivíduo usou outros comportamentos compensatórios inadequados, tais como jejuns ou exercícios excessivos, mas não se envolveu regularmente na indução de vômitos ou no uso indevido de laxantes, diuréticos ou enemas. 
Anexo 3 - Termo de consentimento livre e esclarecido

\author{
HOSPITAL DAS CLÍNICAS DA FACULDADE DE MEDICINA DA \\ UNIVERSIDADE DE SÃO PAULO-HCFMUSP
}

TERMO DE CONSENTIMENTO LIVRE E ESCLARECIDO

\title{
DADOS DE IDENTIFICAÇÃO DO SUJEITO DA PESQUISA OU RESPONSÁVEL LEGAL
}

1. NOME:

DOCUMENTO DE IDENTIDADE № :

SEXO:.$M \square F \square$

DATA NASCIMENTO: .......................

ENDEREÇO.

№

APTO:

BAIRRO:

CIDADE

CEP:

TELEFONE: DDD

2.RESPONSÁVEL LEGAL

NATUREZA (grau de parentesco, tutor, curador etc.)

DOCUMENTO DE IDENTIDADE № :

SEXO :.$M \square F \square$

DATA NASCIMENTO:

ENDEREÇO

№

APTO:

BAIRRO:

CEP:.

TELEFONE: DDD

CIDADE

\section{DADOS SOBRE A PESQUISA}

1. TÍTULO DO PROTOCOLO DE PESQUISA : Checagem do corpo em transtornos alimentares: relação entre comportamentos e cognições

PESQUISADOR : .Adriana Trejger Kachani

CARGO/FUNÇÃO:nutricionista

INSCRIÇÃO CONSELHO REGIONAL № 17184

UNIDADE DO HCFMUSP:Instituto de Psiquiatria

3. AVALIAÇÃO DO RISCO DA PESQUISA:

$$
\begin{array}{lll}
\text { RISCO MíNIMO } & \mathbf{X} & \text { RISCO MÉdIO } \\
\text { RISCO BaIXo } & \square & \text { RISCO MAIOR }
\end{array}
$$

4.DURAÇÃO DA PESQUISA : 3 anos. 


\section{HOSPITAL DAS CLÍNICAS DA FACULDADE DE MEDICINA DA UNIVERSIDADE DE SÃO PAULO-HCFMUSP}

1. Nós queremos saber se você costuma checar de alguma maneira seu ganho de peso e qual a frequência que costuma fazer isso;

2. Para nos ajudar você só terá que conversar um pouco conosco e responder alguns questionários;

3. Precisaremos também verificar sua altura e peso;

4. Nossos procedimentos não Ihe trarão desconforto ou risco nenhum;

5. Não há benefício direto para o participante, mas com sua ajuda poderemos melhorar o tratamento de pacientes com transtornos alimentares;

6. Em qualquer etapa do estudo, você terá acesso aos profissionais responsáveis pela pesquisa para esclarecimento de eventuais dúvidas. $O$ principal investigador é a nutricionista Adriana Kachani, que pode ser encontrada no AMBULIM, F: 3069-6975. Se você tiver alguma consideração ou dúvida sobre a ética da pesquisa, entre em contato com o Comitê de Ética em Pesquisa (CEP) - Rua Ovídio Pires de Campos, 225 - 5a andar - tel: 3069-6442 ramais 16, 17, 18 ou 20, FAX: 3069-6442 ramal 26 - Email cappesq@hcnet.usp.br;

7. É garantida a liberdade de retirada de consentimento a qualquer momento e deixar de participar do estudo, sem qualquer prejuízo à continuidade de seu tratamento na Instituição;

8. As informações obtidas serão analisadas em conjunto com outros pacientes, não sendo divulgada a identidade de nenhum paciente;

9. Você tem o direito de ser mantido atualizado sobre os resultados parciais das pesquisas, quando em estudos abertos, ou de resultados que sejam do conhecimento dos pesquisadores;

10. Não há despesas pessoais para o participante em qualquer fase do estudo, incluindo exames e consultas. Também não há compensação financeira relacionada à sua participação. Se existir qualquer despesa adicional, ela será absorvida pelo orçamento da pesquisa;

11. Utilizaremos os dados e o material coletado somente para esta pesquisa. 
Acredito ter sido suficientemente informado a respeito das informações que li ou que foram lidas para mim, descrevendo o estudo "Checagem de peso em transtornos alimentares:associações entre comportamentos e cognições."

Eu discuti com a nutricionista Adriana Kachani sobre a minha decisão em participar nesse estudo. Ficaram claros para mim quais são os propósitos do estudo, os procedimentos a serem realizados, seus desconfortos e riscos, as garantias de confidencialidade e de esclarecimentos permanentes. Ficou claro também que minha participação é isenta de despesas e que tenho garantia do acesso a tratamento hospitalar quando necessário. Concordo voluntariamente em participar deste estudo e poderei retirar o meu consentimento a qualquer momento, antes ou durante o mesmo, sem penalidades ou prejuízo ou perda de qualquer benefício que eu possa ter adquirido, ou no meu atendimento neste Serviço.

Assinatura do paciente/representante legal

Data

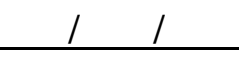

Assinatura da testemunha

Data

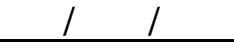

Para casos de pacientes menores de 18 anos, analfabetos, semi-analfabetos ou portadores de deficiência auditiva ou visual.

(Somente para o responsável do projeto)

Declaro que obtive de forma apropriada e voluntária o Consentimento Livre e Esclarecido deste paciente ou representante legal para a participação neste estudo.

Data

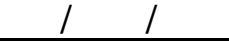




\section{Anexo 4 - Ficha de entrada}

Idade: Tempo de tratamento:

Peso atual: Peso habitual: Peso desejado:

Altura: $\mathrm{H}^{2}$ : IMC:

Estado Civil: ( ) casada

( ) solteira

( ) divorciada

( ) viúva

Filhos:

( ) não

( ) sim. Quantos?

Opção sexual: ( ) heterossexual ( ) homossexual

Nível educacional:

( ) EF. completo

( ) EM. completo

( ) EM. incompleto

( ) Superior completo

( ) Superior incompleto

Situação ocupacional:
( ) estudante
( ) dona de casa
( ) funcionária registrada
( ) desempregada
( ) funcionária sem registro

Está em dieta atualmente? ( ) sim ( ) não 


\title{
Anexo 5 - Autorização ginecologia
}

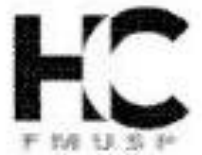

\author{
Universidade de São Paulo \\ Faculdade de Medicina \\ Divisăo de Ginecologia \\ Prot. Dr Edmund C. Baracat
}

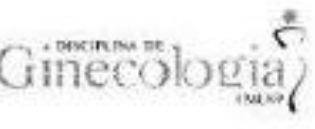

São Paulo, 31 de março de 2009

\section{AUTORIZACĀO}

Autorizo a aluna Adriana Trejger Kachani, nutricionista do Programa de Atençâo à Mulher Dependente Química (PROMUD) do Instituto de Psiquiatria do HCFMUSP, a realizar o seu projeto de pesquisa para defesa de doutorado "Checagem do corpo em transtornos alimentares: relaçăo entre comportamentos e cogniçc̄es", em nosso Serviço.

Para tanto, a aluna poderá ter acesso às pacientes e prontuários.

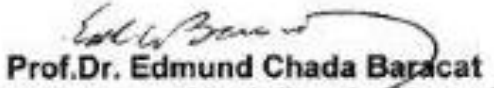

Professor Titular da Disciplina de Ginecologia da

Faculdade de Medicina da Universidade de Săo Paulo

Diretor da Divisăo de Clínica Ginecológica 


\section{Anexo 6 - Questionário de Checagem Corporal (Body Checking and Avoidance Questionnaire - BCAQ)}

Este questionário é sobre comportamentos que você tem (ou evita ter) para verificar seu corpo.

NAS ÚLTIMAS QUATRO SEMANAS, você...

\begin{tabular}{|c|c|c|c|c|c|c|}
\hline & $\begin{array}{l}\text { Nenhuma } \\
\text { vez - não } \\
\text { me } \\
\text { interesso }\end{array}$ & $\begin{array}{c}\text { Pelo } \\
\text { menos } \\
\text { uma vez } \\
\text { na } \\
\text { semana }\end{array}$ & $\begin{array}{l}\text { Todos } \\
\text { os dias }\end{array}$ & $\begin{array}{c}\text { 1-2 } \\
\text { vezes } \\
\text { por dia }\end{array}$ & $\begin{array}{c}\text { Mais de } \\
3 \text { vezes } \\
\text { ao dia }\end{array}$ & $\begin{array}{c}\text { Nenhuma } \\
\text { vez - evito } \\
\text { para não } \\
\text { me } \\
\text { Chatear }\end{array}$ \\
\hline \multicolumn{7}{|l|}{ Beliscou } \\
\hline \multicolumn{7}{|l|}{...suas coxas } \\
\hline \multicolumn{7}{|l|}{...sua barriga } \\
\hline \multicolumn{7}{|l|}{...seu bumbum } \\
\hline \multirow{2}{*}{\multicolumn{7}{|c|}{\begin{tabular}{l|l}
...seu rosto & \\
Olhou no espelho para conferir...
\end{tabular}}} \\
\hline & & & & & & \\
\hline \\
\hline \multicolumn{7}{|l|}{... suas coxas } \\
\hline \multicolumn{7}{|l|}{...sua barriga } \\
\hline \multirow{2}{*}{\multicolumn{7}{|c|}{$\begin{array}{l}\text {...seu rosto } \\
\text { Apalpou ... }\end{array}$}} \\
\hline & & & & & & \\
\hline \multicolumn{7}{|l|}{...suas coxas } \\
\hline \multicolumn{7}{|l|}{...sua barriga } \\
\hline \multicolumn{7}{|l|}{...seu bumbum } \\
\hline \multicolumn{7}{|l|}{...seu rosto } \\
\hline \multicolumn{7}{|l|}{$\begin{array}{l}\text {...suas costelas (para } \\
\text { verificar o } \\
\text { quanto estão salientes) }\end{array}$} \\
\hline \multicolumn{7}{|l|}{$\begin{array}{l}\text {...seus ossos da clavícula } \\
\text { ("saboneteira") }\end{array}$} \\
\hline \multicolumn{7}{|c|}{ Usou uma fita métrica em volta ... } \\
\hline \multicolumn{7}{|l|}{...das suas coxas } \\
\hline \multicolumn{7}{|l|}{...sua barriga } \\
\hline \multirow{2}{*}{\multicolumn{7}{|c|}{$\begin{array}{l}\text {...seu quadril } \\
\text { Você... }\end{array}$}} \\
\hline & & & & & & \\
\hline \multicolumn{7}{|l|}{$\begin{array}{l}\text {...usou o número de suas } \\
\text { roupas para julgar o } \\
\text { tamanho de seu corpo? }\end{array}$} \\
\hline \multicolumn{7}{|l|}{$\begin{array}{l}\text {...comparou o tamanho de } \\
\text { seu corpo com o de outras } \\
\text { pessoas? }\end{array}$} \\
\hline \multicolumn{7}{|l|}{$\begin{array}{l}\text {...ao sentar-se, monitorou } \\
\text { o quanto suas coxas se } \\
\text { esparramam? }\end{array}$} \\
\hline \multicolumn{7}{|l|}{$\begin{array}{l}\text {...mediu a circunferência } \\
\text { de seu pulso (com os } \\
\text { dedos ou pelo tamanho do } \\
\text { relógio)? }\end{array}$} \\
\hline ...se pesou? & & & & & & \\
\hline
\end{tabular}




\section{Anexo 7 - Escala de Checagem Corporal e Cognições (Body Checking Cognitions Scale - BCCS)}

Responda, numa escala de 1-5, o quanto estes pensamentos vêm à sua cabeça quando pesa o seu corpo. Pontue 1 para menor frequência e vá aumentando até 5 para frequência máxima.

\begin{tabular}{|l|l|l|l|l|l|}
\hline $\begin{array}{l}\text { 1- Checar o corpo hoje me dá uma noção para decidir o } \\
\text { quanto eu posso comer amanhã. }\end{array}$ & $\mathbf{2}$ & $\mathbf{3}$ & $\mathbf{4}$ & $\mathbf{5}$ \\
\hline $\begin{array}{l}\text { 2- Eu penso que checar o corpo me dará segurança a } \\
\text { respeito do meu tamanho. }\end{array}$ & & & & \\
\hline $\begin{array}{l}\text { 3- Eu penso que checar o corpo ajudará a me acalmar } \\
\text { quando me sentir ansiosa em relação a meu peso e } \\
\text { aparência. }\end{array}$ & & & & & \\
\hline 4- Checar o corpo me ajuda a controlar o peso. & & & & \\
\hline 5- Checar o corpo é uma coisa boa de se fazer. & & & & \\
\hline $\begin{array}{l}\text { 6- Checar o corpo não me deixa perder o controle sobre o } \\
\text { que eu como. }\end{array}$ & & & & \\
\hline 7- Checar o corpo me faz sentir melhor. & & & & & \\
\hline 8- Ao checar meu corpo, eu sei o quanto engordei. & & & & & \\
\hline $\begin{array}{l}\text { 9- Checar o corpo ajuda a confirmar o que as balanças } \\
\text { mostram. }\end{array}$ & & & & & \\
\hline $\begin{array}{l}\text { 10- Ë importante para mim continuar checando o meu } \\
\text { corpo porque me sinto sempre enorme. }\end{array}$ & & & & & \\
\hline $\begin{array}{l}\text { 11- Tenho que checar o corpo para saber onde o peso está } \\
\text { se acumulando. }\end{array}$ & & & & & \\
\hline $\begin{array}{l}\text { 12- Continuo checando na esperança de que um dia eu } \\
\text { fique feliz com minha aparência. }\end{array}$ & & & & & \\
\hline $\begin{array}{l}\text { 13- Se eu parar de checar o corpo, meu peso vai aumentar } \\
\text { muito. }\end{array}$ & & & & & \\
\hline $\begin{array}{l}\text { 14- Checar o corpo é a forma mais precisa de eu saber } \\
\text { como está minha aparência. }\end{array}$ & & & & & \\
\hline $\begin{array}{l}\text { 15- Se eu resistir a checar meu corpo, vou me sentir pior. } \\
\text { 16- Eu penso que checar o corpo vai me dizer como eu me } \\
\text { sinto. }\end{array}$ & & & & & \\
\hline $\begin{array}{l}\text { 17- Não consigo me lembrar como eu sou se eu não me } \\
\text { checar. }\end{array}$ & & & & & \\
\hline $\begin{array}{l}\text { 18- Eu penso que checar o corpo me fará sentir melhor } \\
\text { entre outras pessoas. }\end{array}$ & & & & \\
\hline $\begin{array}{l}\text { 19- Checar o corpo me mostra quanto eu tenho que fazer } \\
\text { mais atividade física. }\end{array}$ & & & & \\
\hline
\end{tabular}




\section{Anexo 8 - Teste de Atitude Alimentar (EAT)}

Número de

Identificação:

Responda as questões marcando um $X$ na coluna que melhor se aplicar.
$\mathbf{S}=$ sempre
$\mathbf{A V}=$ às vezes
MF = muito frequentemente
$\mathbf{F} \quad=$ frequentemente
$\mathbf{R}=$ raramente
$\mathbf{N}=$ nunca

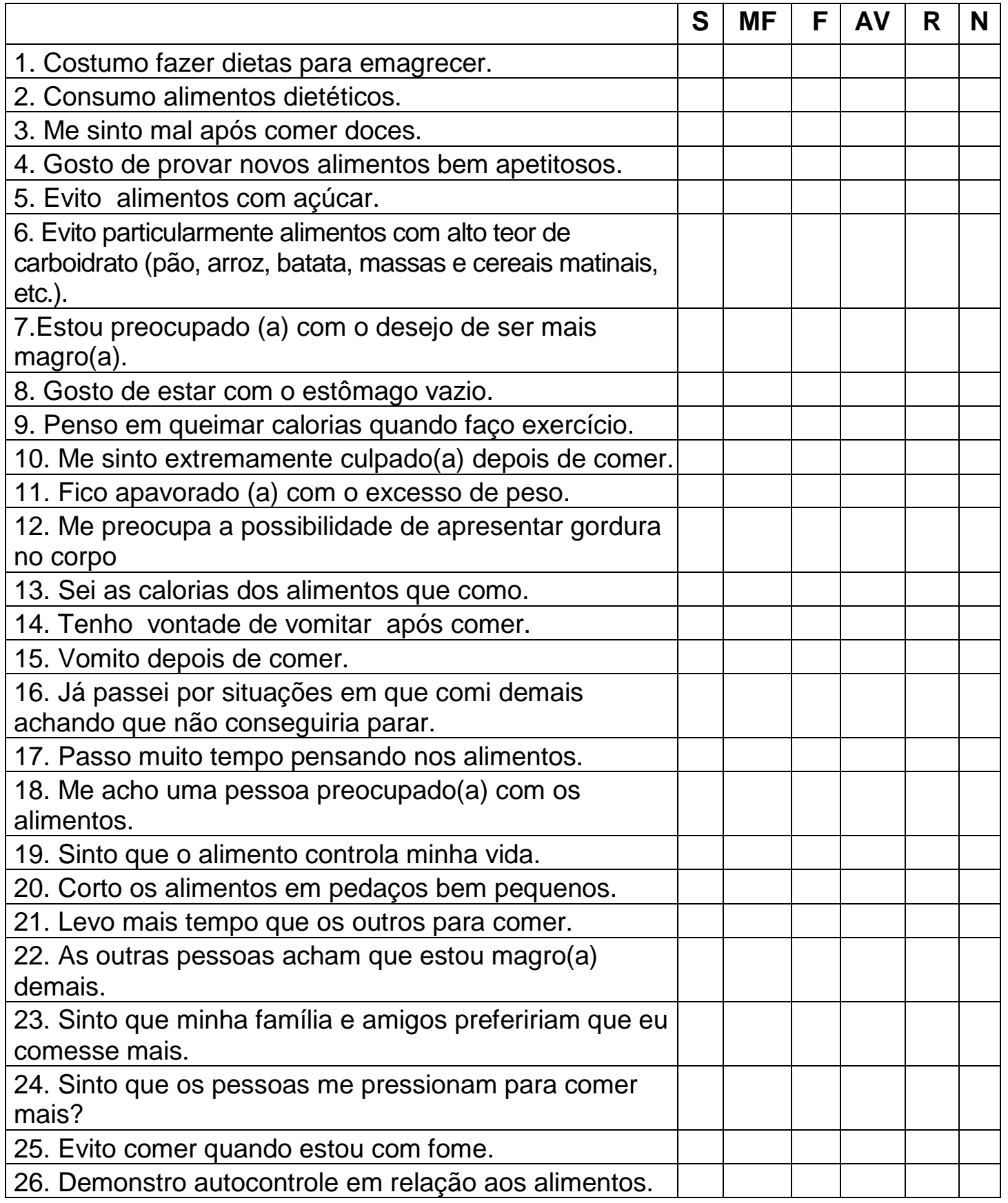


Anexo 9 - Teste de Investigação Bulímica de Edinburg (BITE)

Número de Identificação:

Responda as questões com relação ao que vem sentindo nos últimos 3 meses:

1. Você tem um padrão de alimentação regular no seu dia a dia?

Sim () Não ()

2. Você faz dietas rígidas?

Sim ( ) Não ()

3. Sente-se fracassando quando sai da dieta uma vez ?

Sim () Não ()

4. Você conta as calorias de tudo que come, mesmo quando não está de dieta?

Sim ( ) Não ( )

5. Você já jejuou por um dia inteiro?

Sim ( ) Não ( )

*6....Se já jejuou, qual a frequência ?

( ) dias alternados (5)

( ) 2 a 3 vezes por semana (4)

( ) uma vez por semana (3)

( ) de vez em quando (2)

( ) somente 1 vez (1)

*7. Você usa alguma das seguintes estratégias para auxiliar sua perda de peso?

\begin{tabular}{|l|c|c|c|c|c|c|c|}
\cline { 2 - 8 } \multicolumn{1}{c|}{} & Nunca & $\begin{array}{c}\text { De vez } \\
\text { em } \\
\text { quando }\end{array}$ & $\begin{array}{c}1 \text { vez/ } \\
\text { semana }\end{array}$ & $\begin{array}{c}2 \text { a 3 } \\
\text { vezes/ } \\
\text { Semana }\end{array}$ & $\begin{array}{c}\text { Todo } \\
\text { dia }\end{array}$ & $\begin{array}{c}2-3 \\
\text { vezes/ } \\
\text { dia }\end{array}$ & $\begin{array}{c}5 \text { ou } \\
\text { mais } \\
\text { vezes/dia }\end{array}$ \\
\hline $\begin{array}{l}\text { Tomar } \\
\text { comprimidos }\end{array}$ & 0 & 2 & 3 & 4 & 5 & 6 & 7 \\
\hline Tomar diuréticos & 0 & 2 & 3 & 4 & 5 & 6 & 7 \\
\hline Tomar laxantes & 0 & 2 & 3 & 4 & 5 & 6 & 7 \\
\hline Vômitos & 0 & 2 & 3 & 4 & 5 & 6 & 7 \\
\hline
\end{tabular}


8. O seu padrão de alimentação prejudica muito a sua vida?

Sim ( ) Não ( )

9. Você poderia dizer que o alimento dominou sua vida?

Sim ( ) Não ( )

9. Você come sem parar até sentir-se obrigado por apresentar um mal-estar físico?

Sim ( ) Não ( )

11. Há momentos em que você só consegue pensar nos alimentos?

Sim ( ) Não ( )

12. Você come moderadamente na frente dos outros e depois exagera em particular?

Sim ( ) Não ( )

13. Você sempre pode parar de comer quando quer?

Sim ( ) Não ( )

14.Você já sentiu um incontrolável desejo para comer e comer sem parar? Sim ( ) Não ( )

15. Quando está ansioso(a), você tende a comer muito?

Sim ( ) Não ( )

16. O pensamento de tornar-se gordo(a) o(a) apavora?

Sim ( ) Não ( )

17. Você já comeu grande quantidade de alimento muito rapidamente (sem ser numa refeição principal)?

$\operatorname{Sim}($ ) Não ( )

18. Você se envergonha de seus hábitos alimentares?

Sim ( ) Não ( )

19. Você se preocupa com o fato de não ter controle sobre o quanto você come?

Sim ( ) Não ( )

20. Você se volta para o alimento para aliviar algum tipo de desconforto?

Sim ( ) Não ( )

21. Você é capaz de deixar alimento no prato ao final de uma refeição?

Sim ( ) Não ( )

22. Você engana os outros sobre o quanto você come?

Sim ( ) Não ( ) 
23. O quanto você come é determinado pela fome que sente?

Sim ( ) Não ( )

24. Você já teve episódios exagerados de alimentação?

Sim ( ) Não ( )

25.Se sim, estes episódios o(a) deixaram mal?

Sim ( ) Não ( )

26. Se você têm esses episódios, eles ocorrem só quando você está sozinho(a)?

Sim ( ) Não ( )

*27. Se você tem esses episódios, qual a frequência?

( ) quase nunca (1)

( ) 1 vez por mês (2)

( ) 1 vez por semana (3)

( ) 2 a 3 vezes por semana (4)

( ) diariamente (5)

( ) 2 a 3 vezes por dia (6)

28. Você iria até as últimas consequências para satisfazer um desejo exagerado de comer?

Sim ( ) Não ( )

29. Se você come demais, sente-se muito culpado(a)?

Sim ( ) Não ( )

30. Você já comeu escondido(a)?

Sim ( ) Não ( )

31. Seus hábitos alimentares são o que você poderia considerar normais?

Sim ( ) Não ( )

32. Você se considera alguém que come compulsivamente?

Sim ( ) Não ( )

33. Seu peso varia mais que $2,5 \mathrm{Kg}$ em uma semana?

Sim ( ) Não ( ) 


\title{
Anexo 10 - Escala de Figuras de Stuntkard
}

Nome:

Observe a série de figuras abaixo.

Escreva a palavra "eu" embaixo daquela que melhor representa você atualmente.

Escreva a palavra "saudável" embaixo daquela que você considera uma imagem de corpo saudável.

Escreva a palavra “desejável” embaixo daquela que você gostaria de ser.
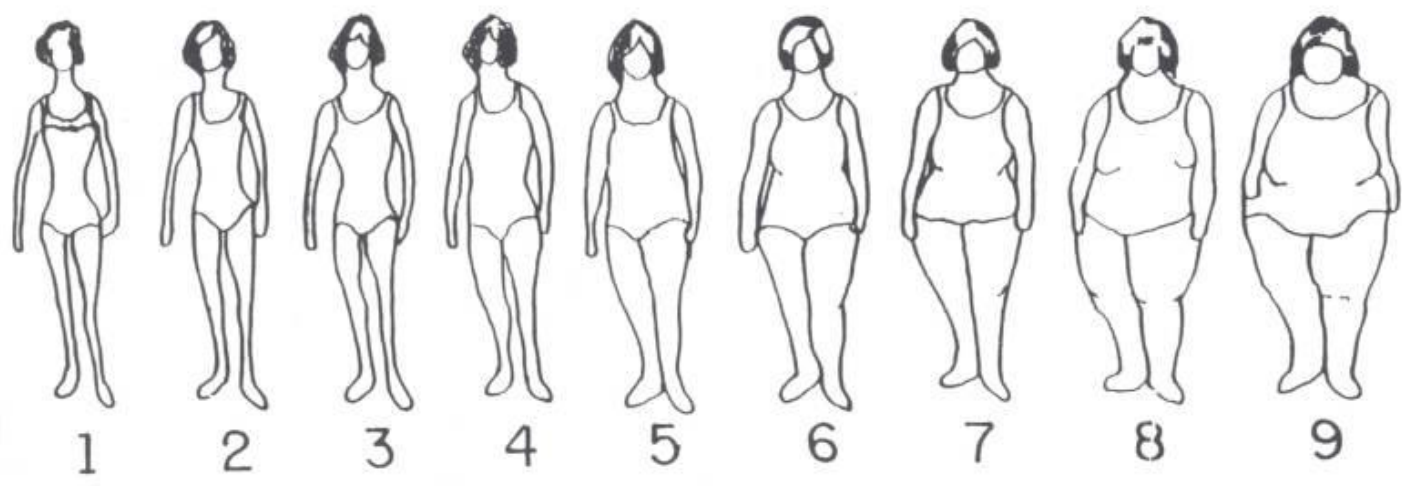

4

\begin{abstract}
6
\end{abstract}

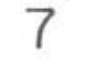

8

9 


\section{Anexo 11 - Questionário de Imagem Corporal (Body Shape Questionnaire - BSQ)}

Número de Identificação:

Responda as questões de acordo como você tem se sentido nas últimas QUATRO SEMANAS, em relação à sua aparência . Por favor, leia cada questão e faça um círculo apropriado. Use a legenda abaixo:
1. Nunca
2.Raramente
3.Ás vezes
4.Frequentemente

5. Muito frequentemente

6.Sempre

1. Sentir-se entediado(a) faz você se preocupar com sua forma física?
1
23
4
5
6

2. Você se preocupa tanto com sua forma física a ponto de achar que deve fazer dieta?
1
$\begin{array}{lll}2 & 3 & 4\end{array}$
5
6

3. Você acha que suas coxas, quadril ou nádegas são grandes demais para o restante de seu corpo?
1
$2 \quad 3 \quad 4$
$5 \quad 6$

4. Você tem sentido medo de ficar gordo(a) - ou mais gordo(a) do que está?
1
$2 \quad 3 \quad 4$
$5 \quad 6$

5. Você se preocupa com o fato de seu corpo não ser bem firme?
1
$\begin{array}{lll}2 & 3 & 4\end{array}$
5
6

6. Ao sentir-se satisfeito(a), como após uma grande refeição, você se acha gordo(a)?
1
$\begin{array}{lll}2 & 3 & 4\end{array}$
$5 \quad 6$

7. Você já se sentiu tão mal a respeito do seu corpo que chegou a chorar?
1
$\begin{array}{lll}2 & 3 & 4\end{array}$
56

8. Você já evitou correr, pelo fato de que seu corpo poderia balançar?
1
$\begin{array}{lll}2 & 3 & 4\end{array}$
5
6

9. Estar com pessoas magras Ihe deixa preocupado(a) em relação ao seu corpo?
1
$2 \quad 3 \quad 4$
5 
10. Você já se preocupou com suas coxas poderem espalhar-se ao você se sentar?
1
23
4
5
6

11. Você já se sentiu gorda mesmo ao comer uma pequena quantidade de alimento?
1
$2 \quad 3 \quad 4$
$5 \quad 6$

12. Você repara o corpo de outras pessoas e, ao se comparar, sente-se em desvantagem?
1
$2 \quad 3 \quad 4$
56

13. Pensar na sua forma física interfere em sua capacidade de se concentrar em outras atividades (como assistir TV, lê ou escutar uma conversa)?
1
23
4
5
6

14. Estar nu(a), por exemplo, durante o banho, faz você se sentir gordo(a)?
1
234
5
6-

15. Você tem evitado usar roupas que o(a) fazem notar as formas do seu corpo?
1
$2 \quad 3 \quad 4$
56

16. Você se imagina eliminando partes de seu corpo?
1
$\begin{array}{lll}2 & 3 & 4\end{array}$
56

17. Comer doces ou outros alimentos ricos em calorias faz você se sentir gordo(a)?
1
$2 \quad 3 \quad 4$
5
6

18. Você já deixou de participar de eventos sociais, festas, por sentir-se mal em relação ao seu corpo?
1
$23 \quad 4$
5
6

19. Você se sente excessivamente grande e arredondado(a)?
1
$\begin{array}{lll}2 & 3 & 4\end{array}$
5
6

20. Você já teve vergonha do seu corpo?
1
$\begin{array}{lll}2 & 3 & 4\end{array}$
5
6

21. A preocupação com seu corpo lhe leva a fazer dieta?
1
$\begin{array}{lll}2 & 3 & 4\end{array}$
5
6

22. Você se sente mais contente em relação ao seu corpo quando está de estômago vazio, como por exemplo pela manhã?
1
23
4
5
6 
23. Você acha que seu corpo atual decorre de uma falta de autocontrole?
1
$\begin{array}{llll}2 & 3 & 4\end{array}$
5
6

24. Você se preocupa com a possibilidade de outras pessoas estarem vendo dobras na sua cintura ou estômago?
1
$\begin{array}{lll}2 & 3 & 4\end{array}$
5
6

25. Você acha injusto que outras pessoas sejam mais magras do que você?
1
$\begin{array}{lll}2 & 3 & 4\end{array}$
5
6

26. Você já vomitou para se sentir mais magro(a)?
1
$\begin{array}{lll}2 & 3 & 4\end{array}$
5
6

27. Quando acompanhada, você fica preocupada em estar ocupando muito espaço (por exemplo, sentado num sofá ou no banco de um ônibus)?
1
$\begin{array}{lll}2 & 3 & 4\end{array}$
5
6

28. Você se preocupa com o fato de estarem surgindo dobrinhas em seu corpo?
1
$\begin{array}{lll}2 & 3 & 4\end{array}$
$5 \quad 6$

29. Ver seu reflexo (por exemplo, num espelho ou na vitrine de uma loja) faz você sentir-se mal em relação ao seu corpo?
1
23
4
56

30. Você belisca áreas de seu corpo para ver o quanto há de gordura?
1
$\begin{array}{lll}2 & 3 & 4\end{array}$
5
6

31. Você evita situações nas quais as pessoas possam ver seu corpo (por exemplo, vestiários ou banhos de piscina)?
1
23
4
56

32. Você toma laxantes para se sentir mais magro(a)?
1
23
4
56

33. Você tem consciência do seu corpo quando em companhia de outras pessoas?
1
$\begin{array}{lll}2 & 3 & 4\end{array}$
5
6

34. A preocupação com seu corpo Ihe faz sentir que deveria fazer exercícios?

1

$\begin{array}{lll}2 & 3 & 4\end{array}$

5

6 


\section{Anexo 12 - Inventário de Depressão de Beck (Beck et al., 1961)}

Este questionário consiste em 21 grupos de afirmações. Depois de ler cuidadosamente cada grupo, faça um círculo em torno do número $(0,1,2,3)$ próximo a afirmação, em cada grupo, que descreve melhor a maneira que você tem se sentido na última semana, incluindo hoje. Se várias afirmações em grupo parecerem se aplicar igualmente bem, faça um círculo em cada uma. Tome o cuidado de ler todas as afirmações, em cada grupo, antes de fazer a sua escolha.

1. 0 Eu não me sinto triste.

1 Eu me sinto triste

2 Estou sempre triste e não consigo sair disto.

3 Estou tão triste e infeliz que não consigo suportar.

2. 0 Não estou especialmente desanimado quanto ao futuro.

1 Eu me sinto desanimado quanto ao futuro.

2 Acho que nada tenho a esperar.

3 Acho o futuro sem esperança e tenho a impressão de que as coisas não podem melhorar.

3. 0 Não me sinto um fracasso.

1 Acho que fracassei mais do que uma pessoa comum.

2 Quando olho para trás, na minha vida, tudo o que posso ver é um monte de fracassos.

3 Acho que, como pessoa, sou um completo fracasso.

4. 0 Tenho tanto prazer em tudo como antes.

1 Não sinto mais prazer nas coisas como antes.

2 Não encontro um prazer real em mais nada.

3 Estou insatisfeito e aborrecido com tudo.

5. 0 Não me sinto especialmente culpado.

1 Eu me sinto culpado grande parte do tempo.

2 Eu me sinto culpado na maior parte do tempo.

3 Eu me sinto sempre culpado.

6. 0 Não acho que esteja sendo punido.

1 Acho que posso ser punido.

2 Creio que serei punido.

3 Acho que estou sendo punido. 
7. 0 Não me sinto decepcionado comigo mesmo.

1 Estou decepcionado comigo mesmo.

2 Estou enojado de mim.

3 Eu me odeio.

8. 0 Não me sinto, de qualquer modo, pior que os outros.

1 Sou crítico em relação a mim por minhas fraquezas ou erros.

2 Eu me culpo por minhas falhas.

3 Eu me culpo por tudo de mal que me acontece.

9. 0 Não tenho quaisquer ideias de me matar.

1 Tenho ideias de me matar, mas não as executaria.

2 Gostaria de me matar.

3 Eu me mataria se tivesse oportunidade.

10. 0 Não choro mais do que o habitual.

1 Choro mais agora do que costumava.

2 Agora choro o tempo todo.

3 Costumava ser capaz de chorar, mas agora não consigo, mesmo que o queira.

11. 0 Não sou mais irritado agora do que já fui.

1 Fico aborrecido ou irritado mais facilmente do que de costume.

2 Atualmente me sinto irritado o tempo todo.

3 Não me irrito mais com as coisas que costumavam me irritar.

12. 0 Não perdi o interesse pelas outras pessoas.

1 Estou menos interessado pelas outras pessoas do que costumava estar.

2 Perdi a maior parte do meu interesse pelas outras pessoas.

3 Perdi todo o meu interesse pelas outras pessoas.

13. 0 Tomo decisões tão bem quanto antes.

1 Adio as tomadas de decisões mais do que costumava.

2 Tenho mais dificuldade em tomar decisões do que antes.

3 Não consigo mais tomar decisões.

14. 0 Não acho que minha aparência está pior do que costumava ser.

1 Estou preocupado por estar parecendo velho e sem atrativos.

2 Acho que há mudanças permanentes na minha aparência que me fazem parecer sem atrativos.

3 Acredito que pareço feio. 
15. 0 Posso trabalhar tão bem quanto antes.

1 Preciso de um esforço extra para fazer alguma coisa.

2 Tenho que me esforçar muito para fazer alguma coisa.

3 Não consigo mais fazer trabalho algum.

16. 0 Consigo dormir tão bem quanto o habitual.

1 Não durmo tão bem quanto costumava.

2 Acordo uma a duas horas mais cedo do que habitualmente e tenho dificuldades em voltar a dormir.

3 Acordo várias horas mais cedo do que costumava e não consigo voltar a dormir.

17. 0 Não fico mais cansado do que o habitual.

1 Fico cansado com mais facilidade do que costumava.

2 Sinto-me cansado ao fazer qualquer coisa.

3 Estou cansado demais para fazer qualquer coisa.

18. 0 Meu apetite não está pior do que o habitual.

1 Meu apetite não é tão bom quanto costumava ser.

2 Meu apetite está muito pior agora.

3 Não tenho mais nenhum apetite.

19. 0 Não tenho perdido muito peso, se é que perdi algum recentemente.

1 Perdi mais de dois quilos e meio.

2 Perdi mais de cinco quilos.

3 Perdi mais de sete quilos.

Estou tentando perder peso de propósito, comendo menos. Sim（） Não（ ）

20. 0 Não estou mais preocupado com minha saúde do que o habitual.

1 Estou preocupado com problemas físicos, tais como dores, indisposição do estômago ou prisão de ventre.

2 Estou muito preocupado com problemas físicos e é difícil pensar em outra coisa.

3 Estou tão preocupado com meus problemas físicos que não consigo pensar em qualquer outra coisa.

21. 0 Não notei qualquer mudança recente no meu interesse por sexo.

1 Estou menos interessado por sexo do que costumava estar.

2 Estou muito menos interessado em sexo atualmente.

3 Perdi completamente meu interesse por sexo. 


\section{Anexo 13 - Escala Yale-Brown de Sintomas Obssessivos- Compulsivos (Yale-Brown de Obsessive-Compulsive Scale -YBOCS)}

Assinale com um " $\mathrm{X}$ " os sintomas que apresentou no passado ou que ainda existem no momento presente.

Sublinhe os que considerar mais importantes. Obs.: Os itens assinalados com * podem não ser sintomas do TOC.

\section{OBSESSÕES}

\section{A. Obsessões com agressão:}

Passado Presente

( ) ( ) medo de ferir-se

( ) ( ) medo de ferir os outros

( ) ( ) imagens violentas ou horríveis

( ) ( ) medo de falar obscenidades ou insultar outras pessoas

( ) ( ) medo de fazer coisas que causem embaraço*

( ) ( ) medo de executar impulsos indesejáveis(p. ex. ferir amigos).

( ) ( ) medo de que possa roubar coisas

( ) ( ) medo de que possa ferir outros por não ter sido suficientemente cuidadoso

( ) ( ) medo de ser responsabilizado por algum acontecimento terrível. (Ex.: incêndio, assalto)

Outros:(descrever)

\section{B. Obsessões com contaminação:}

Passado Presente

( ) ( ) preocupação ou aversão a resíduos ou secreções corporais (p.

( ) ( ) preocupação com sujeira ou germes, ou pó

( ) ( ) preocupação excessiva com contaminantes ambientais (p. ex. asbesto, radiação, lixo tóxico)

( ) ( ) preocupação excessiva com itens de limpeza do lar (p. ex.

detergentes, solventes)

( ) ( ) preocupação excessiva com animais (p. ex. insetos)

( ) ( ) preocupação de que possa ficar doente por causa do contato com contaminantes

( ) ( ) preocupação de que outros possam ficar doentes pela

disseminação de contaminantes (agressivo)

( ) ( ) nenhuma outra preocupação além da sensação de estar contaminado*

( ) ( ) incomodo com substâncias viscosas ou resíduos. 


\section{Obsessões com conteúdo sexual}

Passado Presente

$\begin{array}{lll}\text { ( ) } & \text { ( ) } & \begin{array}{l}\text { pensamentos, imagens ou impulsos sexuais perversos ou } \\ \text { proibidos }\end{array} \\ \text { ( ) } & (\text { ) } & \text { envolvendo crianças ou incesto } \\ \text { ( ) } & (\text { ) } & \text { envolvendo homossexualidade* } \\ \text { ( ) } & (\text { ) } & \text { comportamento sexual em relação a outros (agressivo)* }\end{array}$

Outro(s)

D. Obsessões de armazenagem e poupança: (colecionar, guardar objetos inúteis) (distinguir de hobies e preocupação com objetos de valor sentimental ou monetário)

descrever:

E. Obsessões religiosas: (escrupulosidade)

Passado Presente

( ) ( ) $\begin{aligned} & \text { preocupação excessiva com blasfêmias ou } \\ & \text { sacrilégios } \\ & \text { excesso de preocupação com certo/errado e } \\ & \text { moral }\end{aligned}$

outra(s)

\section{F. Obsessões de simetria, exatidão ou alinhamento:}

Passado Presente

acompanhadas por pensamento mágico ( $p$.ex. preocupação

( ) ( ) que a mãe sofrerá um acidente a menos que as coisas estejam no local exato)

( ) ( ) não acompanhadas por pensamento mágico

\section{G. Obsessões diversas:}

Passado Presente

( ) ( ) necessidade de saber ou lembrar

( ) ( ) medo de dizer certas coisas ou palavras

( ) ( ) medo de não dizer a coisa de maneira exata ou correta

$($ ) ( ) medo de perder coisas

( ) ( ) imagens intrusivas (não violentas)

( ) ( ) sons, palavras ou música intrusivas insensatas

( ) ( ) incomodação por certos sons/barulhos*

( ) ( ) preocupação excessiva com determinados números, palavras

( ) ( ) preocupação excessiva com cores (significado especial)

( ) ( ) medos supersticiosos

outras 


\section{H. Obsessões somáticas:}

Passado Presente

( ) ( ) preocupação excessiva com doenças*

( ) ( ) preocupação excessiva com partes ou aspecto do corpo (p. ex. dismorfofobia)*

outra

\section{COMPULSÕES}

\section{A. Compulsões por limpeza/lavagem:}

Passado Presente

( ) ( ) lavagem excessiva ou ritualizada das mãos

( ) ( ) banho, escovar dentes, arrumação ou rotina de higiene excessivas ou ritualizadas

( ) ( ) envolver-se excessivamente com itens de limpeza da casa ou objetos (talheres, móveis, etc)

( ) ( ) outras medidas para prevenir ou evitar contato com contaminantes

(descrever):

\section{B. Compulsões de verificação ou controle:}

Passado Presente

( ) ( ) verificar fechaduras, fogão, utensílios, etc.

( ) ( ) verificar várias vezes se feriu ou não outros

( ) ( ) verificar se não se feriu ou não se não vai ferir outros

( ) ( ) verificar se nada de terrível aconteceu ou vai acontecer

( ) ( ) verificar se não cometeu nenhum erro

( ) ( ) verificações ligadas ao corpo ou a doenças

outras 


\section{Repetições:}

Passado Presente

( ) ( ) reler ou rescrever repetidamente parágrafos, páginas;

( ) ( ) necessidade de repetir atividades rotineiras (p. ex. sair/entrar pela porta,sentar/levantar da cadeira)

outra(s)

D. Compulsões de contagem:

Passado Presente (descrever)

( ) ( )

\section{E. Compulsões por ordem/arranjos/sequências}

Passado Presente

( ) ( ) Necessidade de simetria, sequência, ou alinhamento

( ) ( ) outro(s)

\section{F. Compulsões por acumular/colecionar:}

(distinguir de hobies e preocupação com objetos de valor monetário ou sentimental - por. ex. ler cuidadosamente correspondência inútil, empilhar jornais velhos, preocupação por lixo, colecionar objetos inúteis)

Passado Presente (descrever)

( ) ( )

\section{G. Compulsões diversas:}

Passado Presente

\begin{tabular}{|c|c|c|}
\hline ( ) & $(）$ & $\begin{array}{l}\text { rituais mentais (outros além de contar/checar, repetir } \\
\text { mentalmente) }\end{array}$ \\
\hline ( ) & () & fazer listagens excessivas \\
\hline ) & $(\quad)$ & necessidade de perguntar, falar ou confessar \\
\hline ) & $(\quad)$ & necessidade de tocar, bater de leve ou roçar em objetos* \\
\hline ) & $(）$ & rituais envolvendo piscar, ou olhar fixamente* \\
\hline ) & $(\quad)$ & $\begin{array}{l}\text { medidas para evitar ferir-se ( ), ferir a outros ( ) ou evitar } \\
\text { consequências desastrosas ou ruins ( ). } \\
\text { Descrever as medidas }\end{array}$ \\
\hline ) & $(\quad)$ & comportamentos ritualizados para comer* \\
\hline ) & $(\quad)$ & comportamentos supersticiosos \\
\hline ) & $(\quad)$ & tricotilomania (arrancar cabelos)* \\
\hline ) & $(\quad)$ & $\begin{array}{l}\text { outros comportamentos auto - mutilantes ou auto - danosos } \\
\text { (beliscar-se, picar-se)* }\end{array}$ \\
\hline
\end{tabular}

Outros comportamentos não descritos: 


\section{Anexo 14 - Aprovação CAPpesq}
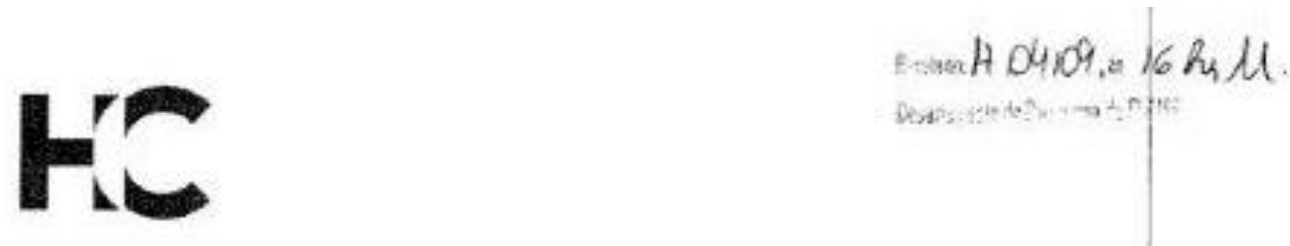

\section{APROVAÇÃO}

A Comissão de Élica paro Anólise de Projetos de Pesquisa CAPPesq da Diretoria Clínica do Hospital dos Clínicas e da Facuidade de Medicino da Universidade de Sõo Paulo, em sessāo de 15/04/2009. AProvou o Profocolo de Pesquiso $n^{\circ}$ 0029/09, intifulado: 'CHECAGEM DO CORPO EM TRANSTORNOS ALIMENTARES: RELAÇÃO ENTRE COMPORTAMENTOS E COGNIÇŌES apresentado pelo Departamento de PSIQuIATRIA. inclusive 0 Termo de Consentimento Livre e Esclarecido.

Cabe ao pesquisadior elaborar e apresentar d CAPPesq. os relatórios parciais e final sobre a pesquisa (Resoluçäo do Conselho Nacional de Soúde $n^{\circ} 196$, de 10/10/1996, inciso (x.2, letra "c").

Pesquisador (a) Responsóvel: Profa. Dra. Patrícia Brulentrinker Hochgrai Pesquisadior (a) Executante: Adriana Trejger Kachani

CAPPesq. 16 de Abri de 2009

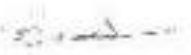

Prof. Dr. Eduardo Massad Presidente da Comissdo de Ética para Anćlise de Projetos de Pesquisa

Comissa de Etca para Analse de Propatos de Pesquisa do HiCFMUSP e da FMUSP Direforia Clinica do Hospital das Clinicas da Froculiade de Nediena de Univeredado de Sko Paulo Rua Ovidio Pires de Campos. 225, $5^{\circ}$ andar - CEP 05403010 - Sap Paulo - SP Fone: 0113069 6442 Fax 01130696492 e-ma1:

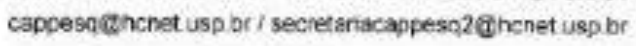


12 REFERÊNCIAS 
Abdi H. Bonferroni and Sidak corrections for multiple comparisons, in N.J. Salkind (ed.): Encyclopedia of Measurement and Statistics. Thousand Oaks, CA: Sage; 2007.

Alfano L, Hildebrandt T, Bannon K, Walker C, Walton K. The impact of gender on the assessment of body checking behavior. Body Image. 2011; 8:20-5.

Almeida GAN, Santos JE, Pasian SR, Loureiro SR. Percepção de tamanho corporal de mulheres: estudo exploratório. Psicol Estud. 2005;10:27-35.

Altabe M, Thompson JK. Menstrual cycle, body image and eating disturbance. Int J Eat Disord. 1990; 9:395-401.

Alvarenga MS. Bulimia nervosa: avaliação do padrão e comportamento alimentares. Tese (doutorado) - Faculdade de Ciências Farmacêuticas da Universidade de São Paulo (USP). Faculdade de Economia, Administração e Contabilidade da USP. Faculdade de Saúde Pública da USP - Curso de Pós graduação Interunidades em Nutrição humana Aplicada. 2001. 284 p.

Alvarenga MS, Dunker KLL, Romano ECB, Philippi ST. Terapia nutricional para transtornos alimentares. In: Philippi ST, Alvarenga M. Transtornos alimentares. Barueri: Manole, 2004. p.209-26.

Alvarenga MS, Philippi ST, Lourenço BH, Sato PM, Scagliusi FB. Insatisfação com a imagem corporal em universitárias brasileiras. J Bras Psiquiatr. 2010; 59(1):44-51. 
American Dietetic Association (ADA). Position of the American Dietetic Association: nutritional intervention in the treatment of anorexia, bulimia nervosa and binge eating. J Am Diet Assoc. 1994; 94(8): 902-7.

American Dietetic Association (ADA). Position of the American Dietetic Association: nutritional intervention in the treatment of anorexia, bulimia nervosa and eating disorders not otherwise specified (EDNOS). J Am Diet Assoc. 2001; 102(7): 810-9.

American Psychiatric Association (APA). Diagnostic and statistical manual of mental disorders (4th ed.). Washington DC: American Psychiatric Association; 1994.

Annis NM, Cash TF, Hrabosky Jl. Body image and psychosocial differences among stable average weight, currently overweight, and formerly overweight women: the role of stigmatizing experiences. Body Image. 2004; 1: 155-67.

Araújo LA. Escalas de avaliação de transtorno obsessivo-compulsivo em adultos. Rev.Psiq Clin. 1998; 25(6): 307-9.

Araújo LA. Escalas de avaliação de transtorno obsessivo-compulsivo em adultos. In: Gorenstein C, Andrade LHSG, Zuardi AW. Escalas de avaliação clínica em psiquiatria e psicofarmacologia. São Paulo: Lemos-Editorial; 2000. p. 165-6.

Armitage P, Berry, G, Statistical Methods in Medical Research, 3 ed, Oxford: Blackwell Science, 1994.

Ball-Rokeach SJ, DeFleur ML. A dependency model of mass media effects. Communication Research. 1976; 3(1):3-21.

Barros DD. Imagem corporal: a descoberta de si mesmo. Hist Ciênc Saúde. 2005; $12(2): 547-54$. 
Baudrillard J. A sociedade de consumo. Rio de Janeiro: Edições 70, 1991.

Beck AT, Ward $\mathrm{CH}$, Mendelson M, Mock J, Erbaugh J. An inventory for measuring depression. Arch Gen Psychiatry. 1961; 4:561-71.

Beck AT, Freeman A, Davis DD. Cognitive therapy of personality disorders. $2^{\text {nd }}$. Edition. New York, NY: Guilford, 2004.

Becker AE, Burwell RA, Gilman SE, Herzog DB, Hamburg P. Eating behaviours and attitudes following prolonged exposure to television among ethnic Fijian adolescent girls. Br J Psychiatry. 2002; 180:509-14.

Beren SE, Hayden HA, Wilfley DE, Grilo CM. The influence of sexual orientation on body dissatisfaction in adult men and women. Int $J$ Eat Disord. 1996; 20: 135-41.

Berlucchi G, Aglioti S. The body in the brain: neural bases of corporeal awareness. Trends Neurosciences. 1997; 20: 560-4.

Birkeland R, Thompson K, Herbozo S, Roehrig M, Cafri G, Van den Berg P. Media esposure, mood, and body image dissatisfaction: an experimental test of person versus product priming. Body Image. 2005; 2:53-61.

Blinder BJ, Cumella EJ e Sanathara VA. Psychiatric comorbities of female inpatients with eating disorders. Psychosom Medicine. 2006; 68:454-52.

Blumler JG. The role of theory in uses and gratifications studies. Communication Research. 1979; 6(1):9-36.

Boghi A, Sterpone S, Sales S, D’Ágata F, Bradac GB, Zullo G, Munno D. In vivo evidence of global and focal brain alterations in anorexia nervosa. Neuroimaging. 2011; 192: 154-9. 
Branco LM, Hilário MOE, Cintra IP. Percepção e satisfação corporal em adolescentes e a relação com seu estado nutricional. Rev Psiq Clin. 2006;33(6):292-6.

Brasiliano S. Comorbidade entre dependência de substâncias psicoativas e transtornos alimentares: perfil e evolução de mulheres em um tratamento específico para dependência química. [tese] São Paulo: Faculdade de Medicina da Universidade de São Paulo; 2005.

Brouwer AC, Mirabel-Sarron C, Guelfi JD. Lês troubles dês conduites alimentaires: évaluation dês troubles obsessionels compulsifs et leur influence sur l'expression clinique des troubles. Ann Med Psychol. 2009., doi 10.1016/j.amp.2009.08.015.

Bruch H Perceptual and conceptual disturbances in anorexia nervosa. Psych Med. 1962; 24:187-94.

Bulik CM. Anxiety, depression, and eating disorders. In: Fairburn CG, Brownell KD. Eating disorders and obesity. $2^{\text {nd }}$. Ed. NY, London: The Guilford Press, 2002. p. 193-8.

Bulik CM, Tozzi F, Anderson C, Mazzeo SE, Aggen S, Sullivan PF. The relation between eating disorders and components of perfectionism. Am J Psychiatry. 2003; 160:366-8.

Bulik CM, Wade TD, Heath AC, Martin NG, Stunkard AJ, Eaves LJ. Relating body mass index to figural stimuli: population-based normative data for Caucasians. Int J Obes. 2001; 25: 1517-24.

Bussab WO, Morettin PA. Estatística Básica. 6ํeㅁ, São Paulo: Saraiva; 2009. 
Byely L, Archibald AB, Graber J, Brooks-Gunn J. A prospective study familial and social influences on girl's body image and dieting. Int J Eat Disord. 2000; 28:155-64.

Calugi S, Dalle-Grave R, Guisi M, Sanavio E. Validation of the body checking questionnaire (BCQ) in a eating disorders population. Behav Cogn Psychoter. 2006; 34: 233-42.

Canpolat BI, Orsel S, Akdemir A, Ozbay $\mathrm{MH}$. The relationship between dieting and body image, body ideal, self-perception and body mass index in Turkish Adolescents. Int J Eat Disord. 2005; 37:150-5.

Cantril $\mathrm{H}$, Gaudet $\mathrm{H}$, Hertzog $\mathrm{H}$. The invasion from mars. Princeton: Princeton University Press; 1940.

Castilho SM. Imagem corporal nos transtornos alimentares: aspectos clínicos e psicopatológicos [dissertação de mestrado]. São Paulo: Faculdade de Medicina da Universidade de São Paulo; 1999.

Castilho SD, Barras Filho AA. Crescimento pós menarca. Arq Bras Endocrinol Metabol. 2000; 44(3) :195-204.

Claudino AM, Borges MBF. Critérios diagnósticos para os transtornos alimentares: conceitos em evolução. Rev. Bras. Psiquiatr. 2002; 24 (supl III):7-12.

Cochran SD, Mays VM, Alegria M, Ortega NA, Takeuchi D. Menthal health and substance use disorders among latino and asian american lesbian, gay and bissexual adults. J Consult Clin Psychol. 2007; 75:785-794.

Cohen J, Cohen P, West SG, Aiken LS. Applied multiple regression/correlation analysis for the behavioral sciences. (3rd ed.) Hillsdale, NJ: Lawrence Erlbaum Associates; 2003. 
Conover WJ. Practical Nonparametric Statistics. 3rd ed. New York: Wiley; 1998. P.388-95..

Conti MA. Os aspectos que compõe o conceito de imagem corporal pela ótica do adolescente. Rev Bras Crescimento Desenv Hum. 2008; 18(3): 240-53.

Cooper PJ, Taylor MJ, Cooper Z, Fairburn CG. The development and validation of the Body Shape Questionnaire. Int. J Eat Disord. 1987; $6(4): 485-94$.

Cooper MJ, Todd G, Wels A. Contents, origins and consequences of dysfunctional beliefs in anorexia and bulimia nervosa. Behav Res Ther 1992; 30:501-11.

Cordás TA, Hochgraf PB. O BITE: instrumento para a validação de bulimia nervosa - versão para o português. J Bras Psiq. 1993; 42:141-4.

Cordás TA, Neves JEP. Escalas de avaliação de transtornos alimentares. In: Gorenstein C, Andrade LHSG, Zuardi AW. Escalas de avaliação clínica em psiquiatria e psicofarmacologia. São Paulo: Lemos-Editorial; 2000. p. 345-53.

Cordás TA, Salzano FT, Rios SR. Os transtornos alimentares e a evolução no diagnóstico e no tratamento. In: Philippi ST, Alvarenga M. Transtornos alimentares. Barueri: Manole, 2004. p. 39-62.

Craske MG, Pontillo DC. Cognitive biases in anxiety disorders and their affect on cognitive-behavioral treatment. Bull Menninger Clin. 2001; 65:58-77.

Crawford D, Campbell K. Lay definitions of ideal weight and overweight. Int J Obes. 1999; 23:738-45.

De Berardis D, Carano A, Gambi F, Campanella D, Giannetti P, Ceci A, Mancini E, La Rovere R, Cicconetti A, Penna L, Di Matteo D, Scorrano B, 
Cotellessa C, Salermo RM, Serroni N, Ferro FM. Alexithymia and its relationships with body checking and body image in a non-clinical female sample. Eat Behav. 2007; 8:296-304.

Delinsky SS, Wilson GT. Mirror exposure for the treatment of body image disturbance. Int J Eat Disord. 2006; 39(2):108-16.

Diaz-Marsa M, Carrasco JL, Saiz J. A study of temperament and personality in anorexia and bulimia nervosa. J Personal Disord. 2000; 14(4):352-9.

Di Pietro M, Silveira DX. Internal validity, dimensionality and performance of the Body Shape Questionnaire in a group of Brazilian college students. Rev Bras Psiquiatr. 2009; 31(1):21-4.

Dionne MM, Davis C. Body image variability: the influence of bodycomposition information and neuroticism on young women's body dissatisfaction. Body Image. 2004; 1:335-49.

Dunkley, Wertheim, Paxton. Examination of a model of multiple sociocultural influences on adolescents girl's body dissatisfaction and dietary restraint. Adolesc. 36 (142), 2001.

Fairburn CG. Cognitive behavior therapy and eating disorders. Nova YorK: The Guilford Press, 2008. 324p.

Fairburn CG, Shafran R, Cooper Z. A cognitive behavioural theory of anorexia nervosa. Behav Res Ther. 1999; 37: 1-13.

Fairburn CG, Cooper Z, Shafran R. Cognitive behaviour therapy for eating disorders: a "transdiagnostic" theory and treatment. Behav Res Ther. 2003; 41:509-28. 
Farrel C, Shafran R, Fairburn CG. Mirror cognitions and behaviors in people concerned about their body shape. Behav Cogn Psychoter. 2004; 32:225-9.

Festinger L. A theory of social comparison process. Human relations. 1954; $7(2): 117-40$.

Fichter MM, Quadflieg N, Georgopoulou E, Xepapadakos F, Fthenakis EW. Time trends in eating disturbances in Young Greek migrants. Int $J$ Eat Disord. 2005; 36(4): 310-22.

Fisher RA. On the interpretation of chi-square from contingency tables and the calculation of P. J R Stat Soc. 1922; 85:87-94.

Field AE, Cheung L, Wolf AM, Herzog DB, Gortmaker SL, Colditz GA. Exposure to the mass media and weight concerns among girls. Pediatrics. 1999; 103;E36.

Fingeret MC, Gleaves DH, Pearson CA. On the methodology of body image assessment: the use of figural rating scales to evaluate body dissatisfaction and the ideal body standards women. Body Image. 2004; 1:207-12.

Fontenelle LF, Cordás TA, Sassi E. Transtornos alimentares e os espectros do humor e obsessivo-compulsivo. Rev Bras Psiquiatr. 2002; 24 (Supl III): 24-8.

Forbush K, Heatherton TF, Keel PK. Relationships between perfeccionism and specific disordered eating behaviors. Int J Eat Disord. 2007; 40(1): 37-41.

Foster GD, Matz PE. Weight loss and changes in body image. In: Cash TF, Pruzinsky T. Body image. The Guilford Press: New York, 2004. p. 405-13.

French SA, Story M, Remafedi G, Resnick MD, Blum RW. Sexual orientation and prevalence of body dissatisfaction and eating behaviors: a population based study adolescents. Int J Eat Disord. 1996; 19(2):119-26. 
Gardner RM, Friedman BN, Jackson NA. Methodological concerns when using silhouettes to mesure body image. Percept Mot Skills. 1998; 86: 387-95.

Garner DM. Body image and anorexia nervosa. In: Cash TF, Pruzinsky T. Body image. NY, London: The Guilford Press, 2004. p.295-303.

Garner DM, Olmsted M , Polivy J. Development and validation of a multidimensional Eating Disorder Inventory for anorexia nervosa and bulimia. Int J Eat Disorders. 1983; 2:15-34.

Garner DM, Garfinkel PE. The Eating Attitudes Test: index of the symptoms of anorexia nervosa. Psychol Med. 1979; 9:273-9.

Garner DM, Garfinkel PE. Handbook of treatment for eating disorders. New York: The Guilford Press; 1997.

Gendall KA, Sullivan PE, Joyce PR, Carter FA, Bulik CM. The nutrient intake of women with bulimia nervosa. Int J Eat Disord. 1997; 21(2):115-27.

Gleaves DH, Cepeda-Benito A, Williams TL, Cororve MB, Fernadez-Nieto MC, Villa J. Body image preferences of self and others: a comparison of spanish and american male and female college students. Eat Disord. 2000; 8: 269-82.

Goodman WK, Price LH, Rasmussen AS. The Yale Brown ObsessiveCompulsive Scale YBOCS Part I Development, use and reliability. Arch Gen Psychiatry. 1989a; 46: 1006-11.

Goodman WK, Price LH, Rasmussen AS. The Yale Brown ObsessiveCompulsive Scale YBOCS Part II Validity. Arch Gen Psychiatry. 1989b; 46: 1012-6. 
Gorenstein C, Andrade L. Validation of a Portuguese version of the Beck Depression Inventory and the State-Trait Anxiety Inventory in Brazilian subjects. Braz J Med Biol Res. 1996; 29: 453-7.

Gorenstein C, Andrade L. Inventário de Depressão de Beck: propriedades psicométricas da versão em português. Rev Psiq Clin. 1998; 25(5): 245-50.

Gorenstein C, Andrade L. Inventário de Depressão de Beck - propriedades psicométricas da versão em português. In: Gorenstein C, Andrade LHSG, Zuardi AW. Escalas de avaliação clínica em psiquiatria e psicofarmacologia. São Paulo: Lemos Editorial; 2000. p.89-95.

Gorgati SB, Amigo VL. Anorexia nervosa: manifestações clínicas, curso e prognóstico. In: Claudino AM, Zanella, MT. Transtornos alimentares e obesidade. São Paulo: Manole; 2005. p.39-48.

Gowers SG, Shore A. Development of weight and shape concerns in the aetiology of eating disorders. Br J Psychiatry. 2001; 179:236-42.

Graham MA, Eich C, Kepphart B, Peterson D. Relationship among body image, sex and popularity of hight school studentes. Percept Mot Skills. 2000; 90:1187-93.

Grant JP. Handbook of total parenteral nutrition. Philadelphia: WB Saunders Company, 1980.

Gross RM e Nelson ES. Perceptions of parenteral messages regarding eating and weight and their impact on disordered eating. J College Stud Psychoter. 2000; 15(2):57-78.

Gwirtzmann HE, Gerner RH. Neurochemichal abnormalities in anorexia nervosa: similarities to affective disorders. Biol Psychiatry. 1981; 16:991-5. 
Haase AM, Mountford V, Waller G. Understanding the link between body checking cognitions and behaviors: the role of social physique anxiety. Int $J$ Eat Disord. 2007; 40: 241-6.

Haase AM, Mountford V, Waller G. Associations between body checking and disordered eating behaviors in nonclinical women. Int $J$ eat Disord. 2011; 44: 465-468.

Haimovitz D, Lanskey LM, O'Reilly R. Fluctuations in body satisfaction across situations. Int J Eat Disord. 1993; 13:77-84.

Halmi KA, Tozzi F, Thornton LM, Crow S, Fichter MM, Kaplan AS, Keel P, Klump KL, Lilenfeld LR, Mitchell JE, Plotnicov KH, Pollice C, Rotondo A, Strober M, Woodside DB, Berrettini WH, Kaye WH, Bulik CM. The relation among perfectionism, obsessive-compulsive personality disorder and obsessive-compulsive disorder in individuals with eating disorders. Int $J$ Eat Disord. 2005; 38:371-4.

Hamilton K, Waller G. Media influences on body size estimation in anorexia and bulimia - an experimental study. Br J Psychiatry. 1993; 162:837-40.

Hammond K. Avaliação dietetica. in: Mahan LK, Escott-Stump S. Krause: alimentos, nutrição e dietoterapia. 10ª . Ed. São Paulo: Roca, 2002. p.341-66.

Harrison AA. A Psicologia como ciência social. São Paulo: Cultrix, 1975. 526p.

Hay PJ. Epidemiologia dos transtornos alimentares: estado atual e desenvolvimentos futuros. Rev Bras Psiquiatr. 2002; 24(SupllI): 13-7.

Hefferman K. Eating disorders and weight concern among lesbians. Int J Eat Disord. 1996; 19(2): 127-38. 
Heinberg LJ, Thompson JK. The effects of figure size feedback (positivevs negative) and target comparison group (particularistic vs. universalistic) on body image disturbance. Int J Eat Disord. 1992; 12:441-8.

Heinberg LJ, Thompson JK. Body image and televised images of thinness and attractiveness: a controlled laboratory investigation. J Social Clin Psychol. 1995; 14: 325-38.

Herzog DB, Nussbaum KM, Marmor AK. Comorbididy and outcome in eating disorders. Psychiatr Clin North Am 1996; 19 (4):843-59.

Henderson M, Freeman CPL. A self-rating scale for bulimia. The BITE. Br J Psychiatry. 1987; 150: 18-84.

Henriques GR, Calhoun LG, Cann A. Ethnic differences in women's body dissatisfaction: an experimental investigation. J Soc Psychol. 1996; 136:689-97.

Houaiss, Instituto Antônio. Míni Houaiss, dicionário da Língua Portuguesa. Rio de Janeiro: Objetiva, 2004. 907 p.

Hsu LK. Can dieting cause an eating disorder? Psychol Med. 1997; 27(3):509-13.

Inui A, Asakawa A, Kasuga M, Kamikawa S, Uemoto M, Watanabe, T. Paracental cortical atrophy in patients with eating disorders. Am J Med. 2002; 112:681-3.

Jansen A, Nederkoorn C, Mulkens. Selective visual attention for ugly and beautiful body parts in eating disorders. Behav Res Ther. 2005; 43: 183-96.

Jansen A, Smeets T, Martjin C, Nederkoorn C. I see what you see: the lack of a self-serving body-image bias in eating disorders. $\mathrm{Br} J$ Clin Psychol. 2006; 45:123-35. 
Jimerson DC, Lesem MD, Kaye WH. Eating disorders and depression: is there a serotonin connection? Biol Psychiatry. 1990;28:443-554.

Jones A, Evans M, Bamford B, Ford $H$. Exploring quality of life for eatingdisordered patients. Eur Eat Disord Rev. 2008; 16:276-86.

Kachani AT, Barbosa ALR, Brasiliano S, Cordás TA, Hochgraf PB, Conti MA. Tradução, adaptação transcultural para o português (Brasil) e validação de conteúdo da Body Checking and Cognitions Scale (BCCS). Rev Psiq Clín . $2011 ; 38(1): 13-8$.

Kachani AT, Hochgraf PB, Brasiliano S, Barbosa ALR, Cordás TA, Conti MA. Psychometric evaluation of the "Body Checking and Avoidance Questionnaire $\mathrm{BCAQ}$ - adapted into Portuguese. Eat Weight Disord. No prelo.

Kakeshita IS, Almeida SS. Relação entre índice de massa corporal e a percepção da autoimagem em universitários. Rev Saúde Pública. 2006; 40(3): 497-504.

Kamimura MA, Baxmann A, Sampaio LR, Cuppari L. Avaliação nutricional. In: Cuppari L. Nutrição clínica no adulto. São Paulo: Manole; 2002. p. 71-109.

Kaplan S, Busner J, Pollak S. Perceived weight, actual weight and depressive symptoms in a general adolescent sample. Int J Eat Disord. 1988; 7:107-13.

Katz E, Blumler JG, Gurenvitch M. Usos y gratificaciones de la comunicación de masas. in: Moragas M. Sociologia de La comunicación de masas II: estructuras, funciones y efectos. Barcelona: Gustavo Gili, 1974. p. 127-71.

Kendall PC, Hollon SD, Beck AT, Hammen Cl, Ingran RE. Issues and recommendations regarding use of the Beck Depression Inventory. Cogn Ther Res. 1987; 11:89-299. 
Kennedy SH, Kaplan AS, Garfinkel PE, Rockert W, Toner B, Abbey SE. Depression in anorexia nervosa and bulimia nervosa: discriminating depressive symptoms and episodes. J Psycosom Res. 1994; 20:207-40.

Kiefer I, Leitner B, Bauer R, Rieder A. Body weight: the male and female perception. Soz Praventivmed. 2000; 45:274-8.

Kinsbourne M. The brain and body awareness. In: Csah TF, Pruzinski T. Body image. 2004. P. 22-9.

Kirk RE. Experimental design: procedures for the behavioral sciences. $3^{\text {rd }}$. edition. Belmond (CA): Brooks/Cole, 1995.

Kjaerbye-Yhygesen A, Munk C, Ottesen B, Kjaer SK. Why do slim women consider themselves too heavy? A characterization of adult women considering their body weight as too heavy. Int J Eat Disord. 2004; 35:275-85.

Kotait MS, Barillari ML, Conti MA. Escalas de avaliação do comportamento alimentar. In: Cordás TA, Kachani AT. Nutrição em Psiquiatria. Porto Alegre: Artmed, 2009. p. 59-76.

Kraemer H, Kupfer D. Size of treatment effects and their importance to clinical research and practice. Biol Psychiatry. 2005; 59(11): 990-6.

Lilenfeld LRR, Wonderlich S, Riso LP, Crosby R, Mitchell J. Eating disorders and personality: a methodological and empirical review. Clin Psychol Rev. 2006; 26: 299-320.

Levine MP, Smolak L. Body image development in adolescence. In: Cash TF \& Pruzinsky T. Body Image. New York, London: Guilford Press, 2004. 
Lobera IJ, Fernández JS, Humanes SE. Transtornos de la conducta alimentaria y la personalidad - um estúdio com El MCMI-II. Aten Primaria. 2009; 41(4):201-6.

Luff GM, Gray JJ. Complex messages regarding a thin ideal appearing in teenage girls magazines from 1956 to 2005. Body Image. 2009; 6:133-6.

Machado SC, Costa RF, Machado JC, Salzano FT, Oliveira CG, Cordás TA. Aspectos clínicos dos transtornos alimentares. In: Alvarenga, PG, Andrade AG. Fundamentos em psiquiatria. São Paulo: Manole; 2007. p. 267-82.

Madrigal H, Sanchez-Villegas A, Martinez-González MA, Kearney J, Gibney MJ, Irala J, et al. Underestimation of body mass index through perceived body image as compared to self-reported body mass index in the European Union. Public Health. 2000;114(6):468-73.

Magalhães MN, Lima ACP. Noções de Probabilidade e Estatística. São Paulo: IME-USP, 2000.

Milos G, Spindler A, Ruggiero G, Klaghofer R, Schnyder U. Comorbidity of obsessive compulsive disorders and duration of eating disorders. Int $J$ Eat Disord. 2002; 31:284-9.

Mitchell JE, Laine DC. Monitored binge-eating behavior in pacients with bulimia. Int J Eat Disord. 1985; 4(2):177-83.

Miwa H, Nakanishi I, Kodama R, Kondo T. Cerebellar atrophy in a patient with anorexia nervosa. Int J Eat Disord. 2004; 36:238-41.

Miyake $\mathrm{Y}$, Okamoto $\mathrm{Y}$, onoda K, Kurosadi M, Shirao N, Okamoto $\mathrm{Y}$, Yamawaki S. Brain activation during the perception of distorted body images in eating disorders. Neuroimaging. 2010a; 181: 183-92. 
Miyake Y, Okamoto Y, Onoda K, Shirao N, Okamoto Y, Otagaki Y, Yamawaki S. Neural processing of negative Word stimuli concerning body image in patients with eating disorders: na fMRI study. Neuroimage. 2010b; 50:1333-9.

Montero MD. La información periodística y su influencia social. Barcelona: Labor/ Universitat Autônoma de Barcelona; 1993.

Moore F, Keel PK. Influence of sexual orientation and age on disordered eating attitudes and behaviors in women. Int J Eat Disord. 2003; 34:370-4.

Moreira LAC, Azevedo ABG, Queiroz D, Moura I, Santo DE, Cruz R et al. Body image in a sample of undergraduate medical students from Salvador, Bahia, Brazil. J Bras Psiquiatr. 2005; 54(4):295-7.

Morgan CM, Vecchiatti IR, Negrão AB. Etiologia dos transtornos alimentares: aspectos biológicos, psicológicos e sócio-culturais. Rev Bras Psiquiatr. 2002; 24 (supl III):18-23.

Morgan CM, Claudino AM. Epidemiologia e etiologia. In: Claudino AM, Zanella MT. Transtornos alimentares e obesidade. São Paulo: Manole; 2005. p.15-23.

Mountford V, Haase A, Waller G. Body checking in the eating disorders: associations between cognitions and behaviors. Int $J$ Eat Disord. 2006;39:708-15.

Mountford V, Haase AM, Waller G. Is body checking in the eating disorders more closely related to diagnosis or to symptom presentation? Behav Res Ther. 2007; 45:2704-11.

Moya T, Cominato L. Complicações clínicas. in: Weinberg C. Transtornos alimentares na infância e adolescência. São Paulo: Sá Editora, 2008. p. 89-113. 
Myers PN, Bioccia FA. The elastic body image: the effect of televison advertising and programming on body image distortions in young women. J Communication. 1992; 42(3): 108-33.

Nahoum V. La belle femme ou le stade du mirroir en histoire. Communications. 1987; 46:22-32.

Nasser M. Eating disorders across cultures. Psychiatry. 2006; 5(11): 392-5.

Nemeroff CJ, Stein RI, Diehl NS, Smilck KM. (1994). From the Cleavers to the Clintons: role choice and body orientation as reflected in magazine article content. Int J Eat Disord. 1994; 16:167-76.

Neter J, Kutner MH, Nachtsheim CJ, Li W. Applied Linear Statistical Models. Boston: McGraw-Hill, 2004.

Niemeyer F, Kruse MHL. Construindo sujeitos anoréxicos: discursos da Revista Capricho. Rev Texto Contexto Enferm. 2008; 17(3):457-65.

Novaes JV. Com que corpo eu vou? Sociabilidade e usos d corpo nas mulheres das camadas altas e populares. Rio de Janeiro: Editora PUC-Rio, 2010. 214p.

Nunes MA, Bagatini LF, Abuchaim AL, Kung A, Ramos D, Silva JA, Someuzi L, Pinheiro A. Distúrbios de conduta alimentar: considerações sobre o Teste de Atitudes Alimentares (EAT). Rev ABP-APAL. 1994; 16:7-11.

Ogden J, Evans C. The problem with weighing: effects of mood, self steem and body image. Int J Obes. 1996; 20:272-7.

Ogden J, Whyman C. The effect of repeated weighing on psychological state. Eur Eat Disord Rev. 1997; 5:121-30. 
Ortega RM, Requejo AM, Quintas E, Sanchez-Quiles B, López-Sobaler AM, Andrés P. Estimated energy balance in female university students: differences with respect to body mass índex and concern about body weight. Int J Obes. 1996; 20:1127-9.

Palmer HD, Jones MS. Anorexia nervosa as a manifestation of compulsive neurosis: a study of psychogenic factors. Arch Neurol Psychiatry. 1939; 41:856-60.

Parkes SA, Saewyc EM, Cox DN, Mackay LJ. Relationship between body image and stimulants use among Canadian adolescents. J Adolescent Health. 2008; 43:616-8.

Patton GC, Selzer R, Coffey C, Carlin JB, Wolfe R. Onset of adolescent eating disorders: population based cohort study over 3 years. BMJ. 1999; 318:765-8.

Paxton SJ, Schutz HK, Wertheim EH, Muir SL. Friendship clique and peer influences on body image concerns, dietary restraint, extreme weight-loss behaviors, and binge eating in adolescents girls. J Abnorm Psychol. 1999; 108:255-66.

Pereira JCR. Análise de Dados Qualitativos: estratégias metodológicas para ciências da saúde, humanas e sociais. 3a ed. São Paulo: EDUSP/ FAPESP; 2001.

Phillips KA, Diaz SF. Gender differences in body dysmorphic disorder. J Nerv Ment Dis. 1997;185(9): 570-7.

Phillips KA, Albertini RS, Siniscalchi JM, Khan A, Robinson M. Effectiveness of pharmacotherapy for body dysmorphic disorder: a chart-review study. J Clin Psychiatry. 2001;62(9):721-7. 
Puhl R, Brownell KD. Stigma, discrimination and obesity. In: Fairburn CG, Brownell KD. Eating disorders and obesity. $2^{\text {nd }}$. Edition. New York: Guilford Press, 2002. p 108-12.

Rapaport MH. Prevalence, recognition and treatment of comorbid depression and anxiety. J Clin Psychiatry. 2001; 62:6-10.

Ratsam M, Gillberg C, Gillberg IC. Anorexia nervosa 6 years after onset: II. Comorbity psychiatric problems. Compr Psychiatry. 1995; 36:70-6.

Reas DL, Whisenhunt BL, Netemeyer R, Wiliamson DA. Development of the Body Checking Questionnaire: a self report measure of body checking behaviors. Int J Eat Disord. 2002;31:324-33.

Romano ECB. Bulimia nervosa: o que os pacientes nomeiam compulsão? São Paulo, 2002. Dissertação (Mestrado) Faculdade de Saúde Pública. Universidade de São Paulo.

Rosen JC Cognitive behavioral image therapy. In: DM Garner, PE Garfinkel. Handbook of treatment for eating disorders. $2^{\text {nd }}$ edition. New York: Guilford Press; 1997. p. 188-201.

Rosen JC. Body image assessment and treatment in controlled studies of eating disorders. Int J Eat Disord. Nov 1996; 20(4):331-43.

Rosen G, Ross A. Relantionship of body image to self-concept. J Consult Clin Psychol. 1968; 32(1):100.

Rosen JC, Srebnik D, Saltzberg E, Wendt S. Development of a body image avoidance questionnaire. Psychol Assess. 1991; 3:32-7.

Russel GFM. Bulimia nervosa: on ominous variant of anorexia nervosa. Psychol Med. 1979;9: 429-48. 
Saikali CJ, Soubhia CS, Scalfaro BM, Cordás TA. Imagem corporal nos transtornos alimentares. Rev Psiq Clin. 2004; 31(4): 164-6.

Salkovskis PM. The importance of behavior in the maintenance of anxiety and panic: a cognitive account. Behav Psychoter. 1991; 19:6-19.

Sallet PC, Alvarenga PG, Ferrrão Y, Mathis MA, Torres AR, Marques A, Hounie AG, Fossaluza V, Rosario MC, Fontenelle LF, Petribu K, FleitlichBilyk B. Eating disorders in patients with obsessive-compulsive disrder: prevalence and clinical correlates. Int J Eat Disord. 2010; 43: 315-25.

Sapoznik A, Abussamra EV, Amigo VL. Bulimia nervosa: manifestações dlínicas, curso e prognóstico. In: Claudino AM, Zanella, MT. Transtornos alimentares e obesidade. São Paulo: Manole; 2005. p.49-57.

Scagliusi FB, Alvarenga M, Polacow VO, Cordás TA, Queiroz G, Coelho DF, Philippi ST ; Lancha Junior AH. Concurrent and discriminant validity of the Stunkard S Figure Rating Scale adapted into Portuguese. Appetite. 2006; 47:77-82.

Scagliusi FB, Lourenço BH. A ditadura da beleza e suas consequências no discurso nutricional. In: Alvarenga MS, Scagliusi FB, Philippi ST. Nutrição e transtornos alimentares. Barueri: Manole, 2010. p.59-83.

Schoeller DA. The energy balance equation: looking back and looking forward are two different views. Nutr Rev. 2009; 67(5):249-50.

Schomer EZ, Kachani AT. Imagem corporal. In: Cordás TA, Kachani AT. Nutrição em psiquiatria. Porto Alegre: Artmed, 2009. p. 107-118.

Sciacca JP, Melby CL, Hyner GC, Brown AC, Femea PL. Body Mass Index and perceived weight status in young adults. J Community Health. 1991; 16(3): 159-68. 
Shafran R, Fairburn CG, Robinson P, Lask B. Body checking and its avoidance in eating disorders. Int J Eat Disord. 2004a; 35:93-101.

Shafran R, Robinson P. Thought-shape fusion in eating disorders. $\mathrm{Br} \mathrm{J}$ Clin Psychol. 2004; 43:399-407.

Shafran R, Lee M, Payne E, Fairburn CG. An experimental analysis of body checking. Behav Res Ther. 2007; 45:113-21.

Shaw HE, Stice E, Springer DW. Perfectionism, body dissatisfaction and selfesteem in predicting bulimic symtomatology: lack of replication. $J$ Eat Disord. 2004; 36:41-7.

Shepherd LM, Neumark-Sztainer D, Beyer KM, Story M. Should we discuss weight and calories in adolescent obesity prevention and weightmanagement programs? Perspective of adolescent girls. JADA. 2006; 106(9):1454-8.

Shi Z, Lien N, Kumar BN, Holmboe-Ottesen G. Perceptions of weight and associated fators of adolescents in Jiangsu Province, China. Public Health Nutr. 2007; 10(3):298-305.

Siegel S, Castellan NJ. Nonparametric Statistics. New York: McGraw-Hill. 2ed. 1988.

Skreblin L, Sujoldzic A. Acculturation process and its effects on dietary habits, nutritional behavior and body image in adolescents. Coll Antropol. 2003. $27(2):$ 469-77.

Skrzypeck S, Wehmeier PM, Remschmidt H. Body image assessment using body size estimation in recent studies on anorexia nervosa. A brief review. Eur Chil Adolesc Psychiatry. 2001; 10(4): 215-21. 
Slade PD. Body image in anorexia nervosa. Br J Psychol. 1988; 153(supl 2):20-2.

Slade PD. What is body image? Behav Res Ther. 1994; 32(5): 497-502.

Smeets E, Tiggermann M, Kemps E, Mills JS, Hollitt S, Roefs A, Jansen A. Body checking induces an attentional bias for body-related cues. Int $J$ Eat Disord. 2011; 44: 50-7.

Souza PJ. Elementos de teoria e pesquisa da comunicação e dos media. 2a․ ed. 2006. Porto, Portugal. 823 p. Disponível em: htttp://www.bocc.ubi.pt/pag/Souza-jorge-pedro-elementos-teoria-pesquisacomunicacao-media.pdf/. Acesso em: 28 de agosto de 2009.

Speranza M, Corcos M, Godart N, Loas G, Guilbaud, Jeammet P et al. Obsessive-compulsive disorders in eating disorders. Eat Behav. 2001; 2:193-207.

Spindler A, Milos G. Links between eating disorder symptom severity and psychiatric comorbidity. Eat Behav. 2007; 8:364-73.

Sternberg RJ. Percepção In: Psicologia cognitiva. Porto Alegre: ArtMed, 2000. 111-148.

Stice E, Schupak-Neuberg E, Shaw HE, Stein RI. Relation of media exposure to eating disorder symptomatology: an examination on mediating mechanisms. J Abnorm Psychol. 1994; 103(4): 836-40.

Stice E. Risk and manitenence factors for eating pathology: a meta-analytic review. Psychol Bull. 2002a; 128: 825-48.

Stice E. Sociocultural influences on body image and eating disturbance. In: Fairburn CG, Brownell KD. Eating disorders and obesity. $2^{\text {nd }}$. Edition. New York: Guilford Press, 2002b. p.103-7. 
Stice E. Body image and bulimia nervosa. In: Cash TF, Pruzinsky T. Body image. NY, London: The Guilford Press, 2004. p. 304- 21.

Stice E, Shaw HE. Role of body dissatisfaction in the onset and maintenance of eating pathology: a synthesis of research findings. J Psychosom Res. 2002; 53 (5): 985-93.

Stunkard A., Sorensen T, Schlusinger F. Use of Danish adoption register for the study of obesity and thinness. In: Kety S, Rowland LP, Sidman RL, Matthysse SW. The genetics of neurological and psychiatric disorders. New York, NY: Raven; 1983. p. 115-120.

Stunkard A. Eating disorders: the last 25 years. Appetite. 1997;29:181-90.

Swayze VW, Andersen AE, Andreasen NC, Arndt S, Sato Y, Ziebell S. Brain tissue volume segmentation in patients with anorexia nervosa before and after weight normalization. Int J Eat Disord. 2003; 33:33-44.

Tavares MCGC. Imagem corporal: conceito e desenvolvimento. Barueri: Manole, 2003. p. 147.

Taylor SE, Brown JD. Illusion and well-being: a social psychological perspective on menthal health. Psychol Bull. 1988; 103: 193-210.

Taylor SE, Brown JD. Positive illusions and well-being revisited: separating fact from fiction. Psychol Bull. 1994; 116: 21-7.

Taylor MJ, Cooper PJ. Body size overestimation and mood. $\mathrm{Br} J$ Clin Psychol. 1986; 25:153-4.

Taylor MJ, Cooper PJ. An experimental study of the effect of mood on body size perception. Behav Res Ther. 1992; 30:53-8. 
Tiggermann M, Pickering AS. Role of television adolescent women's body dissatisfaction and drive for thinness. Int J Eat Disord. 1996; 20(2):199-203.

Thompson DA, Berg KM, Shatford LA. The heterogeneity of bulimic symptomatology: cognitive and behavioural dimensions. Intern $J$ Eat Disord. 1987;6:215-34.

Thompson JK, Coovert DL, Pasman LN, Robb J. Body image and food consumption: three laboratory studies of perceived calorie content. Int $J$ Eat Disord. 1993; 14:445-57.

Timermam F, Scagliusi FB, Cordás TA. Acompanhamento da evolução dos distúrbios de imagem corporal em pacientes com bulimia nervosa, ao longo do tratamento multiprofissional. Rev Psiq Clín. 2010; 37(3): 113-7.

Torres AR, Ferrão YA, Miguel EC. Transtorno dismórfico corporal: uma expressão alternativa do transtorno obsessivo-compulsivo? Rev Bras Psiquiatr. 2005; 27(2):1-3.

Van den Berg P, Thompson JK, Obremski-Brandon K, Coovert M. The tripartite influence model of body image and eating disturbance. A covariate structure modeling investigation testing the meditational role of appearance comparison. J Psychosom Res. 2002; 53: 1007-20.

Vieira S. Introdução à bioestatística. Rio de Janeiro: Campus, 1998.

Vilela JEM, Lamounier JA, Delaretti-Filho MA, Barros-Neto JR, Horta GM. Transtornos alimentares em escolares. J Pediatria (RJ). 2004; 80(1):49-59.

Vitalle MSS, Tomioka CY, Juliano Y, Amancio OMS. Índice de massa corporal, desenvolvimento puberal e sua relação com a menarca. Rev Assoc Med Bras. 2003; 49 (4): 429-33. 
Vocks S, Bush M, Gronemeyer D, Schlte D, Herpertz S, Suchan B. Neural correlates of viewing photographs of one's own body and another woman's body in anorexia and bulima nervosa: an fMRI study. J Psychiatry Neurosci. 2010; 35(3): 163-76.

Vocks S, Kosfelder J, Wucherer M, Wachter A. Does habitual body avoidance and checking behavior influence the decrease of negative emotions during body exposure in eating disorders? Psychother Res. 2008; $18(4): 412-9$.

Walker DC, Anderson DA, Hildebrandt T. Body checking behaviors in men. Body Image. 2009; 6:164-70.

Waller G, Sines J, Meyer C, Mountford V. Body checking in the eating disorders: association with narcissistic characteristics. Eat Behav. 2008; 9:163-9.

Wardle J, Foley E. Body image: stability and sensitivity of body dissatisfaction and body size estimation. Int J Eat Disord. 1989; 8:55-62.

Weinberg C, Cordás TA. Do altar às passarelas. São Paulo: Annablume, 2006. p.110.

Williamson DA, White MA, York-Crowe E, Steward TM. Cognitive-behavioral theories of eating disorders. Behav Modif. 2004; 28:711-38.

White JH, Davison GC, Haaga DA, White K. Cognitive bias in the articulated thoughts of depressed and non-depressed psychiatric patients. J Nerv Ment Dis. 1992; 180:77-81.

Wing RR, Hill JO. Sucessful weight loss maintenance. Ann Rev Nutr. 2001; 21:323-341. 
Wonderlich SA. Personality and eating disorders. In: In: Fairburn CG, Brownell KD. Eating disorders and obesity. $2^{\text {nd }}$. Ed. NY, London: The Guilford Press, 2002. P. 204-9.

World Health Organization (WHO). Obesity: preventing and managing the global epidemic. Report of a WHO, Consultation on Obesity. Geneva: WHO; 1997.

Wu KD. Eating disorders and obsessive-compulsive disorder: a dimensional approach to purported relations. J Anxiety Disord. 2008; 22:1412-20.

Yaryura-Tobias MA, Pinto A, Neziroglu F. The integration of primary anorexia nervosa and obsessive-compulsive disorder. Eat Weight Disord. 2001; 6:174-80. 